\title{
PLANNING AQUATIC ECOSYSTEM RESTORATION MONITORING PROGRAMS
}

\author{
by \\ Ronald M. Thom \\ Battelle Marine Sciences Laboratory \\ Sequim, Washington 98382 \\ (360) $683-4151$ \\ and \\ Katharine F. Wellman \\ Battelle Seattle Research Center \\ Seattle, Washington $98105-5428$ \\ (206) 528-3323 \\ for \\ U.S. Army Corps of Engineers \\ Institute for Water Resources \\ Alexandria, Virginia 22310-3868 \\ U.S. Army Corps of Engineers \\ Waterways Experiment Station \\ Vicksburg, Mississippi 39180-6199
}

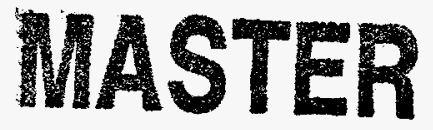

Evaluation of Environmental IWR Report 96-R-23

Investments Research Program January 1997 


\title{
DISCLAIMER
}

This report was prepared as an account of work sponsored by an agency of the United States Government. Neither the United States Government nor any agency thereof, nor Battelle Memorial Institute, nor any of their employees, makes any warranty, express or implied, or assumes any legal liability or responsibility for the accuracy, completeness, or usefulness of any information, apparatus, product, or process disclosed, or represents that its use would not infringe privately owned rights. Reference herein to any specific commercial product, process, or service by trade name, trademark, manufacturer, or otherwise does not necessarily constitute or imply its endorsement, recommendation, or favoring by the United States Government or any agency thereof, or Battelle Memorial Institute. The views and opinions of authors expressed herein do not necessarily state or reflect those of the United States Government or any agency thereof.

\author{
PACIFIC NORTHWEST NATIONAL LABORATORY \\ operated by \\ BATTELLE MEMORIAL INSTITUTE \\ for the \\ UNITED STATES DEPARTMENT OF ENERGY \\ under Contract DE-AC06-76RLO 1830
}

Printed in the United States of America

Available to DOE and DOE contractors from the Office of Scientific and Technical Information, P.O. Box 62, Oak Ridge, TN 37831; prices available from (615) $576-8401$.

Available to the public from the National Technical Information Service, U.S. Department of Commerce, 5285 Port Royal Rd., Springfield, VA 22161 


\section{DISCLAMMER}

Portions of this document may be illegible in electronic image products. Images are produced from the best available original document. 


\section{PREFACE}

This study was conducted as part of the Evaluation of Environmental Investments Research Program (EEIRP). The EEIRP is sponsored by the Headquarters, U.S. Army Corps of Engineers (Corps). It is jointly assigned to the U.S. Army Engineers Water Resources Support Center (WRSC) Institute for Water Resources (IWR) and the U.S. Army Engineer Waterways Experiment Station (WES) Environmental Laboratory (EL). Mr. William J. Hansen of IWR is the Program Manager, and Mr. H. Roger Hamilton is the WES Program Manager. Program Monitors during this study were Mr. John W. Bellinger and Mr. K. Brad Fowler, Corps Headquarters. The field review group members who provide complete Program direction and their District or Division affiliations are as follows: Mr. David Carney, New Orleans; Mr. Larry M. Kilgo, Lower Mississippi Valley; Mr. Richard Gorton, Omaha; Mr. Bruce D. Carlson, St. Paul; Mr. Glendon L. Coffee, Mobile; Ms. Susan E. Durden, Savannah; Mr. Scott Miner, San Francisco; Mr. Robert F. Scott, Fort Worth; Mr. Clifford J. Kidd, Baltimore; Mr. Edwin J. Woodruff, North Pacific; and Dr. Michael Passmore, formerly Walla Walla, currently WES. The work was conducted under the Engineering Environmental Investments Work Unit of the EEIRP. Dr. J. Craig Fischenich of the Environmental Engineering Division (EED), WES, and Ms. Joy Muncy of the Technical Analysis and Research Division (TARD), IWR, are the Principal Investigators.

The objectives of this work unit are to 1) identify relevant approaches and features for environmental investment measures to be applied throughout the project life; 2) develop methods to access the effectiveness of the approach or feature for providing the intended environmental output; 3) develop and provide guidance for formulating environmental projects; and 4) provide guidance for formulating and identifying relevant cost components of alternate restoration plans.

The objective of this report is to provide a unified approach to planning, implementing, and interpreting monitoring programs for restoration projects. The report is directed at Corps planners to help them identify factors to consider in a monitoring program, and in designing and implementing an efficient, cost-effective program. The report format follows that of a monitoring program and proceeds from identification of goals, through selection of monitoring methods, and finally to interpretation and dissemination of results. The report reviews the use of monitoring results to implement corrective actions to assure that performance goals are met. This report brings together a number of previously published but somewhat unrelated reports that have attempted to develop monitoring approaches.

The work was performed by Pacific Northwest National Laboratory, operated by Battelle Memorial Institute, under terms of a contract with the Corps, IWR. Dr. Ronald M. Thom was the Project Manager. Ms. Joy Muncy was Contract Manager.

The report was prepared under the general supervision at IWR of Mr. Michael Krouse, Chief, TARD; and Mr. Kyle E. Schilling, Director, IWR; and at EL of Mr. Norman R. Francingues, Chief, EED, and Dr. John W. Keely, Director, EL. 
Several individuals provided critical input to this document. These individuals included Mary Kentula, Jeff Brandt, Amy Borde, Susan Thomas, Meg Pinza, Hilary Neckles, Ivan Lines, Gretchen Haslip, John Armstrong, and Arnold Van der Valk. Joy Muncy, William Hansen, and J. Craig Fischenich provided excellent comments on various versions of the report. 


\section{TABLE OF CONTENTS}

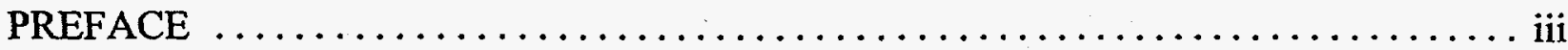

LIST OF TABLES $\ldots \ldots \ldots \ldots \ldots \ldots \ldots \ldots \ldots \ldots \ldots \ldots \ldots \ldots \ldots \ldots \ldots \ldots \ldots \ldots \ldots \ldots \ldots$ viii

LIST OF FIGURES $\ldots \ldots \ldots \ldots \ldots \ldots \ldots \ldots \ldots \ldots \ldots \ldots \ldots \ldots \ldots \ldots \ldots$ viii

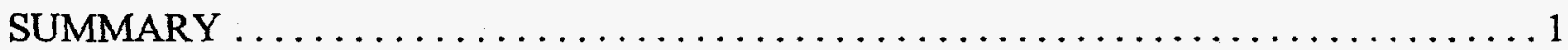

DETAILED PROCESS DESCRIPTION $\ldots \ldots \ldots \ldots \ldots \ldots \ldots \ldots \ldots \ldots \ldots \ldots \ldots \ldots \ldots \ldots \ldots$

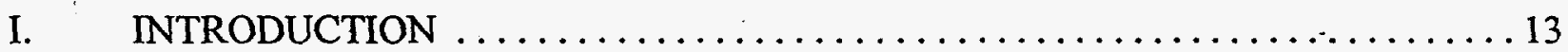

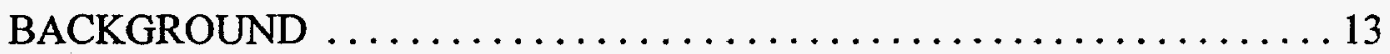

PURPOSE, OBJECTIVES, AND AUDIENCE $\ldots \ldots \ldots \ldots \ldots \ldots \ldots \ldots 14$

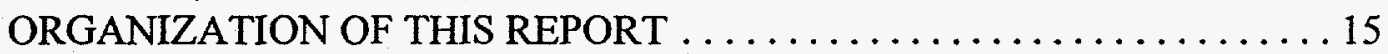

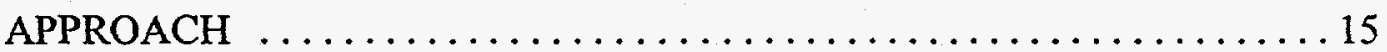

II. BACKGROUND OF AQUATIC RESTORATION MONITORING ........... 19

III. MONITORING AS PART OF A RESTORATION PROJECT $\ldots \ldots \ldots \ldots \ldots \ldots 27$

COMPONENTS OF A SOUND MONITORING PROGRAM $\ldots \ldots \ldots \ldots 27$

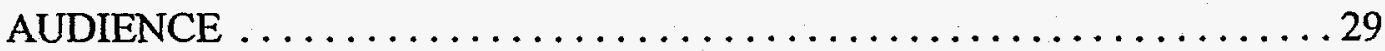

WHEN TO DEVELOP THE MONITORING PLAN $\ldots \ldots \ldots \ldots \ldots \ldots . \ldots 30$

IV. DEVELOPING A MONITORING PROGRAM .................... 31

STEP 1: DEFINE THE RESTORATION VISION, GOALS, AND OBJECTIVES .............................. 31

STEP 2: DEVELOP THE CONCEPTUAL MODEL $\ldots \ldots \ldots \ldots \ldots \ldots 32$

Step 2A: Review Conceptual Model Examples to Help

Formulate Your Model ....................41

Step 2B: Conduct Baseline Studies to Help Formulate the Model . . . 44

Step 2C: Formulate Your Conceptual Model ............... 44

STEP 3: CHOOSE PERFORMANCE CRITERIA $\ldots \ldots \ldots \ldots \ldots \ldots \ldots . \ldots \ldots$

Step 3A: Link Performance to Goals $\ldots \ldots \ldots \ldots \ldots \ldots \ldots \ldots . \ldots \ldots$

Step 3B: Develop the Criteria $\ldots \ldots \ldots \ldots \ldots \ldots \ldots \ldots \ldots \ldots \ldots$

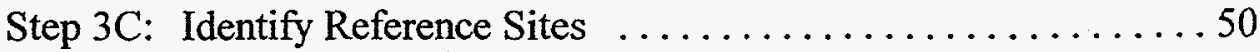

STEP 4: CHOOSE MONITORING PARAMETERS

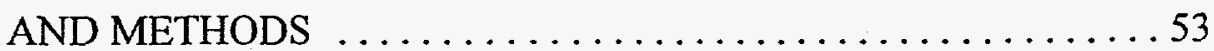

Step 4A: Choose Efficient Monitoring Parameters ............ 53

Step 4B: Choose Methods for Sampling Design, Sampling,

Sample Handling, and Sample Processing $\ldots \ldots \ldots \ldots 55$ 
Step 4C: Incorporate Supplemental Parameters .............. 57

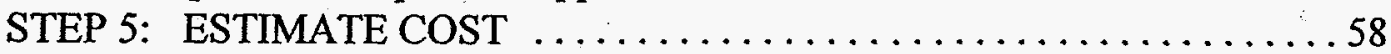

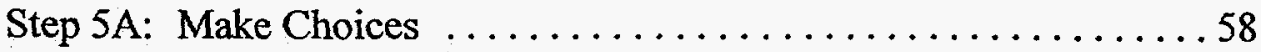

Step 5B: Outline Cost Components ...................60 60

Step 5C: Determine Present Value of Costs . . . . . . . . . . . 65

STEP 6: CATEGORIZE THE TYPES OF DATA ................66

STEP 7: DETERMINE THE LEVEL OF EFFORT AND DURATION $\ldots .68$

Step 7A: Incorporate Landscape Ecology $\ldots \ldots \ldots \ldots \ldots \ldots .68$

Step 7B: Determine Timing, Frequency, and

Duration of Sampling . . . . . . . . . . . . . . . . 69

Step 7C: Develop Statistical Framework ................ 74

Step 7D: Choose the Sampling Level ................. 75

V. IMPLEMENTING AND MANAGING THE MONITORING PROGRAM $\ldots \ldots \ldots 77$

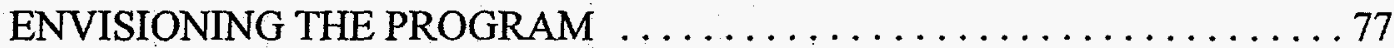

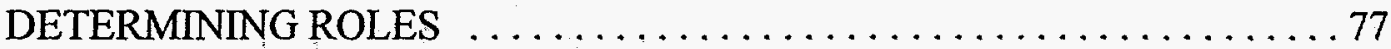

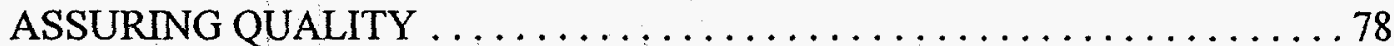

INTERPRETING RESULTS . . . . . . . . . . . . . . . . . . . . 79

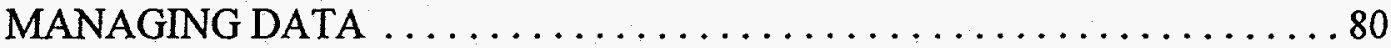

MANAGING CONTRACTS ........................ 80

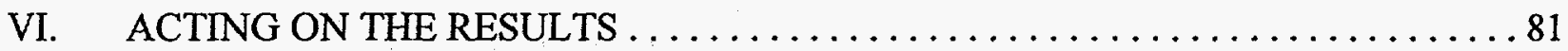

MONITORING AS A MANAGEMENT TOOL $\ldots \ldots \ldots \ldots \ldots \ldots \ldots . \ldots 1$

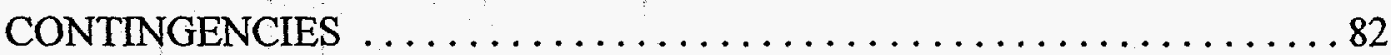

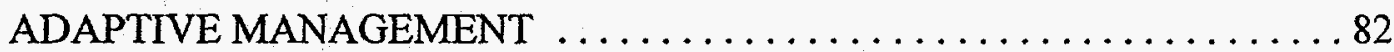

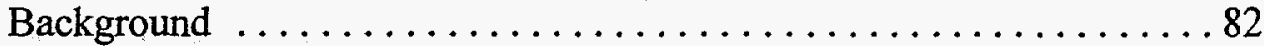

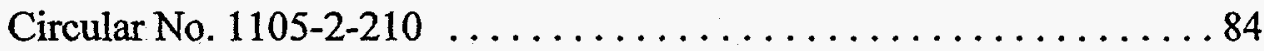

DOCUMENTING AND REPORTING $\ldots \ldots \ldots \ldots \ldots \ldots \ldots \ldots \ldots \ldots$

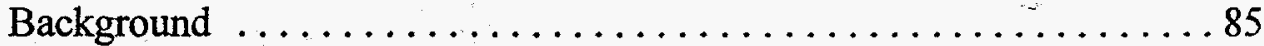

Documentation of Project Information $\ldots \ldots \ldots \ldots \ldots \ldots \ldots \ldots$. 86

Outline for a Monitoring Report $\ldots \ldots \ldots \ldots \ldots \ldots \ldots \ldots$. 87

Length of the Monitoring Report .................... 91

Dissemination of the Results ......................91

VII. LITERATURE CITED $\ldots \ldots \ldots \ldots \ldots \ldots \ldots \ldots \ldots \ldots \ldots \ldots \ldots \ldots \ldots \ldots \ldots \ldots \ldots$

APPENDIX A: EXAMPLES OF MONITORING PARAMETER SELECTION . . . . . . 103 


\section{LIST OF TABLES}

II.1 Publications that present relevant information on monitoring of

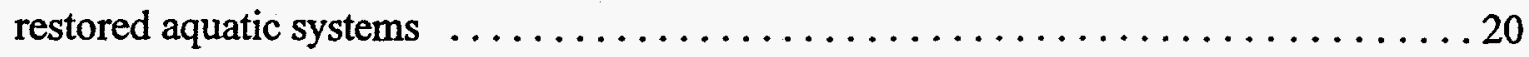

III.1 Monitoring as part of a restoration project $\ldots \ldots \ldots \ldots \ldots \ldots \ldots \ldots \ldots \ldots \ldots \ldots \ldots \ldots \ldots$

IV.1 Examples of restoration project goals for various types of restoration projects . . . . 33

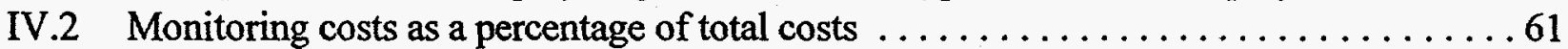

IV.3 An example of timing and schedule for wetland mitigation site

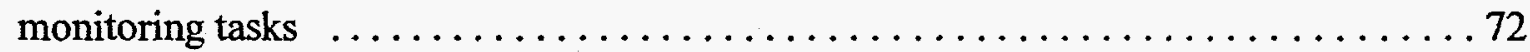

VI.1. Information recommended for inclusion in a data base on restoration projects . . . . 888

VI.2 Main sections and contents of a general performance monitoring report $\ldots \ldots \ldots \ldots 90$

A.1 Wetland functions and measures for assessing restored

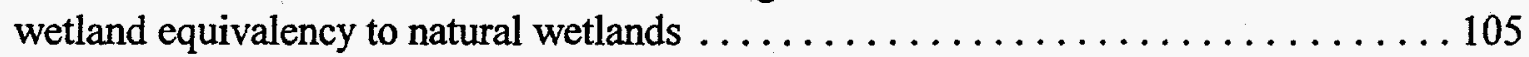

A.2 Rational, uses, and general methods for assessment of restored

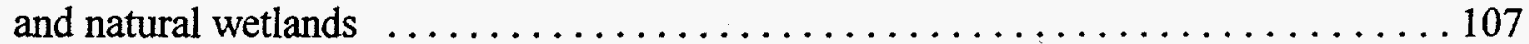

A.3 Candidate indicators for inland surface waters and wetlands

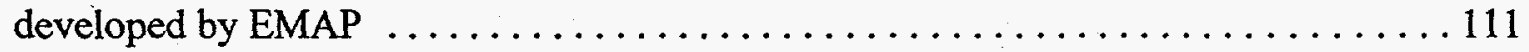

A.4 List of selected Community and Estuarine Profile reports published

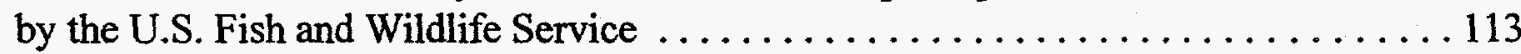

\section{LIST OF FIGURES}

I.1 Flow diagram of monitoring program components $\ldots \ldots \ldots \ldots \ldots \ldots \ldots \ldots \ldots$

IV.1 A conceptual model for a stream restoration project $\ldots \ldots \ldots \ldots \ldots \ldots \ldots \ldots \ldots \ldots \ldots \ldots \ldots \ldots$

IV.2 Conceptual model for Chesapeake Bay submerged aquatic vegetation $\ldots \ldots \ldots \ldots \ldots 43$

IV.3 Examples of ecological performance curves . ....................... 49

IV.4 Eelgrass transplant monitoring data from Grays Harbor, Washington .......... 50

VI.1 Diagram of components of adaptive management strategy

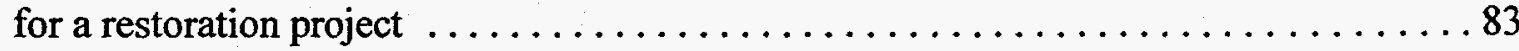




\section{SUMMARY}

This condensed description provides an overview of the process for developing a monitoring program. The detailed description of the process begins on page 13.

\section{INTRODUCTION}

U.S. Army Corps of Engineers (Corps) Circular No. 1105-2-210 (Corps 1995) provides guidance for ecosystem restoration activities in the Corps' Civil Works Program. The document specifies that a carefully designed monitoring program lies at the heart of management of the project. The present report was written to facilitate the design of a restoration project monitoring program. The purpose of this report is to provide a systematic approach to planning, implementing, and interpreting monitoring programs for restoration projects.

The monitoring program is a valuable tool that a restoration project manager uses to determine the project success. Monitoring programs vary widely in level of effort and cost from small, simple programs to large and complex programs. The process defined below can be used to design a program at most levels, because the basic aspects (e.g., performance criteria, parameter selection, sampling intensity) of a monitoring program should be considered at any level.

Uses of the information from a well designed monitoring program:

1. . the project manager can make decisions on how to make cost-effective, mideolirse corrections based upon solid data

? . the project manager can demonstrate to others that the project is meeting (or exceeding) performance goals.

4 the program adds to the understanding of how to best restore systems and contributes signifreantly to the state-of the art of ecological restoration.

\section{MONITORING AS PART OF A RESTORATION PROJECT}

A restoration project has five basic parts or phases. Monitoring should be conceived during the planning phase when the goals and performance criteria are developed for the project. Baseline

Phases of a restoration project:

1. planining

2. construction

3. assessment of performance

4. management of the system

5. dissemination of results. studies required to provide more information on the site, to develop project goals, and to refine the monitoring plan often are conducted during the planning phase, and can be considered the initial phase of the monitoring program. Baseline information can form a very useful data set on preproject conditions against which performance of the system can be evaluated. Monitoring during construction phase is done primarily to assure that the 
restoration plans are correctly carried out and that the natural habitats surrounding the site are not unduly damaged. Actual performance monitoring is implemented in the assessment phase. Management of the system includes both management of the monitoring program as well as application of the results to make midcourse corrections in the system. Finally, results are disseminated to make people aware of the progress of the system, and ultimately, to improve the technology of restoration.

\section{COMPONENTS OF A MONITORING PROGRAM}

Based upon a thorough review of marine monitoring programs, some of which had been in place for over 30 years, the National Research Council (NRC) recommended the following factors applicable to ensure a sound monitoring program (NRC 1990):

- clear monitoring program goals and objectives that are meaningful and that provide the basis for scientific investigation

- appropriate allocation of attention and resources for data collection, management, synthesis, interpretation, and analysis

The goals of a restoration monitoring program are as follows:

- assess the performance of the restoration project relative to the project goals

- provide information that can be used to improve the performance of the project

- provide infornation to interested parties.

- quality assurance procedures and peer review

- supportive research beyond the primary program

- flexible programs that allow modifications where changes in conditions or new information suggests the need

- useful and accessible monitoring information available to all interested parties.

\section{WHEN TO DEVELOP THE MONITORING PROGRAM}

The monitoring plan should be developed in conjunction with planning for the restoration project. Once the goals and objectives for the project are established in the project planning phase, the performance of the system must be considered. At this time, planners must consider how they will judge whether the system is progressing toward its intended goals. 


\section{DEVELOPING A MONITORING PROGRAM}

\section{STEP 1: DEFINE THE RESTORATION VISION, GOALS, OBJECTIVES}

Each restoration project is, at some point, a visual image in the minds of people involved in the project. This vision is the overarching goal upon which the restored ecosystem is developed. The vision can then be refined into a project-specific goal statement. These goals are most useful if they are written so they can be converted into conditions that can be evaluated with appropriate measurements. The project objectives are the steps that will result in attainment of the goal.

The goals that are set for the project drive the monitoring program design. Above all, it is important to do the following:

- make goals as simple and unambiguous as possible

- relate goals directly to the vision for the project

- set goals that are feasibly measured or assessed in the monitoring program.

\section{STEP 2: DEVELOP THE CONCEPTUAL MODEL}

A conceptual model is a useful tool for developing linkages between project-specific goals and parameters that can be used to assess performance. In fact, a conceptual model is a useful tool throughout the planning process, because it forces individuals planning the restoration project to identify the following:

- direct and indirect connections among the physical, chemical, and biological components of the ecosystem

- principal components upon which to focus restoration and monitoring efforts.

A conceptual model typically has the following general form:

Controlling Factors

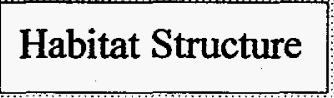

Habitat Function

\section{Step 2A: Review Conceptual Model Examples to Help Formulate Your Model}

It is best to spend some time reviewing conceptual models from your region and for the system that is being restored. 


\section{Step 2B: Conduct Baseline Studies to Help Formulate the Model}

Baseline studies may be necessary to supply the following required information:

- to define conditions without the project

- to identify required actions to restore the system

- to help design the restoration project

- to help design the monitoring program.

\section{Step 2C: Formulate Your Conceptual Model}

The principal factors that control the development and maintenance of the habitat structure, the important habitat characteristics, and the functions for which the habitat was restored are identified in the model. From this information, the parameters to monitor can be more easily selected.

\section{STEP 3: CHOOSE PERFORMANCE CRITERIA}

\section{Step 3A: Link Performance to Goals}

A link between the performance of the system and the goals of the project is critical. If the goals are stated in a clear manner and can be reworded as a set of testable hypotheses, performance criteria can be developed. Performance criteria are standards by which to evaluate measurable or otherwise observable aspects of the restored system and thereby indicate the progress of the system toward meeting the project goals. The closer the tie between goals and performance criteria, the better the ability to judge progress.

\section{Step 3B: Develop the Criteria}

The primary reason for conducting the monitoring program must be kept in mind: to assess progress and to indicate the steps required to fix a system that is not meeting expectations. Hence, it is not necessary to develop a large number of complex measures if a small, simple set of measures will suffice.

Development of criteria is often accomplished by a small group of individuals with system expertise. Larger groups, which

The task of developing performance criteria involves the following.

- linking criteria to the goals for the project

- Iinking criteria to the actual measurement parameters

- specifyng the bounds or limit values for the criteria. may add useful information and input, could tend to create monitoring programs that are too complex or elaborate. Criteria are usually developed through an iterative process that involves listing measures of performance relative to goals and refining these to arrive at the most efficient and relevant set of criteria. 


\section{Step 3C: Identify Reference Sites}

Sites established in reference systems serve three prinary functions:

- they can be used as nodels for developing restoration actions for a site

- they provide a torget fron which performance goals can be derived and against which progress toward these goals can be compared

- they provide a control systen by Which "natural' fluctuations, unrelated to the restoration action, can be assessed:

A reference site or sites should be monitored along with the restored site. Although pre- and post-construction comparisons of the system are useful in documenting the effect of the project, the level of performance can only be judged relative to reference systems.

\section{STEP 4: CHOOSE MONITORING PARAMETERS AND METHODS}

\section{Step 4A: Choose Efficient Monitoring Parameters}

The performance criteria specify the expected structure, function, and appearance of the system, whereas the monitoring parameters are the aspects of the system's structure and function that can be measured.

Develop Measures. This part of the planning process is conducted to develop a scientifically-based, relatively easily-measured set of parameters that provide direct feedback on performance of a system toward meeting the project goals.

There is an overwhelming array of parameters for monitoring aquatic systems and wetlands (e.g., Erwin 1990). The NRC (1992) recommended that at least three parameters should be selected and that they include physical, hydrological, and ecological measures; too few parameters may provide insufficient information to evaluate performance or may provide information that is difficult to interpret.

The conceptual model discussed in Step 2 can be used to select monitoring parameters. Key parameters that provide information on the controlling factors, structure, and function should be selected to provide a strong data set for the system. The basic approach for developing a set of parameters involves the following steps:

1) simplify the system into controlling, structural, and functional components

2) identify one or more key parameters within each of the components

3) justify a subset of parameters from this initial set based on ecological considerations and the project goal. 
Select Region and System-Specific Parameters. The relevance of evaluation criteria depends highly on the system type, region, and question under consideration. Criteria development must be based on a thorough knowledge of the system under consideration. Although there is a vast array of system-specific studies, it is useful to consult a document (see those listed in the main body of the report) that summarizes the fundamental knowledge about the system.

Step 4B: Choose Methods for Sampling Design, Sampling, and Sample Handling and Processing

The basic questions to ask when selecting methods for monitoring are as follows:

- does the method efficiently provide accurate data on the parameters?

- does the method provide reasonable replicable data?

- is the method feasible within time and cost constraints?

Monitoring methods include sampling design, sampling methods, and sample handling and processing. Monitoring methods used on restoration projects in the United States have been extremely varied (Shreffler et al. 1995). Most parameters that might be included in a restoration monitoring program are well established. Any methods used for sampling a particular parameter should have a documented protocol.

\section{Step 4C: Incorporate Supplemental Parameters}

Although the focus of the monitoring program is on parameters that relate directly to assessment of performance, data on other parameters are often useful and may add considerably to interpretation of the results. For example, in a case in which stream flow is not part of the performance goal, it could nonetheless affect a stated goal of stream water temperature. Data on stream flow gathered from gauging stations serviced by the U.S. Geological Survey (USGS), might then be accessed during the monitoring program for a forest riparian restoration project. When planning the monitoring program, it is a good idea to identify sources of potentially useful data and to develop a plan for systematically acquiring the data.

\section{STEP 5: ESTIMATE COST}

\section{Cost Components}

Program Planning. Program planning is an important and often ignored component of a monitoring cost assessment. Program planning involves the determination of monitoring goals and strategies, acceptable and unacceptable results, and potential contingencies for addressing unacceptable results, and it should include agency and interested stakeholder coordination. 
Quality Assurance. A commitment to quality is an integral part of any monitoring program. At a minimum, it includes an independent review of the program to ensure that it meets the project goals, data quality objectives, and expectations of the project manager. The major cost component of quality assurance (QA) is labor (on a per-hour basis), including the indirect costs of benefits and overhead.

Data Management. Programs should have a data management plan that includes specifications that start with sample tracking (i.e., that define the protocols and procedures) and conclude with the final archiving of the information. This generally includes pre-project planning and coordination. The effort is project-dependent, but can range from essentially zero in small programs to a major cost in large multidisciplinary programs. Major costs include staff labor time for data manager, data entry, database maintenance, computer time, and data audits.

Field Sampling Program. Sampling may range from the very simple, such as photo monitoring, wildlife observations, and behavioral observations (e.g., feeding, resting, movement), to the more complex, such as nutrient and contaminant measurements, water quality parameter measurements, plankton group measurement, productivity measurement in water column and substrate surface, macrophytes/vegetation sampling, and hydrological monitoring. The cost components for a complex program may include project management and field staff labor; subcontracts for specific field sampling or measurement activities (including costs of managing and overseeing the subcontracted activities); mobilization and demobilization costs; purchase, rental, or lease of equipment; supplies; travel; and shipping.

Laboratory Sample Analysis. For some complex projects, the analysis of samples collected in the field is critical to determining the effectiveness of restoration actions. Analysis may involve the sampling of chemical, physical, and biological components of the system. Samples requiring laboratory analysis may range from simple water chemistry parameters, such as turbidity, to highly complex and expensive tests, such as organic contaminant analyses and toxicity assays. The cost components of laboratory sample analysis are usually estimated in terms of dollars per sample.

Data Analysis and Interpretation. The analysis of field and laboratory data and their interpretation make up one of the final, critical steps. Analysis and interpretation may require the expertise of trained personnel and may include database management, which can be conducted by a data management specialist if the data are complex, or a technician or project manager if they are relatively straightforward.

Draft and Final Report Preparation. One of the final steps in the monitoring program is to prepare a draft and final report outlining the restoration action, monitoring goals, methods, and findings. These documents are meant to serve as interpretative reports, synthesizing the field and lab data analysis results. The generation of these reports will probably require a certain amount of management/meeting time and will be handled by a research scientist with the aid of a research assistant. Report production costs will depend on the type and quality of reports requested.

Presentation of Results at Professional Meetings. Though not often considered a critical component of a monitoring program, presentation of program results at professional meetings should be 
considered appropriate. The two major cost components of a presentation are labor and per diem for the duration of the conference, workshop, or meeting.

Management of System. Management consists of activities of the project manager and support staff, such as coordination meetings, contractor meetings, report review, contract management, and related tasks. Costs include labor, travel, and supplies. Project management may include day-to-day administration, management, and support services associated with the monitoring program.

\section{STEP 6: CATEGORIZE THE TYPES OF DATA}

There are several types of data gathered as part of the monitoring program that may be useful in developing the program or that may provide additional information on the performance of the system. The project manager should also be aware of available information that is not part of the monitoring program, but that could be useful to it. Consultation with agency personnel, local universities and consultants, citizen environmental groups (e.g., Audubon chapters), and landowners in the area can reveal information of this type.
Tpes of data for various phases of a project.
4. during planining for the project
- 1 develop baseline data at the site
6. during construction.
- 1 nonitor construction activities
5. immediately following construction
. . gather as buill information
9. after censtruction
- 1 gather post-construction data
.. condirct specil studies as needed.

\section{STEP 7: DETERMINE THE LEVEL OF EFFORT AND DURATION}

How much monitoring is required? The answer to this question is dependent on the goals and performance criteria for the project as well as on the type of ecological system being restored. A monitoring program does not need to be complex and expensive to be effective. The appropriate level of effort is that which will produce a well-designed, systematic program that targets key parameters tied to performance criteria and that reports the results of the monitoring effort in a concise and informative way.

\section{Step 7A: Incorporate Landscape Ecology}

The uncertainty associated with the system is a major determinant in the level of effort. A restoration project with high uncertainty and/or very restrictive performance criteria may require a very elaborate and complex monitoring program.

The size or scale of a project affects its complexity. As heterogeneity increases, the problem of effectively sampling the entire system becomes more complex. This means that the system does 
not reside in a vacuum. At the very least, the project manager must be cognizant of the potential effect on system performance by such things as road noise, dogs, dune buggies, air pollution, waterborne contamination, stream flow diversions, human trampling, grazing animals, and a myriad other elements.

\section{Step 7B: Determine Timing, Frequency, and Duration of Sampling}

The monitoring program should be carried out according to a systematic schedule. The plan should include a start date, the time of the year during which field studies should take place, the frequency of field studies, and the end date for the program. Timing, frequency, and duration are dependent on the aspects of system type and complexity, controversy, and uncertainty.

Timing. The monitoring program should be designed prior to conducting any baseline studies. A problem often encountered with this initial sampling is seasonality. Construction may be completed in midwinter, when vegetation and other conditions are not as relevant to the performance criteria and goals of the project, which may focus on midsummer conditions.

The field studies should be carried out during an appropriate time of the year. The driving consideration is the performance criteria. Because weather varies from year to year, it is wise to "bracket" the season with the sampling. For example, sampling temperature four times during the midsummer may be better than a single sampling in the middle of the season. Monitoring can be performed either by concentrating all tasks during a single site visit, or by carrying out one task or a similar set of tasks at several sites in a single day.

Frequency. Frequency of sampling refers to the period of time between samplings. In general, "new" systems change rapidly and should be monitored more often than older systems. As the system becomes established, it is generally less vulnerable to disturbances. Hence, monitoring can be less frequent. An example of this is annual monitoring of a marsh for the first 3 years, followed by monitoring at intervals of 2-5 years for the duration of the project life or until the system stabilizes.

Duration. The monitoring program should extend long enough to provide reasonable assurances that the system has either met its performance criteria, or that it will or will not likely meet the criteria. A restored system should be reasonably self-maintaining after a certain period of time. Fluctuations on an annual basis in some parameters of the system will occur even in the most stable mature systems. It is important for the program to extend to a point somewhere after the period of most rapid change and into the period of stabilization of the system.

\section{Step 7C: Develop Statistical Framework}

The monitoring study design needs to include consideration of statistical issues, including location of sample collection, the number of replicate samples to collect, the sample size, etc. These decisions should be made based upon an understanding of the accuracy and precision required for the data. The ultimate use of the data must be kept in mind when developing the sampling plan. It is useful to frequently ask, "Will this sampling method give me the answers I need to evaluate how the system is doing relative to the performance criteria and goals?" 


\section{Step 7D: Choose the Sampling Level (number of replicates)}

The appropriate level of sampling or the number of replicates under any particular field or laboratory sampling effort depends on information and needed level of accuracy. Quantity and quality of information desired is in turn dependent in part on the expenditures necessary to carry out the identified components of the sampling plan.

\section{IMPLEMENTING AND MANAGING THE MONITORING PROGRAM}

Management of the monitoring program is perhaps the least appreciated but one of the most important components of a restoration project. Because monitoring continues well after construction activities, there is a natural tendency for the program to lose momentum, for the data to accumulate with little analysis, and for little documentation and dissemination of the information. This section presents methods for preventing or minimizing these problems.

\section{Envisioning the Program}

The project manager must have a vision of the life of the monitoring program, and must see how the program fits into the broader topic of restoration as a viable tool for carrying out the mission of both the agency and the cost-sharing sponsor.

\section{Determining Roles}

The responsibility for carrying out the monitoring program generally is that of the project sponsor. However, responsibility should be established clearly in writing during the development of the restoration project, because this responsibility can last for a decade or more.

\section{Assuring Quality}

The project manager should consider data quality as a high priority in the monitoring program. Scientifically defensible data require that at least minimal QA procedures are in place.

\section{Interpreting Results}

Results of the monitoring program should be interpreted with objectivity, completeness, and relevance to the project objectives. The project manager is at least partially responsible for interpretation of the results generated by the monitoring program. In addition, the local cost-sharing sponsor may bear co-responsibility or full responsibility in interpreting the results. The roles of the project manager and local sponsor need to be determined prior to any data-gathering effort. The project manager should seek appropriate technical expertise as needed.

\section{Managing Data}

Data should be stored in a systematic and logical manner that facilitates analysis and presentation. Planning of the monitoring program should address the types of graphs and tables that 
will be used to summarize the results of the monitoring program. Most monitoring data sets can be organized to allow direct graphing of the data using database or spreadsheet software.

\section{Managing Contracts}

One of the most difficult aspects of managing a monitoring program can be management of the contracts required to conduct the program. Most projects require at least some of the work be contracted to a consultant or another agency. Because monitoring programs are frequently carried out on a seasonal basis, timing is important.

\section{ACTING ON THE RESULTS}

\section{Alternative Actions}

Because these are natural systems, unexpected consequences of restoration activities may occur. The three basic options available to the manager are as follows:

- no action - this alternative is appropriate if the project is generally progressing as expected or if progress is slower than expected but will probably meet project goals within a reasonable amount of time.

- maintenance - this alternative refers to physical actions required to maintain the course of project development toward its goals.

- modification of project goals - monitoring may indicate that the project is not progressing toward goals, but is progressing toward a system that has other highly desirable functions. In this case, the manager may decide that the most cost-effective action would be to modify the project goals rather than to make extensive physical changes to meet original goals for the project.

\section{Adaptive Management}

The Corps circular titled "Ecosystem Restoration in the Civil Works Program" (Corps 1995) states that restoration is uncertain, and that it is prudent to allow for contingencies to address problems during, or after, project construction.

Annual assessments of the progress of the system should be made. At that time, decisions can be made regarding any midcourse corrections or other alternative actions, including modification of goals. The annual assessments would use monitoring data, and may require additional data or expertise from outside the project. Because the overall idea is to make the restoration project "work" while not expending large amounts of funds to adhere to inflexible and unrealistic goals, decisions would be made about the physical actions that may be needed versus alterations in project goals. 


\section{Documenting and Reporting}

Documentation and reporting of the progress and development of the restoration project provides written evidence that can be used for a variety of purposes by the project manager. Three simple concepts are common among the best documented projects:

- a single file was developed that was the repository of all project information

- the events and tasks of the project were recorded chronologically in a systematic manner

- well-written documents (i.e., planning and monitoring) were produced and distributed widely enough to become part of the general regional or national awareness of the project.

Main sections in a general format for a monitoring report should include a title page, summary or abstract, introduction, site description, methods, results, discussion, conclusions, recommendations, acknowledgments, and literature cited. The length of a monitoring report will vary with the size and complexity of the project. Small projects with simple performance goals and criteria, few target parameters, and limited physical modification of the site can

Sone reasons to prepare some form of written documentation:

- demonstrates that the project is being conducted

- demonstrates that the project neets the design criteria and performance critenia

- . assists in discussions, with others about the status of the project.

4. documents details that nay be otherwise forgotten

- provides valiable information to new individuals normally be reported in 10 or fewer pages of double-spaced text, with additional pages for figures and tables. Larger, more complex projects may require up to 30 pages of text.

\section{Dissemination of the Results}

Recipients of the report and other monitoring information should include all interested parties, and those who by regulation must get copies (e.g., all state and federal agencies involved in a permit action). In addition, complete files should be maintained. The audience can include beachgoers, birders, fishers, developers, industry representatives; engineers, government environmental managers, politicians, and scientists. The recipient list and schedule for delivery of the reports should be developed by the project manager. If appropriate, a meeting with interested parties should be held to present the results of the monitoring effort and to discuss the future of the project. Large, complex, and expensive projects may have wide appeal and interest, and meetings on these projects will require more planning. Presentations should be tailored to the audience to provide the information in the clearest and most relevant form. 


\section{DETAILED PROCESS DESCRIPTION}

\section{INTRODUCTION}

The monitoring program is a valuable tool that a restoration project manager uses to determine the project success. Just like engineers used information from early bridge designs to make subsequent bridges stronger, so can the restoration project manager and others use information from restoration projects to design better restoration projects. When the project manager sits down at the table with interested parties to discuss the project, he or she should be confident in having a set of defensible information (i.e., data and observations) upon which to base decisions, and to justify the effort and cost for the restoration project. A monitoring program provides this information.

\section{U.S. Army Corps of Engineers} (Corps) Circular No. 1105-2-210 (Corps 1995) provides guidance for ecosystem

Uses of the infornation from a well designed monitoring program.

- . the project manager ean make decisions on how to make cost-effective, midcourse corrections based upon solid data.

- . the project manager can demonstrate to others that the project is meeting (or exceeding) gerformance geals.

- . the progran adds to the understanding of how to best restore systems and contributes significantly to the state of the art of ceological restoration. restoration activities in the Corps' Civil Works Program. In that document, adaptive management is put forth as the technique to be employed in restoration project because "success can vary due to a variety of technical and site specific factors." The document further specifies that a carefully designed monitoring program lies at the heart of adaptive management. The present report was written to facilitate the design of a restoration project monitoring program.

\section{BACKGROUND}

Hundreds of millions of dollars are invested annually in aquatic restoration through federal programs such as Superfund, the Endangered Species Act, and the Clean Water Act as well as regional, state, and local programs. The Corps plays a significant role in aquatic restoration through both the implementation of water resources and restoration projects and its regulatory authority under Section 404 of the Clean Water Act. The Corps' Evaluation of Environmental Investments Research program (EEIRP) was initiated to provide Corps planners with methods and techniques to aid in development of environmental restoration and mitigation projects. To date, the EEIRP has 
produced documents on several aspects of plan formulation, ranging from conceptual frameworks (Scodari et al. 1995) to costing of restoration projects (Shreffler et al. 1995).

Neither aquatic system restoration nor compensatory mitigation has always been successful. Based largely on a series of early restoration efforts that were poorly carried out and/or monitored, the National Research Council (NRC) concluded that most restoration projects are failures (NRC 1992). Because restoration projects can cost millions of dollars to implement, and because aquatic restoration to date has had poor success, there is a critical need to develop a more systematic and defensible approach to restoration of these ecosystems. The NRC identified several critical aspects of restoration projects that could improve the probability of success. One major factor was monitoring. Monitoring programs associated with restoration and mitigation projects have largely been ineffective in assessing the actual performance of the system. This inadequacy leads to a poor understanding of the problems and limits development of remedial actions to improve the performance of the project. Problems in monitoring programs largely occur during program development and implementation phases. Much of the information generated by monitoring programs ends up filed away or so closely guarded that it is unavailable to others. Because the overall goal on a national level is to improve both the probability and predictability of success for restoration, adequate monitoring is critical. Objective information on restoration and mitigation efforts is needed for the advancement of restoration technology.

There is no unified approach to monitoring and assessing restoration projects within the Corps. Although efforts such as the hydrogeomorphic (HGM) functional assessment method is presently being developed and could serve as a method for monitoring restoration projects (Brinson 1993), full implementation of HGM or any other approach is not likely in the near future. Yet, projects continue to be planned and built, and there is an acute need to conduct systematic evaluations of the success of these efforts in order to assure that the projects meet their objectives and that information gained on the project can be used to plan future projects.

\section{PURPOSE, OBJECTIVE, AND AUDIENCE}

The purpose of this report is to provide a systematic approach to planning, implementing, and interpreting monitoring programs for restoration projects. The objective of the report is to show how a monitoring program proceeds from identification of restoration project goals, through selecting monitoring methods, and finally to interpretation and dissemination of results. The use of monitoring results to implement corrective actions is also described. This report is not a "how to" manual of the specifics of sampling, sample processing, statistical analysis of data, etc., but rather a guide to fundamental elements of a monitoring program for aquatic restoration.

The report presents all major aspects of a monitoring program. Funding and priorities will necessarily limit the level of effort devoted to any specific monitoring program. We address this 
issue in the report, but acknowledge that decisions will have to be made on a case-by-case basis on the level of effort incorporated into a monitoring program. This report presents the components that at the very least, need to be considered to develop credible data. The report provides guidance on selection of key parameters to include in order to eliminate unnecessary data gathering and analysis. Therefore, individuals responsible for programs with very little funding for monitoring can make some systematic decisions about what to include or exclude from the program. The report is directed at Corps planners to help them identify factors to consider in a monitoring program, and to design and to implement an efficient, cost-effective program.

\section{ORGANIZATION OF THIS REPORT}

The report is divided into five major sections following the introduction. The sections include Background of Aquatic Restoration Monitoring (II), Monitoring as Part of a Restoration Project (III), Developing a Monitoring Program (IV), Implementing and Managing the Monitoring Program (V), and Acting on the Results (VI). This organization is designed to lead from an overview of the role of the monitoring plan, through specifics on how to plan an efficient monitoring scheme, how to implement and manage the program, and finally how to interpret and act on the results (Figure I.1). Case studies are interspersed in the report to provide examples of monitoring programs that can be used as models for designing future programs.

\section{APPROACH}

This report was prepared through a search of the literature and discussions with key individuals involved in the implementation of restoration monitoring programs. This information included up-to-date guidelines from the NRC, U.S. Environmental Protection Agency (EPA), and U.S. Fish and Wildlife Service (USFWS) as well as the Corps, and to a limited extent, state and local agencies. Because an overwhelming amount of published and unpublished literature of environmental monitoring studies exists, the literature review focused on "synthesis documents" that summarize and provide guidance on conducting environmental monitoring programs. 


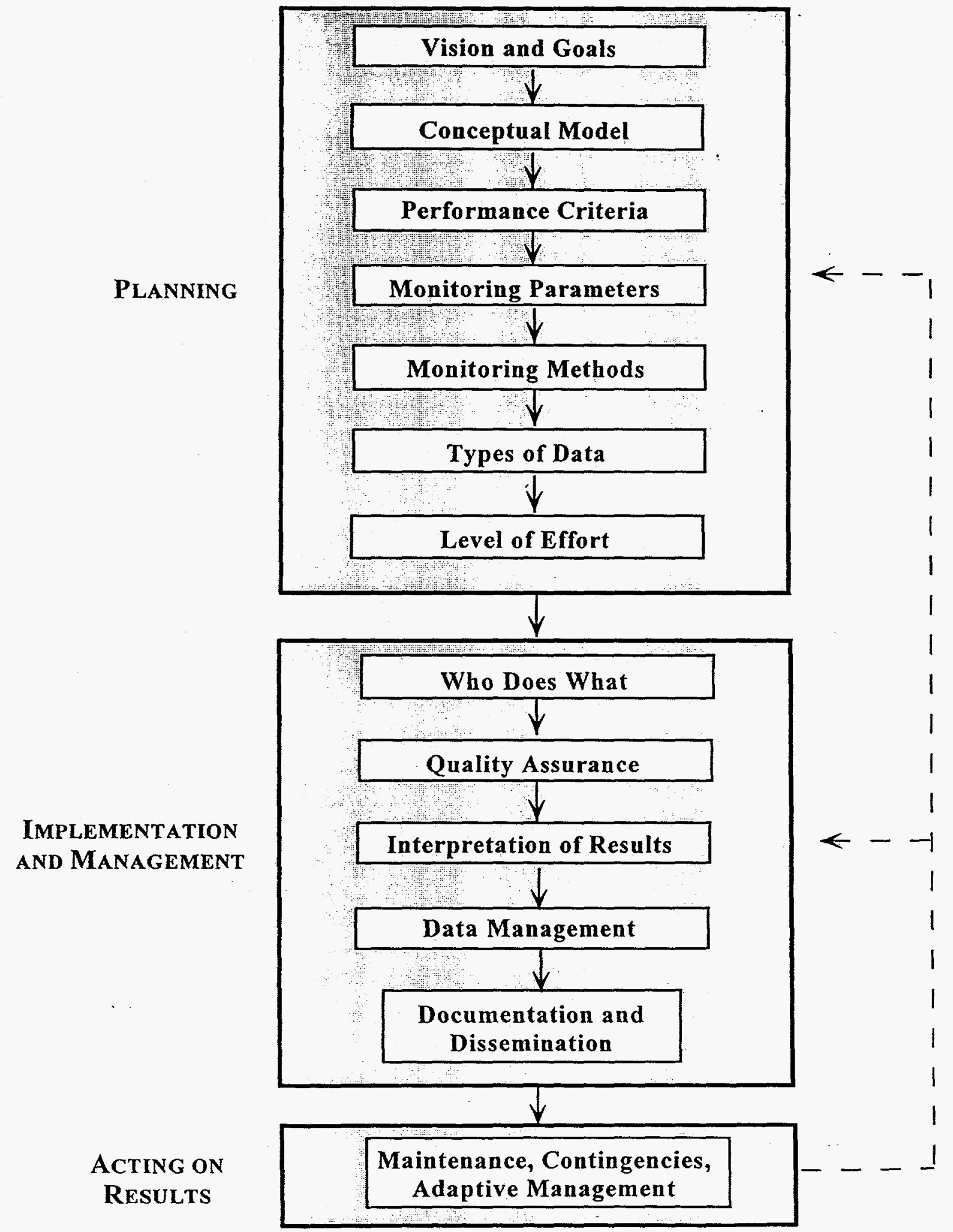

FIGURE I.1. Flow diagram of monitoring program components 
The Institute for Water Resources (IWR) and the Waterways Experiment Station (WES) have produced several documents that guided the development of this report and provided the framework within which it was designed to fit. Documents reviewed were the following: Economic Considerations in Mitigation Planning (The Greeley-Polhemus Group, Inc. 1991), First Steps in Development of a Method for Evaluating Environmental Restoration Projects (Russell et al. 1992), Values of Environmental Protection and Restoration (Klein et al. 1993), Wetland Mitigation Banking (Environmental Law Institute 1994, Brumbaugh and Reppert 1994, Apogee Research, Inc. 1994), Programs for Determining Significance and Prioritization of Environmental Resources (Doll 1994), Review of Monetary and Non-monetary Environmental Investments (Feather et al. 1995a), Prototype Informational Tree for Environmental Plan Formulation and Cost Estimation (Scodari et al. 1995), Compilation and Review of Completed Restoration and Mitigation Studies in Developing Evaluation Framework for Environmental Resources (Feather and Capan 1995a, 1995b), Resource Significance (Apogee Research, Inc. 1995), Trade-off Analysis for Environmental Projects (Feather et al. 1995b), National Review of Non-Corps Restoration Projects (Shreffler et al. 1995), National Review of Corps Restoration Projects (Muncy et al. 1996) and Development of Guidance on Restoration Planning (Yozzo et al. 1996).

The next section covers the background of restoration site monitoring and identifies the key reasons for conducting a monitoring program. In addition, the several major programs in the field of restoration monitoring now underway are described. 


\section{BACKGROUND OF AQUATIC RESTORATION MONITORING}

The ecological "performance" of restored aquatic systems has been monitored at sites throughout the United States. Monitoring programs have varied widely in level of effort, measured parameters, sampling methods, sampling frequency, and duration (Kentula et al. 1992a; Shreffler et al. 1995). Reporting has also varied widely from little or no documentation to publication of results in peer-reviewed scientific journals and books. Much of the variation is related to the availability of funds to support monitoring. Riparian forested wetlands require methods and sampling frequencies different from those appropriate to planktonic systems, for example.

Several recent publications address the need for a more unified and systematic approach to monitoring, especially as related to restoration and mitigation projects (see Table II.1). Some key programs that have a major focus on monitoring restored aquatic systems include the WES Wetland Research Programs directed at the beneficial use of dredged material, the USFWS Waterfowl Enhancement Program, the Coastal Restoration Program

The National Research Council (NRC 1990), reviewed the status of marine environmental monitoring, with the following conclusions:

1. the role of monitoring in environmental management needs to be strengthened

- . monitoring of regional and national status and trends needs to be comprehensive

4. 1honiloring program design needs improvement

1. Information products (documents) need to be more useful. of the National Oceanic and Atmospheric Administration (NOAA), and the Coastal Wetlands Planning, Protection, and Restoration Act Program (CWPPRA). The Corps has a long history of developing methods for creating wetland systems on dredged material, and has produced several key documents detailing monitoring of these systems (e.g., Newling and Landin 1985). The Upper Mississippi River Management System Environmental Management Program (UMRS-EMP) of the Corps has a major monitoring component (Corps 1992). The UMRS-EMP is designed to protect and balance the resources of the Upper Mississippi River Basin and to guide river management. Among the five elements in the program are two that directly address restoration monitoring: (1) habitat rehabilitation and enhancement projects, and (2) long-term resource monitoring. Waterfowl enhancement through USFWS has become routinely successful. The NOAA restoration program is relatively new, but could potentially develop into a major coastal restoration program through implementation of Superfund cleanup actions (Thayer 1992). The CWPPRA was set up to develop a project-oriented program to combat wetland loss in Louisiana (Steyer and Stewart 1992). This program has produced a guidance document on monitoring of CWPPRA projects in Louisiana. 
Table II.1. Publications that present relevant information on monitoring of restored aquatic systems

Bottomland Hardwood Wetlands

Gosselink, J.G., And L.C. Lee. 1989. Cumulative Impact Assessment in Bottomland Hardwood Forests. Wetlands 9:89-174.

Gosselink, J.G., L.C. Lee, and T.A. Muir. 1990. Ecological Processes and Cumulative Impacts. Lewis Publishers, Inc., Chelsea, Michigan.

Central California Coastal Systems

Josselyn, M.N., And J.W. Buchholz. 1984. Marsh Restoration in San Francisco Bay: a Guide to Design and Planning. Technical Report \#3, Tiburon Center for Environmental Studies, San Francisco State University, San Francisco, California.

Coastal Louisiana

Boesch, D.F., M.N. Josselyn, A.J. Mehta, J.T. Morris, W.K. Nuttle, C.A. Simenstad, and D.J.P. Swift. 1994. Scientific Assessment of Coastal Wetland Loss, Restoration and Management in Louisiana. Journal of Coastal Research Special Issue No. 20.

Duffy, W.G. and D. Clark, Editors. 1989. Marsh Management on Coastal Louisiana: Effects and Issues-Proceedings of a Symposium. Biol. Rep. 89(22). Louisiana Department of Natural Resources and U.S. Fish and Wildlife Service, Washington, D.C.

Steyer, G.D. and R.E. Stewart. 1992. Monitoring Program for Coastal Wetlands Planning, Protection, and Restoration Act Projects. Open File report 93-01. U.S. Fish and Wildlife Service, National Wetlands Research Center, Louisiana.

Coastal Southern California

Pacific Estuarine Research Laboratory. 1990. A Manual for Assessing Restored and Natural Coastal Wetlands with Examples from Southern California. California Sea Grant Report No. T-CSGCP-021. La Jolla, California.

Zedler, J.B. 1984. Salt Marsh Restoration: a Guidebook for Southern California. California Sea Grant Report No. T-CSGCP-009. California Sea Grant College Program, Institute of Marine Resources, University of California, La Jolla, California.

Zedler, J.B., C.S. Nordby and B.E. Kus. 1992. The ecology of Tijuana estuary, California: A National Estuarine Research Reserve. National Oceanic and Atmospheric Administration, Office of Coastal Resource Management, Sanctuaries and Reserves Division, Washington, D.C.

Zedler, J.B., Principal Author. 1996. Tidal Wetland Restoration: A Scientific Perspective and Southern California Focus. California Sea Grant Report No. T-038. California Sea Grant College System, University of California, La Jolla, California. 


\section{TABLE II.1. (contd)}

\section{Dredged Material}

Newling, C.J., And M.C. Landin. 1985. Long-term Monitoring of Habitat Development at Upland and Wetland Dredged Material Disposal Sites 1974-1982. Technical Report D-85-5. Dredging Operations Technical Support Program, Waterways Experiment Station, U.S. Army Corps of Engineers, Vicksburg, Mississippi.

\section{Economic Assessment}

Lipton, D.W., K.F. Wellman, I.C. Sheifer, and R.F. Weiher. 1995. Economic Valuation of Natural Resources-- a Handbook for Coastal Resource Policy Makers. Decision Analysis Series No. 5., Coastal Ocean Program, National Oceanic and Atmospheric Administration Silver Spring, Maryland.

Shreffler, D.K., R.M. Thom, M.J. Scott, K.F. Wellman, M.A. Walters, and M. Curran. 1995. National Review of Non-corps Environmental Restoration Projects. IWR Report 95-R-12. Prepared for Institute for Water Resources, U.S. Army Corps of Engineers, Alexandria, Virginia.

\section{EPA Wetlands Research Program}

Abbruzzese, B., A.B. Allen, S. Henderson, and M.E. Kentula. 1988. "Selecting Sites for Comparison with Created Wetlands." In Proceedings of Symposium '87--Wetlands/Peatlands, compiled by C.D.A. Rubec and R.P. Overend, pp. 291-297. Edmonton, Alberta, Canada.

Kentula, M.E., R.P. Brooks, S.E. Gwin, C.C. Holland, A.D. Sherman, and J.C. Sifneos. 1992. An Approach for Improving Decision Making in Wetland Restoration and Creation. EPA/600/R-92/150. U.S. Environmental Protection Agency, Environmental Research Laboratory, Corvallis, Oregon.

Kusler, J.A., and M.E. Kentula, eds. 1990. Wetland Creation and Restoration, the Status of the Science. Island Press, Washington, D.C.

Leibowitz, B. Abbruzzese, P.R. Adamus, L.E. Hughes and J.T. Irish. 1992. A Synoptic Approach to Cumulative Impact Assessment. EPA/600/R-92/167. U.S. Environmental Protection Agency, Environmental Research Laboratory, Corvallis, Oregon.

Magee, T.K., K.A. Dwire, S.E. Gwin, P.W. Shaffer, C.C. Holland, and J. Honea. 1995. Field and Laboratory Operations Report for the Oregon Wetlands Study. EPA/600/R-95/024. U.S. Environmental Protection Agency, Environmental Research Laboratory, Corvallis, Oregon.

Sifneos, J.C., D.L. Frostholm, M.E. Kentula, M. Rylko, and K. Kunz. 1991. A Pilot Study to Compare Created and Natural Wetlands in Western Washington and Evaluate Methods. EPA/600.R-92/013. NTIS Accessions Number PB92 136 811. U.S. Environmental Protection Agency, Environmental Research Laboratory, Corvallis, Oregon.

Fish Habitat Restoration

Adams, M.A., and I.W. Whyte. 1990. Fish Habitat Enhancement, a Manual for Freshwater, Estuarine and Marine Habitats. DFO 4474. Department of Fisheries and Oceans, Canada. 
Planning Aquatic Ecosystem

Restoration Monitoring Programs

TABLE II.1. (contd)

General Systems

Hunsaker, C.T., and D.E. Carpenter, eds. 1990. Environmental Monitoring and Assessment Program. Ecological Indicators. EPA 600/3-90/060. U.S. Environmental Protection Agency, Office of Research and Development, Research Triangle Park, North Carolina.

EPA (U.S. Environmental Protection Agency). 1991. Biological criteria: research and regulation, proceedings of a symposium. EPA-440/5-91-005. U.S. Environmental Protection Agency, Washington, D.C.

\section{General Wetlands}

Brinson, M.M. 1993. A hydrogeomorphic classification for wetlands. Technical Report WRP-DE-4. Wetlands Research Program, U.S. Army Corps of Engineers, Washington, D.C.

Brinson, M.M., Kruczynski, L.C. Lee, W.L. Nutter, R.D. Smith, and D.F. Whigham. 1994. "Developing an approach for assessing the functions of wetlands." In Global Wetlands; Old and New, ed. W.J. Mitsch, Elsevier Science.

Schneller-McDonald, K., and, L.S. Ischinger and G.T. Auble. 1990. Wetland creation and restoration: description and summary of the literature. Biological Report 90(3). U.S. Fish and Wildlife Service, Washington, D.C.

Wheeler, B.D., S.C. Shaw, W.J. Fojt and R.A. Robertson, eds. 1995. Restoration of temperate wetlands. John Wiley \& Sons, New York, New York.

Marine Coastal Restoration General

Desbonnet, A. P. Pogue, V. Lee, and N. Wolff. 1994. Vegetated buffers in the coastal zone--a summary review and bibliography. Coastal Resources Center Technical Report No. 2064. University of Rhode Island Graduate School of Oceanography, Narragansette, Rhode Island.

Dobson, J.E., E.A. Bight, R.L Ferguson, D.W. Field, L.L Wood, K.D. Haddad, H. Iredale III, J.R. Jensen, V.V. Klemas, R.J. Orth, and J.P. Thomas. 1995. National Oceanic and Atmospheric Administration Coastal Change Analysis Program (C-CAP): Guidance for Regional Implementation. NOAA Technical Report Series NMFS 123. U.S. Department of Commerce, Seattle, Washington.

Kiraly, S.J., F.A. Cross and J.D. Buffington, Editors. 1990. Federal coastal wetland mapping programs: a report by the National Ocean Pollution Policy Board's Habitat Loss and Modification Working Group. U.S. Fish and Wildlife Service, Washington, D.C.

Thayer, G.W. 1992. Restoring the Nation's Marine Environment. A Maryland Sea Grant Book. College Park, Maryland.

Vestal, B., A. Reiser, M. Ludwig, J. Kurland, C. Collins and Jill Ortiz. 1995. Methodologies and Mechanisms for Management of Cumulative Coastal Environmental Impacts. Part I--Synthesis, with Annotated Bibliography; Part II--Development and Application of a Cumulative Impacts Assessment 
TABLE II.1. (contd)

Protocol. Decision Analysis Series No. 6. Coastal Ocean Program, National Oceanic and Atmospheric Administration, Silver Spring, Maryland.

National Research Council (NRC)

NRC (National Research Council). 1990. Managing troubled water, the role of marine environmental monitoring. National Academy Press, Washington, D.C.

NRC (National Research Council). 1992. Restoration of aquatic ecosystems. National Academy Press, Washington, D.C.

NRC (National Research Council). 1995. Wetlands: characteristics and boundaries. Draft. National Academy Press, Washington, D.C.

\section{Pacific Northwest Systems}

FEMAT (Forest Ecosystem Management Assessment Team). 1993. Forest ecosystem management: an ecological, economic, and social assessment. U.S. Forest Service, U.S. Department of Agriculture, Washington, D.C..

Shreffler, D.K., and R.M. Thom. 1993. Restoration of Urban Estuaries: New Approaches for Site Location and Design. Prepared for Washington State Department of Natural Resources, Olympia, Washington.

Simenstad, C.A., C.D. Tanner, R.M. Thom and L.L. Conquest. 1991. Estuarine Habitat Assessment Protocol. Prepared for U.S. Environmental Protection Agency, Region 10. Seattle, Washington.

Strickland, R. 1986. Wetland Functions, Rehabilitation, and Creation in the Pacific Northwest: the State of Our Understanding. Publication No. 86-14. Washington State Department of Ecology, Olympia, Washington.

Williams, G.L. 1989. Coastal/Estuarine Fish Habitat Description \& Assessment Manual-Part I Special Habitat Outlines. Prepared for Unsolicited Proposals Program, Supply and Services Canada, Hull, Québec.

\section{Seagrasses}

Batiuk, R.A., R.J. Orth, K.A. Moore, W.C. Dennison, J.C. Stevenson, L.W. Staver, V. Carter, N.B. Rybicki, R.E. Hickman, S. Kollar, S. Bieber, and P. Heasley. 1992. Chesapeake Bay Submerged Aquatic Vegetation Habitat Requirements and Restoration Targets: a Technical Synthesis. U.S. Environmental Protection Agency, Chesapeake Bay Program.

Fonseca, M.S., 1990. "Regional Analysis of the Creation and Restoration of Seagrass Systems." In Wetland Creation and Restoration, the Status of the Science, eds. J.A. Kusler and M.E. Kentula, pp. 175-198. Island Press, Washington, D.C.

Fonseca, M.S. 1992. "Restoring seagrass systems in the United States." In Restoring the Nation's Marine Environment, G.W. Thayer, pp. 79-110. Maryland Sea Grant College Publication UM-SG-TS-92-06, College Park, Maryland. 


\section{TABLE II.1. (contd)}

Fonseca, M.S. No Date. A Guide to Planting Seagrasses in the Gulf of Mexico. Texas A\&M University Sea Grant College Program.

Phillips, R.C. 1982. "Seagrass meadows." In Creation and Restoration of Coastal Plant Communities, ed. R.R. Lewis, pp. 173-202. CRC Press, Boca Raton, Florida.

\section{Spartina alterniflora Marsh Restoration}

Matthews, G.A and T.J. Minello. 1994. Technology and Success in Restoration, Creation, and Enhancement of Spartina alterniflora Marshes in the United States. Volume 1- Executive Summary and Annotated Bibliography. Decision Analysis Series No. 2. Coastal Ocean Program, National Oceanic and Atmospheric Administration, Silver Spring, Maryland.

Wetlands for Wastewater Treatment

Marble, A.D. 1991. A guide to wetland functional design. Lewis Publishers, Boca Raton, Florida.

Phillips, R.C. H.E. Westerdahl, A.L. Mize, and S.A. Robinson. 1993. Summary of Literature Describing the Functional Ability of Wetlands to Enhance Wastewater Quality. Technical Report WRP-CP-2. U.S. Army Engineer Waterways Experiment Station, Vicksburg, Mississippi.

The Wetlands Research Program implemented by the EPA Corvallis Research Laboratory has based much of its research on the premise that in order to create and restore wetlands, a comprehensive program is needed to understand the ecological functions of wetlands (Kentula et al. 1992b). Kentula et al. stated that "efforts to evaluate success of wetland restoration and creation projects have been complicated by a lack of stated project goals and by a lack of agreement on what constitutes success." To help define success of projects, the Program has developed an approach for establishing ecological criteria for wetland restoration and creation based upon their research. Kentula et al. found that monitoring, a key element of the Wetlands Research Program approach, is seldom performed.

Two important concepts have recently emerged as being highly relevant to the field of aquatic ecosystem restoration and monitoring of restored systems. First, the principles of landscape ecology have driven restoration ecologists to look beyond the local restoration site and to consider the surrounding elements of the landscape. This is important in that the restored site depends to a certain degree on inputs and connections with the surrounding environment, and that siting of restoration projects may be facilitated by first considering where restoration might best fit into the landscape (Shreffler and Thom 1993). Monitoring programs must include some information on the factors affecting the restored system on a landscape scale. 
The second concept involves development of a wetland classification system using the hydrogeomorphic approach (Brinson 1993). This approach recognizes that a certain set of physical and hydrological characteristics must be present in order for a wetland to develop and to function properly. In a restoration context, this approach is useful for developing site plans and for monitoring and assessing functional performance. In a recent review of wetland delineation methods, the NRC endorsed the validity of the hydrogeomorphic approach (NRC 1995).

The literature review, which is further summarized in the following sections, generally shows that monitoring programs for restoration vary dramatically from project to project. Many programs have been ineffective in assessing performance of the restored system (NRC 1992; Kentula et al. $1992 \mathrm{~b})$. There is an urgent need to develop a more systematic approach to monitoring restored systems to provide data that can be used to judge the progress of the restored system toward project goals and to assist in the management and maintenance of the system. 


\section{MONITORING AS PART OF A RESTORATION PROJECT}

A restoration project has five basic parts or phases (Table HII.1):

1. planiing

2. construction

3. assessment of performance

4. managemeni of the system:

5. dissemination of results.
Monitoring should be:conceived during the planning phase when the goals and performance criteria are developed for the restoration project. Baseline studies required to provide more information on the site, to develop project goals, and to refine the monitoring plan often are conducted during the planning phase, and can be considered the initial phase of the monitoring program. Baseline information can form a very useful data set on pre-project conditions against which performance of the system can be evaluated.

Monitoring during construction phase is done primarily to assure that the restoration plans are correctly carried out and that the natural habitats surrounding the site are not unduly damaged. Actual performance monitoring is implemented in the assessment phase. Management of the system includes both management of the monitoring program, as well as application of the results to make midcourse corrections in the system. Finally, results are disseminated to make people aware of the progress of the system, and ultimately, to improve the technology of restoration.

\section{COMPONENTS OF A MONITORING PROGRAM}

Based upon a thorough review of marine monitoring programs, some of which had been in place for over 30 years, the NRC (1990) recommended the following factors applicable to ensure a sound monitoring program:

- clear monitoring program goals and objectives that are meaningful and that provide the basis for scientific investigation

- appropriate allocation of time and resources for data collection, management, synthesis, interpretation, and analysis

The goals of a restoration monitoring program are as follows.

- 4 assess the performance of the restoration project relative to the project goals

- - provide information that can be used to improve the performance of the projeet

- . provide information to interested parties.

The objectives of a restoration monitoring program are the steps that will result in attaining the monitoring program goals. 
TABLE III.1. Monitoring as part of a restoration project

Planning

Selecting the restoration strategy

Developing a vision

Selecting habitat type

Developing goals

Developing the conceptual model

Selecting a site

Establishing performance criteria

Engineering a design

Analyzing cost

Budgeting

Scheduling

Financing

Documenting

Conducting peer review

Construction

Converting the vision to a real project
Assessment of performance

Linking performance and goals

Developing methods to assess performance

Establishing timelines and predictions

Determining statistical considerations

Determining reference sites

Management of the project

Conducting adaptive management

Maintaining continuity of the project

Dissemination of results
Baseline monitoring

Initial development of the monitoring plan

Implementation of performance monitoring

Application of monitoring results to improve the progress and success of the restoration project 
- quality assurance procedures and peer review

- supportive research beyond the primary program

- flexible programs that allow modifications where changes in conditions or new information suggests the need

- useful and accessible monitoring information available to all interested parties.

Although the NRC's recommendations appear to be research-oriented, they are designed to ensure that the monitoring programs produce defensible results that satisfy the general objectives, while acknowledging that even the best conceived plan may need revision once implemented. The $\mathrm{NRC}$ also recognizes the need to make the monitoring data readily available and useful.

Using the above recommendations, guidance on how to develop a restoration monitoring program as applied to Corps restoration projects is provided in the following three sections. In Section IV, the parameters to be measured and a rationale for selection are discussed. In addition, the section covers fundamentals of choosing monitoring methods, incorporating cost into decisions, selecting the types of data that will be gathered, and determining the level of effort needed. Program implementation is covered in Section V, which also identifies the important aspects of documentation and reporting. Finally, Section VI discusses how to make decisions on what to do if the project is not developing as planned.

\section{AUDIENCE}

The NRC (1990) pointed out the importance of recognizing the audience interested in the results of the restoration project. This audience can include beach-goers, birders, fishers, developers, industry representatives, engineers, government environmental managers, politicians, and scientists. Hence, the monitoring program can meet many needs. Monitoring information is critical for the project manager to determine whether the project is proceeding toward the goals or if adjustments are neccessary. Furthermore, monitoring provides information essential to the verification
Examples of the aadience and reasons for their interest:

Developers and nanagers

Is the project achieving the stated goals?

How do we need to adjust the project?

How can we minimize cost and maximize performance?

- Scientists and Planners

What can we learn from this project to improve future projects?

How does performance fit predictions?

- Resource Users

Is the resource benefiting?

Is the public benefiting? 
of predictive models and provides managers with a rationale for setting goals in future restoration projects (NRC 1990).

Understanding the audience and its needs is critical to the monitoring effort. Compiling a list of known and potentially interested parties, along with a statement about the use that each party may make of the information is helpful. This list is often easy to compile based upon meetings held during preliminary development of the restoration project, and it can later serve as a mailing list for documents produced by the project.

\section{WHEN TO DEVELOP THE MONITORING PLAN}

The monitoring plan should be developed in conjunction with planning for the restoration project. Once the goals for the project are established in the project planning phase, the performance of the system must be considered. Hence, this is the appropriate time to establish the monitoring plan. Modifications in the plan can be made later, if there is new knowledge about the site or changes in funding level, for example. Development of the monitoring plan need not be long, time-consuming and laborious. The most efficient plans are developed by knowledgeable individuals in a relatively short period of time. Professionals involved in complex monitoring programs can generally develop an efficient plan in less than a week. For simple projects, draft plans can be developed in less than a day.

The next section describes in detail a process for developing a monitoring program. The process is divided into seven main steps. Although some steps can occur simultaneously with others, these steps represents the general order of the process. 


\section{DEVELOPING A MONITORING PROGRAM}

\section{STEP 1: DEFINE THE RESTORATION VISION, GOALS, AND OBJECTIVES}

There is an evolution that occurs in ecosystem restoration projects. The evolution begins with an idea of what the final project will look like and how it will function. In order to facilitate implementation of the project, the idea gets more formally stated as a goal, which leads to clear specifications as to what must actually be done on the ground to make the idea a reality. There are many terms used to label steps in this evolutionary process. We present some definitions of these terms in Step 1. Because the project is being carried out to improve environmental conditions, clearly stated goals, objectives, and specifications are critical to the design process. Furthermore, the goals for the project set the stage for what must be monitored to assess whether the project is successfully meeting the goals for which it was designed. Hence, the project goals are important to the design of the project as well as to the design of the monitoring program. Finally, the objective of the monitoring program is to measure the performance of the project relative to the project goals.

Each restoration project is, at some point, a visual image in the minds of people involved in the project. Major features of the system, such as vegetation distribution, water, and presence of wildlife, are generally included in the image. This vision is the overarching goal upon which the restored ecosystem is based. It requires the ability to attain a clear mental picture of a desired future condition for the ecosystem, and to convey this picture to others. Because restoration of ecosystems is complex, a vision is usually refined and strengthened through interaction with other individuals representing a variety of disciplines.

The vision should be refined into a goal statement, which is also referred to as the planning objective. For example, a planning objective might be to "restore habitat for juvenile salmon prey resources." The project specifications might be to "grade the land to the proper elevation, enhance the substrate, and plant [a specified number of] eelgrass shoots." The important aspect of the goals/planning objectives and specifications is that a relevant monitoring program can be developed around them.

Because the goal is critical to the project and the monitoring program is critical to assessment of success, it is best to develop the monitoring program during the planning phase. Early discussions about the goals for the project can be weighed against the types of information that will be needed to effectively evaluate whether the goals are met. Unrealistic goals can be modified into more realistic (measurable) goals. Goals such as "we will restore the genetic composition of the system
Goals should

- be as simple and unambigurous as possible - relate directly to the vision for the project

- be feasibly measured or assessed in the monitoring program. 
to predisturbance conditions," although theoretically achievable, would be difficult to evaluate. Similarly, a goal to "restore natural biodiversity to the site" can be interpreted in several ways by different people. Measuring "biodiversity" can become problematic and unfeasible.

Example goal statements for a wide variety of aquatic restoration projects are provided in Table IV.1. The goal statements vary considerably in degree of specificity, but generally provide clear directions for the projects. Many of the goals are combinations of goals, objectives, and specifications. Of the hundreds of projects reviewed by Shreffler et al. (1995), most had some goal statement. Those in Table IV.1 are for projects that had supportive documentation on project performance relative to goals and costs for the project.

It is not uncommon for monitoring programs to be designed well after the planning phase, and even after construction. In this case, it may be necessary to involve individuals, agencies, and interested parties in the program-development process. There are two distinct disadvantages to designing a monitoring program after planning and construction. First, the project goals may not have been developed with a monitoring program in mind resulting in goals that are not directly measurable by monitoring parameters. Second, important information regarding pre- and postconstruction conditions may not have been recorded resulting in poor baseline information.

The goals for the restoration project drive the monitoring program design. In Step 2, a method is laid out that directly links goals to monitoring needs. The method centers around development of a conceptual model.

\section{STEP 2: DEVELOP THE CONCEPTUAL MODEL}

A conceptual model is a useful tool for developing linkages between goals and parameters that can be used to assess performance. In fact, a conceptual model is a useful tool throughout the planning process, because it forces individuals planning the restoration project to identify the following:

- direct and indirect connections among the physical, chemical, and biological components of the ecosystem

- principal components upon which to focus restoration and monitoring efforts. 
TABLE IV.1 Examples of project goals for various types of restoration projects (From Shreffler et al. 1995)

\begin{tabular}{|c|c|c|c|c|c|}
\hline Project vame & location & Type of Profect & 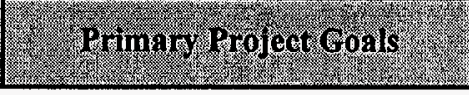 & 2. Monitomg techngues & 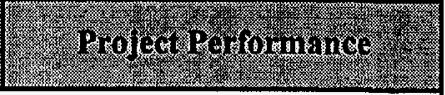 \\
\hline $\begin{array}{l}\text { Hall Branch } \\
\text { Restoration }\end{array}$ & FL & $\begin{array}{l}\text { Bottomland } \\
\text { Hardwood } \\
\text { Forest } \\
\text { Restoration }\end{array}$ & $\begin{array}{l}\text { Establish a forest of indigenous } \\
\text { trees and undergrowth similar to } \\
\text { the natural bottomland forests of } \\
\text { the South Prong Alafia River }\end{array}$ & $\begin{array}{l}\text { Annual monitoring since } 1985 \text { of } \\
\text { tree species, density, and height } \\
\text { at project site and control } \\
\text { wetland immediately } \\
\text { downstream }\end{array}$ & $\begin{array}{l}\text { Both short-term and long-term } \\
\text { performance criteria have been } \\
\text { met }\end{array}$ \\
\hline $\begin{array}{l}\text { Washington State } \\
\text { Ecosystem } \\
\text { Conservation } \\
\text { Program }\end{array}$ & WA & $\begin{array}{l}\text { Enhancement of } \\
\text { Fish and } \\
\text { Wildlife habitat }\end{array}$ & $\begin{array}{l}\text { Create specific hydrologic or } \\
\text { vegetation conditions that benefit } \\
\text { fish and wildlife }\end{array}$ & $\begin{array}{l}\text { Project specific, but typically } \\
\text { includes photo documentation, } \\
\text { wildlife observations, and } \\
\text { mapping at least once per year }\end{array}$ & $\begin{array}{l}\text { Most of the } 100+\text { projects are } \\
\text { meeting performance criteria }\end{array}$ \\
\hline $\begin{array}{l}\text { Slip } 5 \text { Fisheries } \\
\text { Mitigation Area }\end{array}$ & $\overline{W A}$ & $\begin{array}{l}\text { Estuarine } \\
\text { Wetland } \\
\text { Creation }\end{array}$ & $\begin{array}{l}\text { Construct } 2.7 \text { acres of intertidal } \\
\text { and shallow subtidal beach and } \\
\text { enhance prey resources for } \\
\text { juvenile salmonids }\end{array}$ & $\begin{array}{l}\text { Beach topography surveys; } \\
\text { surficial sediment surveys; } \\
\text { diving surveys; epibenthic } \\
\text { invertebrate densities; fish } \\
\text { densities }\end{array}$ & $\begin{array}{l}\text { Ecological performance critieria } \\
\text { were met within } 4 \text { years }\end{array}$ \\
\hline $\begin{array}{l}\text { Broad Dyke Marsh } \\
\text { Rehabilitation } \\
\text { Project }\end{array}$ & $\overline{\mathrm{DE}}$ & $\begin{array}{l}\text { Estuarine } \\
\text { Wetland } \\
\text { Enhancement }\end{array}$ & $\begin{array}{l}\text { Improve water quality, reduce } \\
\text { storm flooding, increase } \\
\text { biological diversity, improve } \\
\text { wetland habitat, improve } \\
\text { recreation, control mosquitos, } \\
\text { control nuisance plants, education }\end{array}$ & None yet developed & None \\
\hline $\begin{array}{l}\text { Doran Beach Marsh } \\
\text { Enhancement Project }\end{array}$ & $\overline{\mathrm{CA}}$ & $\begin{array}{l}\text { Estuarine } \\
\text { Wetland } \\
\text { Enhancement }\end{array}$ & $\begin{array}{l}\text { Enhance wetland marsh habitat } \\
\text { for wildlife }\end{array}$ & None & None \\
\hline
\end{tabular}




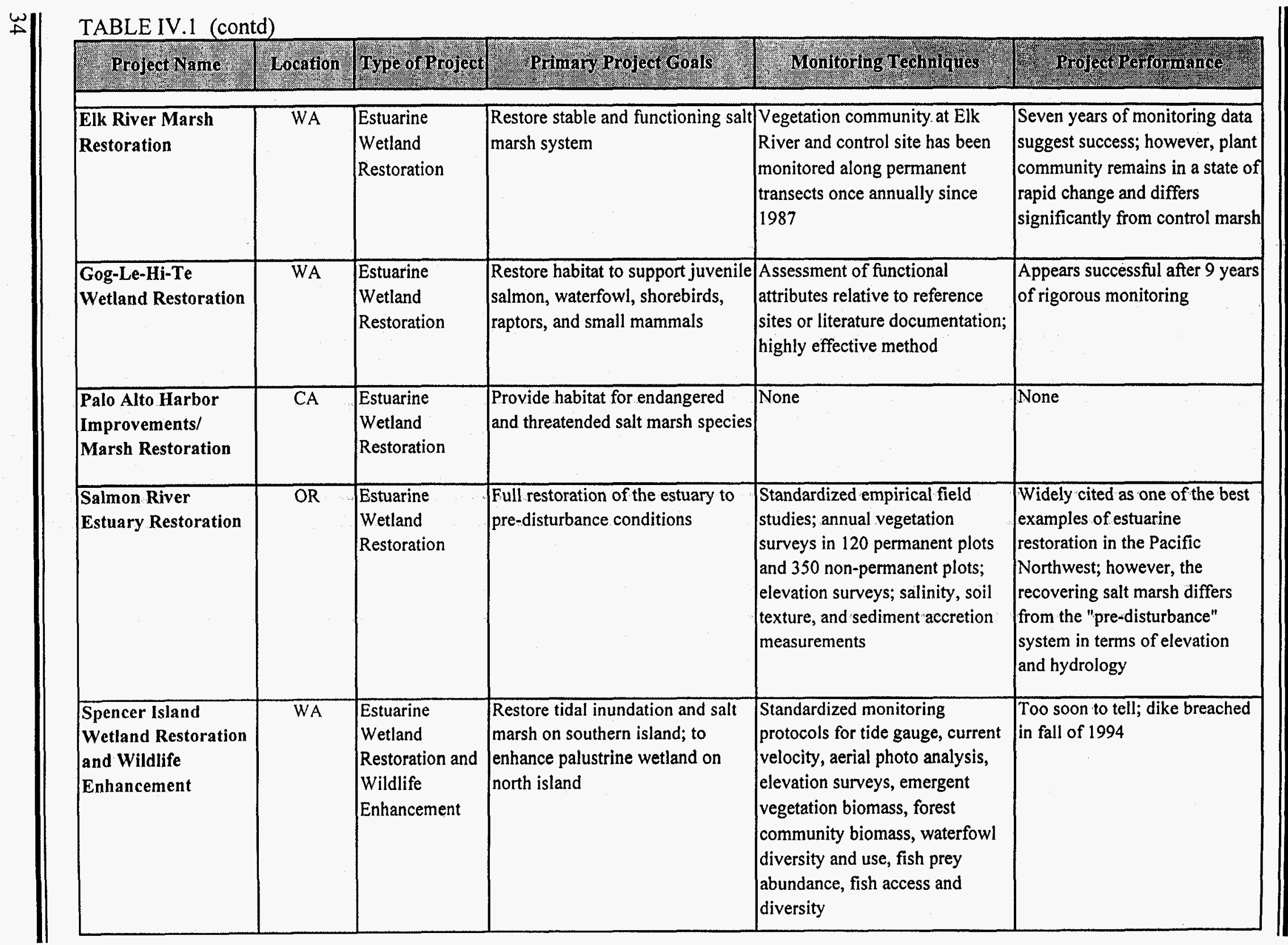


TABLE IV.1 (contd)

\begin{tabular}{|c|c|c|c|c|c|}
\hline Project Name. & Location & Type of Projec & Primary Project Goals & Donitoring Techniques & 7. Project Performance \\
\hline $\begin{array}{l}\text { Stream Restoration } \\
\text { Projects }\end{array}$ & $\mathrm{CA}$ & \begin{tabular}{|l} 
Stream \\
Restoration
\end{tabular} & $\begin{array}{l}\text { Management of sediment in } \\
\text { streams and rivers }\end{array}$ & $\begin{array}{l}\text { Fluvial geomorphology, water } \\
\text { quality, biological habitat, } \\
\text { photodocumentation }\end{array}$ & $\begin{array}{l}\text { Monitoring results are provided } \\
\text { for some projects }\end{array}$ \\
\hline $\begin{array}{l}\text { Prairie Creek Fish } \\
\text { and Wildlife Habitat } \\
\text { Enhancement Project }\end{array}$ & $\mathrm{CA}$ & \begin{tabular}{|l|} 
Stream \\
Enhancement
\end{tabular} & $\begin{array}{l}\text { Control streambank erosion and to } \\
\text { restore high quality instream and } \\
\text { riparian habitat }\end{array}$ & $\begin{array}{l}\text { Site visits, visual observations of } \\
\text { stablization structures, } \\
\text { quantification of transplant } \\
\text { survival }\end{array}$ & $\begin{array}{l}\text { Rock riprap with willow } \\
\text { mattress and tree and limb } \\
\text { deflectors were } 100 \% \text { effective } \\
\text { in stabilizing bank; } 70-75 \% \\
\text { survival of planted riparian } \\
\text { vegetation after } 2 \text { years }\end{array}$ \\
\hline $\begin{array}{l}\text { McDonald Creek } \\
\text { Restoration Project }\end{array}$ & $\mathrm{CA}$ & $\begin{array}{l}\text { Stream } \\
\text { Restoration }\end{array}$ & \begin{tabular}{|l|} 
Reduce sediment input from \\
streambank erosion and to \\
improve spawning and rearing \\
habitat for cutthroat and steelhead
\end{tabular} & $\begin{array}{l}\text { Site visits, visual observations of } \\
\text { stabilization structures, } \\
\text { quantification of transplant } \\
\text { survival }\end{array}$ & $\begin{array}{l}\text { All } 6 \text { instream structures } \\
\text { functioned as designed to } \\
\text { reduce sediment input; } 85 \% \\
\text { survival of trees planted; efforts } \\
\text { to monitor fish populations are } \\
\text { ongoing }\end{array}$ \\
\hline $\begin{array}{l}\text { Mill Creek Channel } \\
\text { Improvements }\end{array}$ & PA & $\begin{array}{l}\text { Stream } \\
\text { Restoration }\end{array}$ & $\begin{array}{l}\text { Control stream bank erosion and } \\
\text { provide a well-defined } \\
\text { maintenance channel }\end{array}$ & None & None \\
\hline $\begin{array}{l}\text { Upper Little Swatara } \\
\text { Creek Adopt-A- } \\
\text { Stream Project }\end{array}$ & $\overline{\mathrm{PA}}$ & \begin{tabular}{|l} 
Stream \\
Restoration
\end{tabular} & $\begin{array}{l}\text { Alleviate stream bank erosion and } \\
\text { restore stream physical features }\end{array}$ & Annual visual inspections & $\begin{array}{l}\text { Revegetation of stream banks } \\
\text { by willow and reed canarygrass, } \\
\text { physical structures blending } \\
\text { well with natural surroundings }\end{array}$ \\
\hline
\end{tabular}




\begin{tabular}{|c|c|c|c|c|c|}
\hline Project Name & Location & Type of Project & Primary Project Goals & Monitoring Techingues & 1020 r roject rem rormance \\
\hline $\begin{array}{l}\text { Tryon Creek } \\
\text { Restoration Project }\end{array}$ & $\overline{C A}$ & $\begin{array}{l}\text { Stream } \\
\text { Restoration }\end{array}$ & $\begin{array}{l}\text { Restore instream fish rearing and } \\
\text { spawning habitat and riparian } \\
\text { wildlife habitat; to increase open } \\
\text { water habitat for birds }\end{array}$ & $\begin{array}{l}\text { Twice monthly bird surveys for a } \\
\text { 1-year period following } \\
\text { construction; before, during, and } \\
\text { after photo documentation; } \\
\text { ongoing general observations; } \\
\text { water quality survey, vegetation } \\
\text { survey, fish and invertebrate } \\
\text { survey }\end{array}$ & $\begin{array}{l}\text { Performance in terms of fish } \\
\text { rearing and spawning is } \\
\text { unknown (i.e., poorly } \\
\text { documented); bird use is } \\
\text { significant and includes one } \\
\text { bald eagle and one peregrine } \\
\text { falcon }\end{array}$ \\
\hline $\begin{array}{l}\text { Water Quality } \\
\text { Monitoring \& } \\
\text { Assessment of } \\
\text { Agricultural BMPs }\end{array}$ & $\overline{F L}$ & $\begin{array}{l}\text { Water Quality } \\
\text { Remediation }\end{array}$ & $\begin{array}{l}\text { Identify viable BMPs that are } \\
\text { effective in reducing nutrient and } \\
\text { sediment loads to receiving waters }\end{array}$ & $\begin{array}{l}\text { Weekly monitoring during } \\
\text { growing season (January to } \\
\text { May); standard water quality } \\
\text { monitoring techniques for ground } \\
\text { and surface water; tissues } \\
\text { analysis of crops, atmospheric } \\
\text { deposition, yield assessment }\end{array}$ & $\begin{array}{l}\text { Project performance is directly } \\
\text { related to meteorological } \\
\text { conditions; modeling helps to } \\
\text { fill data gaps and adjust results } \\
\text { according to weather conditions }\end{array}$ \\
\hline $\begin{array}{l}\text { Clinton County } \\
\text { Solid Waste } \\
\text { Authority } \\
\text { Mitigation Wetland }\end{array}$ & $\overline{P A}$ & $\begin{array}{l}\text { Wetland } \\
\text { Creation }\end{array}$ & $\begin{array}{l}\text { Provide permanent replacement } \\
\text { for } 2.33 \text { acres of wetlands } \\
\text { impacted by landfill construction }\end{array}$ & $\begin{array}{l}\text { Quantitative vegetation surveys, } \\
\text { visual documentation, shallow } \\
\text { water monitoring wells }\end{array}$ & $\begin{array}{l}\text { Results of year 1 (1994) } \\
\text { monitoring not yet available; } 5 \\
\text { years of monitoring will tell } \\
\text { whether the system performs } \\
\text { well relative to performance } \\
\text { goals }\end{array}$ \\
\hline $\begin{array}{l}\text { Highway } 237 \\
\text { Wetland Mitigation } \\
\text { Site }\end{array}$ & $\overline{\mathrm{CA}}$ & $\begin{array}{l}\text { Wetland } \\
\text { Creation }\end{array}$ & $\begin{array}{l}\text { Create new seasonal wetlands by } \\
\text { creating seasonal ponding }\end{array}$ & $\begin{array}{l}\text { Hydrology, sedimentation, } \\
\text { vegetation, soils and wildlife } \\
\text { using quantitative field methods }\end{array}$ & $\begin{array}{l}\text { Monitoring in } 1993 \text { showed that } \\
\text { the system was occupied by a } \\
\text { large number of bird species } \\
\text { and that vegetation was } \\
\text { developing as predicted }\end{array}$ \\
\hline $\begin{array}{l}\text { Municipal } \\
\text { Wastewater } \\
\text { Treatment By } \\
\text { Constructed } \\
\text { Wetlands }\end{array}$ & $\overline{K Y}$ & $\begin{array}{l}\text { Wetland } \\
\text { Creation : }\end{array}$ & $\begin{array}{l}\text { Evaluate the relative advantages } \\
\text { and disadvantages, cost- } \\
\text { effectiveness, and design and } \\
\text { operation factors of } 3 \text { types of } \\
\text { constructed wetlands }\end{array}$ & $\begin{array}{l}\text { Vegetation surveys, water quality } \\
\text { monitoring }\end{array}$ & $\begin{array}{l}\text { All } 3 \text { systems successful at } \\
\text { reducing BOD, TSS, and fecal } \\
\text { coliform, but not NH3-N to } \\
\text { meet permit limits; vegetation } \\
\text { species not a significant factor } \\
\text { in overall performance }\end{array}$ \\
\hline
\end{tabular}


TABLE IV.1 (contd)

\begin{tabular}{|c|c|c|c|c|c|}
\hline Project Name & Location & Type of Project & Primary Project Goals & 1. Monitoring Techiniques & Project Performance \\
\hline \begin{tabular}{|l|} 
Hard Rock Mine \\
Constructed Wetland
\end{tabular} & $\mathrm{AL}$ & $\begin{array}{l}\text { Wetland } \\
\text { Creation }\end{array}$ & \begin{tabular}{|l|} 
Reduce $\mathrm{Fe}, \mathrm{Mn}$, and TSS \\
concentrations in acid mine \\
drainage to compliance levels in a \\
cost-effective, environmentally \\
sound manner
\end{tabular} & $\begin{array}{l}\text { Wastewater characterization and } \\
\text { site hydrology monitoring } \\
\text { included groundwater, soil, water } \\
\text { chemistry, and macrobenthos } \\
\text { using standard EPA methods; } \\
\text { also water quality and flow } \\
\text { monitoring, and anoxic limestone } \\
\text { drain performance data }\end{array}$ & $\begin{array}{l}\text { System met NPDES compliance } \\
\text { requirements }\end{array}$ \\
\hline \begin{tabular}{|l} 
Tidal Marsh \\
Construction
\end{tabular} & $\mathrm{MD}$ & $\begin{array}{l}\text { Wetland } \\
\text { Creation }\end{array}$ & $\begin{array}{l}\text { Physically restore shores to } \\
\text { former higher elevations; to assure } \\
\text { that the restored shore slopes are } \\
\text { sufficiently stable to allow the } \\
\text { successful construction of a } \\
\text { sustained tidal marsh vegetation } \\
\text { community }\end{array}$ & No standard techniques & $\begin{array}{l}\text { Based on } 216 \text { marsh } \\
\text { construction projects, this } \\
\text { bioengineering restoration } \\
\text { technique is quite successful in } \\
\text { controlling upland bank erosion }\end{array}$ \\
\hline $\begin{array}{l}\text { Kennedy Park } \\
\text { Wetland Creation } \\
\text { and Enhancement }\end{array}$ & $\overline{\mathrm{CA}}$ & $\begin{array}{l}\text { Wetland } \\
\text { Creation and } \\
\text { Enhancement }\end{array}$ & $\begin{array}{l}\text { Enhance wildlife habitat values } \\
\text { and wetland diversity }\end{array}$ & None & None \\
\hline $\begin{array}{l}\text { Cowlitz Wildlife } \\
\text { Enhancement, Rainy } \\
\text { Creek Dike }\end{array}$ & $\overline{\text { WA }}$ & $\begin{array}{l}\text { Wetland } \\
\text { Enhancement }\end{array}$ & $\begin{array}{l}\text { Create permanent water source to } \\
\text { improve waterfowl nesting habitat }\end{array}$ & Not specified yet & None \\
\hline Triangle Marsh & $\overline{\mathrm{CA}}$ & $\begin{array}{l}\text { Wetland } \\
\text { Enhancement } \\
\end{array}$ & $\begin{array}{l}\text { Enhance biological productivity, } \\
\text { habitat diversity, water quality, } \\
\text { reduce mosquito breeding, flood } \\
\text { prevention }\end{array}$ & $\begin{array}{l}\text { Five-year monitoring of } \\
\text { hydrology, sedimentation, } \\
\text { vegetation, birds, benthic } \\
\text { invertebrates, water column fish } \\
\text { and macroinvertebrates }\end{array}$ & $\begin{array}{l}\text { After two years tidal flushing } \\
\text { and other features resulted in } \\
\text { marsh vegetation with higher } \\
\text { vigor, occupation by birds, and } \\
\text { transient use by fish }\end{array}$ \\
\hline
\end{tabular}




\begin{tabular}{|c|c|c|c|c|c|}
\hline \multicolumn{6}{|l|}{ TABLE IV.1 (contd) } \\
\hline Project Name & Location & Type of Project & Primary Project Goals & Monitoring Techiniques & - Profect Perromunance \\
\hline $\begin{array}{l}\text { Roberts Landing } \\
\text { Wetland } \\
\text { Enhancement }\end{array}$ & $\overline{\mathrm{CA}}$ & $\begin{array}{l}\text { Wetland } \\
\text { Enhancement }\end{array}$ & $\begin{array}{l}\text { Mitigate for the filling of } 13 \text { acres } \\
\text { of non-tidal wetland }\end{array}$ & No monitoring performed yet & Cannot be determined yet \\
\hline \begin{tabular}{|l|} 
San Leandro \\
Shoreline \\
Marshlands \\
Enhancement Project
\end{tabular} & $\overline{\mathrm{CA}}$ & $\begin{array}{l}\text { Wetland } \\
\text { Enhancement }\end{array}$ & $\begin{array}{l}\text { Restore full or partial tidal action } \\
\text { to three areas }\end{array}$ & None yet & None \\
\hline $\begin{array}{l}\text { Cascade Crossings } \\
\text { Wetland Mitigation } \\
\text { Project }\end{array}$ & $\mathrm{MI}$ & $\begin{array}{l}\text { Wetland } \\
\text { Mitigation }\end{array}$ & $\begin{array}{l}\text { Create } 66 \text { acres of compensatory } \\
\text { wetland mitigation intended to } \\
\text { function primarily in support of } \\
\text { waterfowl }\end{array}$ & \begin{tabular}{|l|} 
Wetland delineation (1987 \\
manual); quantitative vegetating \\
sampling, photo documentation \\
at established reference points, \\
aerial photo documentation, \\
waterfowl sampling
\end{tabular} & $\begin{array}{l}\text { First year monitoring indicates } \\
\text { hydrology has been restored at } \\
\text { the site, but } 4 \text { more years of } \\
\text { monitoring will be required } \\
\text { before performance can be } \\
\text { evaluated }\end{array}$ \\
\hline $\begin{array}{l}\text { Indian River } \\
\text { Boulevard } \\
\text { North Extension } \\
\text { Project }\end{array}$ & $\overline{F L}$ & $\begin{array}{l}\text { Wetland } \\
\text { Mitigation }\end{array}$ & $\begin{array}{l}\text { Provide economical and effective } \\
\text { mosquito control; to enhance } \\
\text { natural resources by restoring tidal } \\
\text { connection to the lagoon system; } \\
\text { improve water quality; } \\
\text { control/remove exotic vegetation }\end{array}$ & $\begin{array}{l}\text { Monthly monitoring of } \\
\text { temperature, salinity, } \mathrm{pH}, \\
\text { turbidity, and dissolved oxygen }\end{array}$ & $\begin{array}{l}\text { Water quality has been } \\
\text { satisfactory and mosquito } \\
\text { production has been controlled; } \\
\text { exotic die-back has occurred in } \\
\text { most low marsh areas }\end{array}$ \\
\hline $\begin{array}{l}\text { Sweetwater Marsh } \\
\text { Mitigation }\end{array}$ & $\overline{\mathrm{CA}}$ & $\begin{array}{l}\text { Wetland } \\
\text { Mitigation }\end{array}$ & $\begin{array}{l}\text { Provide foraging, nesting, and } \\
\text { refugia habitat for least tern and } \\
\text { light-footed clapper rail; to } \\
\text { establish saltmarsh bird's beak }\end{array}$ & $\begin{array}{l}\text { Comparative studies to determine } \\
\text { functional equivalency to } \\
\text { existing reference wetlands; } \\
\text { parameters include soils, } \\
\text { vegetation, epibenthic } \\
\text { invertebrates, fish, channel } \\
\text { benthos, and birds }\end{array}$ & $\begin{array}{l}\text { Based on soil, nutrient, } \\
\text { vegetation, and epibenthos data, } \\
<60 \% \text { functionally equivalent to } \\
\text { reference wetland }\end{array}$ \\
\hline
\end{tabular}


TABLE IV.1 (contd)

\begin{tabular}{|c|c|c|c|c|c|}
\hline Project Name & Location & Type of Projec & Primary Project Goals & Nonitoring techingues & 2. Project Performalice \\
\hline $\begin{array}{l}\text { Christmas Tree } \\
\text { Marsh Restoration }\end{array}$ & $\overline{\mathrm{LA}}$ & $\begin{array}{l}\text { Wetland } \\
\text { Restoration }\end{array}$ & $\begin{array}{l}\text { Convert dead-end abandoned oil } \\
\text { canals to marsh habitat; recycle } \\
\text { discarded Christmas trees; study } \\
\text { type and duration of fertilizer } \\
\text { needed to accelerate the process; } \\
\text { educate public on recycling, } \\
\text { coastal erosion, and loss of } \\
\text { wetlands }\end{array}$ & $\begin{array}{l}\text { Monitoring twice/year for mat } \\
\text { measurement and botanical } \\
\text { survey; site specific studies on } \\
\text { fertilizing regimes and water } \\
\text { quality monitoring }\end{array}$ & $\begin{array}{l}\text { Initial assessment (after } 2 \text { years) } \\
\text { suggests success, but only long- } \\
\text { term monitoring will confirm } \\
\text { the canals are functioning } \\
\text { marshes }\end{array}$ \\
\hline $\begin{array}{l}\text { Connecticut } \\
\text { Department of } \\
\text { Environmental } \\
\text { Protection: Wetland } \\
\text { Restoration }\end{array}$ & $\overline{C T}$ & $\begin{array}{l}\text { Wetland } \\
\text { Restoration }\end{array}$ & Restore stream habitat for wildlife & None yet & None \\
\hline $\begin{array}{l}\text { Des Plaines River } \\
\text { Wetlands } \\
\text { Demonstration } \\
\text { Project }\end{array}$ & IL & $\begin{array}{l}\text { Wetland } \\
\text { Restoration }\end{array}$ & $\begin{array}{l}\text { Restore and create riverine } \\
\text { wetlands, prairie, and forest; to } \\
\text { research the biological, chemical } \\
\text { and physical characteristics of } \\
\text { wetlands; to educate the public, } \\
\text { scientists, and policy makers } \\
\text { about the functions and values of } \\
\text { wetlands }\end{array}$ & \begin{tabular}{|l|} 
Focused on how (1) differing \\
hydraulic loading rates affect \\
water/sediment chemistry, \\
sedimentation rates, plant \\
community development, and \\
primary productivity; and (2) \\
invertebrates, herpetofauna, \\
birds, and mammals responded to \\
restored habitats
\end{tabular} & $\begin{array}{l}\text { Very successful; wetland } \\
\text { dependent macrophytes and } \\
\text { macroinvertebrates have } \\
\text { increased and } 2 \text { state-designated } \\
\text { endangered species are now } \\
\text { breeding on the site. More than } \\
80 \% \text { of pollutants successfully } \\
\text { removed from river }\end{array}$ \\
\hline $\begin{array}{l}\text { NRCS Wetland } \\
\text { Reserve Program }\end{array}$ & $\overline{\mathrm{WA}}$ & $\begin{array}{l}\text { Wetland } \\
\text { Restoration }\end{array}$ & $\begin{array}{l}\text { Restore wetland features to former } \\
\text { agrigultural land }\end{array}$ & $\begin{array}{l}\text { General observations and } \\
\text { photographs taken annually }\end{array}$ & No results yet \\
\hline $\begin{array}{l}\text { Shaker Trace } \\
\text { Wetland Complex }\end{array}$ & $\overline{\mathrm{OH}}$ & $\begin{array}{l}\text { Wetland } \\
\text { Restoration : }\end{array}$ & $\begin{array}{l}\text { Restore a functioning wetland } \\
\text { system on original hydric soils; to } \\
\text { provide habitat for a diversity of } \\
\text { plants and wildlife }\end{array}$ & $\begin{array}{l}\text { Vegetation surveys, weekly } \\
\text { monitoring of amphibians, } \\
\text { reptiles, birds, and aquatic insects }\end{array}$ & $\begin{array}{l}\text { Diversity of waterfowl present } \\
\text { at site, but monitoring data not } \\
\text { yet available for public release }\end{array}$ \\
\hline
\end{tabular}




\begin{tabular}{|c|c|c|c|c|c|}
\hline Project Name & Location & Type of Project & Primary Project Goals. & Monitoring Techniques & Profect Periormance \\
\hline Metzger Marsh & $\overline{\mathrm{OH}}$ & $\begin{array}{l}\text { Wetland } \\
\text { Restoration }\end{array}$ & $\begin{array}{l}\text { Demonstrate practices for } \\
\text { restoring and protecting coastal } \\
\text { wetland habitat through } \\
\text { revegetation, while concurrently } \\
\text { restoring natural hydrologic } \\
\text { functions and increasing habitat } \\
\text { for species such as muskellunge, } \\
\text { northern pike, and black duck }\end{array}$ & \begin{tabular}{|l|} 
Stratified random design for \\
sampling fish, small mammals, \\
herpetofauna, \\
macroinvertebrates, plankton, \\
waterfowl, and plant \\
communities; aerial photographs; \\
GIS mapping; geologic studies; \\
water quality studies
\end{tabular} & $\begin{array}{l}\text { Complete system not done until } \\
10 / 96 \text {; preliminary monitoring } \\
\text { report will be out end of } 1995\end{array}$ \\
\hline \begin{tabular}{|l|} 
Rincon Bayou-- \\
Neuces \\
Marsh Wetlands \\
Restoration \& \\
Enhancement Project \\
\end{tabular} & $\overline{T X}$ & \begin{tabular}{|l|} 
Wetland \\
Restoration and \\
Enhancement
\end{tabular} & $\begin{array}{l}\text { Demonstrate the benefits of } \\
\text { introducing freshwater into a } \\
\text { coastal estuary by means of a } \\
\text { wetland marsh system }\end{array}$ & $\begin{array}{l}\text { tratified random sampling at } \\
\text { treated and untreated sites; } \\
\text { parameters include primary } \\
\text { productivity, macrophytes, } \\
\text { infaunal populations, water } \\
\text { chemistry, contaminants in biota } \\
\text { and sediments, GIS mapping of } \\
\text { vegetation }\end{array}$ & $\begin{array}{l}\text { No monitoring yet; construction } \\
\text { began January } 1995\end{array}$ \\
\hline \begin{tabular}{|l|} 
Campbell River \\
Estuary \\
Enhancement
\end{tabular} & $\begin{array}{c}\text { British } \\
\text { Columbia }\end{array}$ & \begin{tabular}{|l} 
Estuarine \\
Wetland \\
Creation
\end{tabular} & Enhance wild salmon productivity & $\begin{array}{l}\text { No standardized monitoring } \\
\text { techniques; monitoring has } \\
\text { included (1) vegetation growth, } \\
\text { colonization, and productivity, } \\
\text { (2) sampling of zooplankton and } \\
\text { meiofauna and (3) studies of the } \\
\text { use of estuarine habitats by wild } \\
\text { juvenile salmonids }\end{array}$ & $\begin{array}{l}\text { Assessment of the productive } \\
\text { capacity of the new habitats for } \\
\text { wild juvenile salmonids was } \\
\text { confounded by a number of } \\
\text { factors; system met other goals }\end{array}$ \\
\hline \begin{tabular}{|l} 
North Fraser \\
Harbour Habitat \\
Compensation \\
Bank
\end{tabular} & $\begin{array}{c}\text { British } \\
\text { Columbia }\end{array}$ & Mitigation Bank & $\begin{array}{l}\text { Construct stable and viable marsh } \\
\text { habitat to be used for habitat } \\
\text { compensation for future } \\
\text { development proposals }\end{array}$ & $\begin{array}{l}\text { No standardized monitoring } \\
\text { techniques; vegetation coverage } \\
\text { must equal } 75-80 \% \text { within } 5 \\
\text { years; monitoring has included } \\
\text { observations on site stability, } \\
\text { elevation survey, soil analysis, } \\
\text { vegetation \% cover and shoot } \\
\text { density survey }\end{array}$ & $\begin{array}{l}\text { Preliminary indications are that } \\
\text { the habitat bank is performing } \\
\text { well; } 5 \text { years of monitoring will } \\
\text { tell }\end{array}$ \\
\hline
\end{tabular}


Conceptual model development can be followed by numerical modeling efforts, if needed and if funding allows. Because of the critical importance of hydrology to water resource projects and the well developed science of hydrology, hydrologic modeling is frequently carried out in planning restoration projects. Numerical ecological models are much less frequently employed, not as well known, and because ecological models for this purpose are generally not as available. Numerical models can help in the planning process by allowing sensitivity analysis of system aspects (e.g., basin morphology) and the predicted conditions (e.g., hydroperiod; plant stem density).

\section{Step 2A: Review Conceptual Model Examples to Help Formulate Your Model}

This step provides two examples of useful conceptual models. One is of a riparian forest and the other is a model of submerged aquatic vegetation from Chesapeake Bay. It is best to spend some time reviewing conceptual models from your region and for the system that is being restored. Conceptual model formation is relatively simple but takes some practice. Using existing models helps to provide guidance and to remind one of connections that should be considered.

Example: Riparian Forest. An example of a conceptual model is shown in Figure IV.1. In this model, one can identify that restoring riparian vegetation affects the area of habitat and types of aquatic invertebrates by providing food and cooler water temperatures which result from increased shading. Identifying the components (boxes) and connections (arrows) is a useful process in restoration planning.

The model also identifies the factors that affect the riparian vegetation. For the system to be restored, these factors must be reestablished within the range suitable for riparian vegetation development. Monitoring of the critical aspects of these controlling factors is needed to help interpret changes in the system. For example, failure of the vegetation to develop could be indicative of an inadequate hydroperiod. A monitoring program could determine whether this is the cause.

If the goal were simply to restore a riparian forest, then the monitoring requirement might consist only of the critical controlling factor(s) and a measure of the vegetation in the restored site. The vegetation measures would indicate whether the community were a riparian community with the appropriate mix of species, biomass, etc. However, if the goal were to enhance or restore aquatic invertebrate communities associated with riparian systems, then a measure of the invertebrates would be needed. The model in Figure IV.1 identifies food, stream temperature, and water chemistry as key factors linking riparian vegetation with aquatic invertebrates. It would be useful to monitor one or more measures within these main components to indicate possible breakdowns in the linkage between riparian vegetation and aquatic invertebrates. 


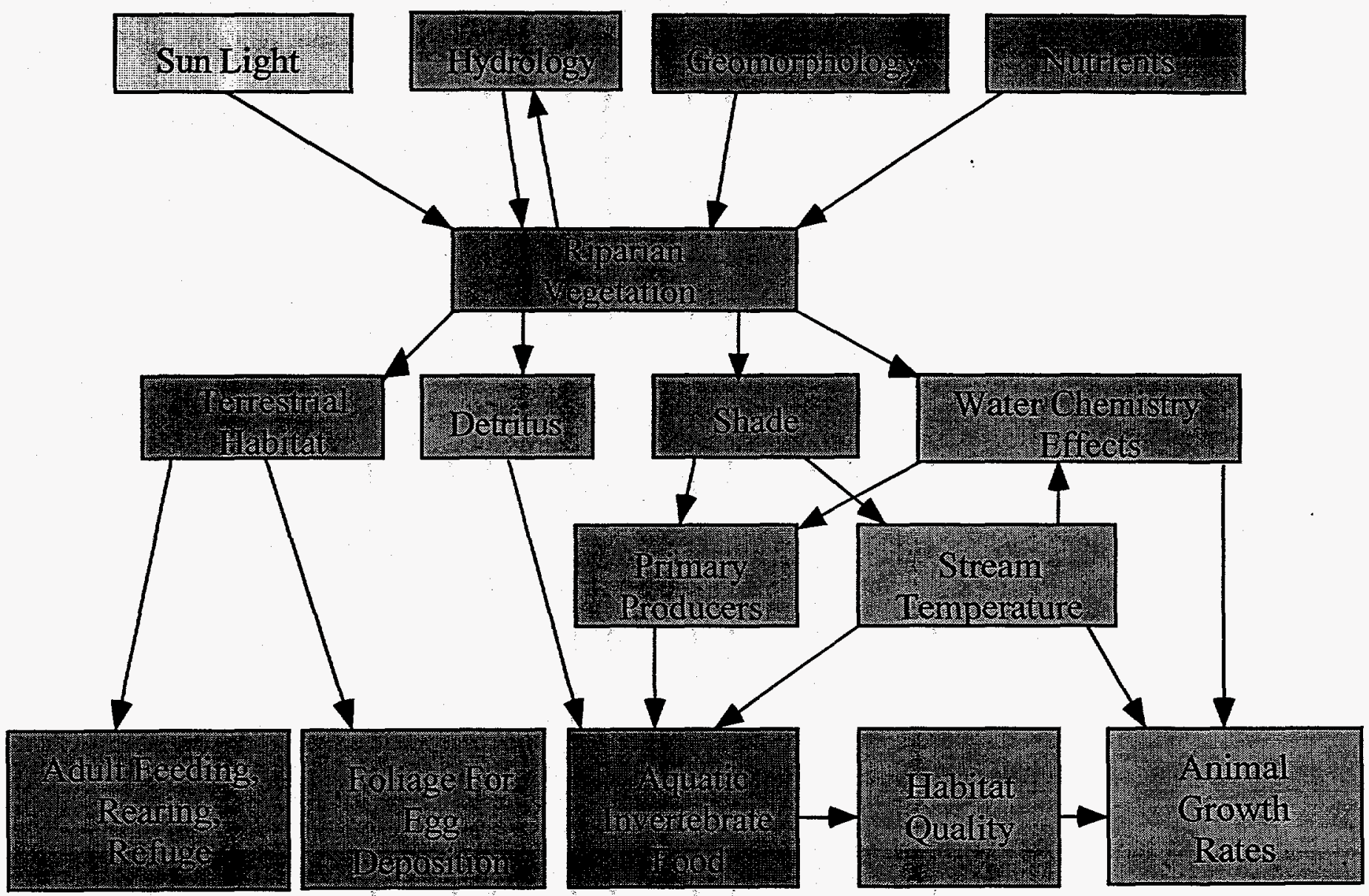

FIGURE IV.1. A conceptual model for a stream restoration project (modified from Mitsch and Gosselink 1993)

Example: Chesapeake Bay. The Chesapeake Bay Program has developed a restoration plan for submerged aquatic vegetation (SAV) that provides an excellent, comprehensive example of how to relate performance criteria to goals through a conceptual model (Batiuk et al. 1992). Once abundant in the bay, SAV suffered massive declines in the 1960s and 1970s due to decreased water clarity. Because SAV requires light to grow, the restoration effort focuses on reducing turbidity caused primarily by increased suspended solids and increased phytoplankton. Much of the increase in phytoplankton abundance has been tied to increased nutrient input into the bay. An extensive body of research conducted over a 10-year period in the bay was used to define the factors controlling SAV abundance. This information was used to develop the conceptual model in Figure IV.2, which shows the main factors (i.e., dissolved inorganic phosphorus and nitrogen) affecting phytoplankton and epiphyte growth, which in turn affect SAV. 


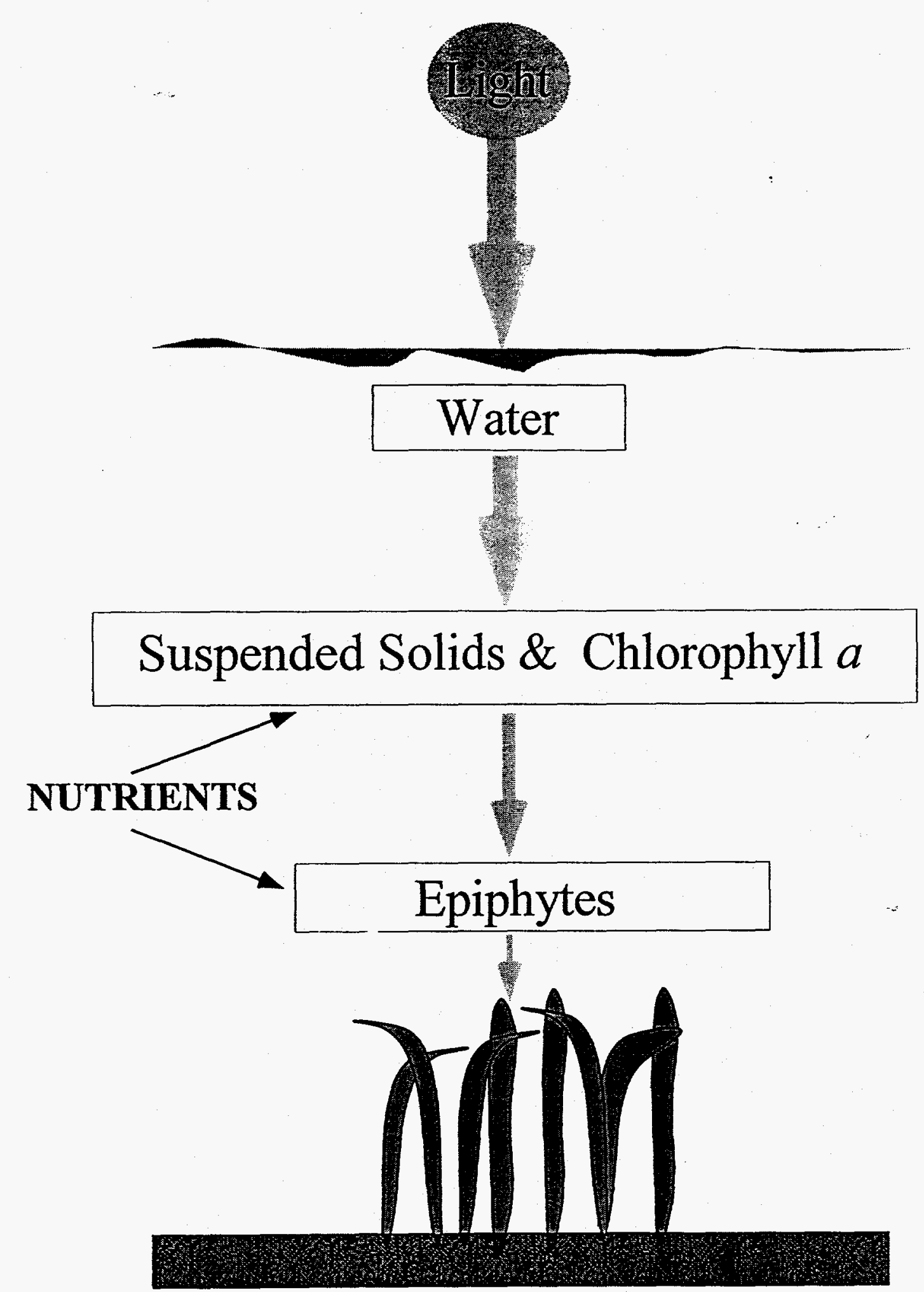

FIGURE IV.2. Conceptual model for Chesapeake Bay submerged aquatic vegetation (redrawn from Batiuk et al. 1992) 
The research in Chesapeake Bay resulted in the development of habitat requirements that must be met for SAV to recover. The factors included a light attenuation coefficient, total suspended solids, chlorophyll a, dissolved inorganic nitrogen, and dissolved inorganic phosphorus. Coupled with water quality models, the Chesapeake Bay Program was able to define the inorganic nutrient-loading levels needed to achieve these habitat requirements and establish restoration targets (i.e., goals). The Chesapeake Bay Program provided an estimate of the maximum area targeted for restoration (e.g., Tier $I=46,025 \mathrm{ha}$ ) and the amount of area restored as of 1990 . These area estimates provide performance criteria for the project and provide a measure of the success in reducing nutrient and sediment input to the bay.

\section{Step 2B: Conduct Baseline Studies to Help Formulate the Model}

Baseline studies may be necessary:

- to define conditions without the project

- to identify required actions to restore the system

- to help design the restoration project

- help design the monitoring program.

For example, measurements of the elevation and slope of marsh benches in the tidal portion of the Chehalis River (Grays Harbor, Washington) were used to design marsh benches in a nearby (within $0.5 \mathrm{~km}$ ) constructed tidal slough (Simenstad et al. 1993). The natural slough provided a valuable "model" upon which to base the design of the constructed system. As a consequence, the constructed slough marsh has undergone rapid development.

Baseline studies can be designed to provide information for judging the success of the restoration project. The baseline information in the Chehalis River project also included other measures of importance, such as stem density. The latter information allowed the development of some performance criteria for the constructed system.

\section{Step 2C: Formulate Your Conceptual Model}

The principal factors that control the development and maintenance of the habitat structure, the important habitat characteristics, and the functions for which the habitat was restored are identified in the conceptual model. From this information, the parameters to monitor can be more easily selected. 
A conceptual nodel typically las the following general form:

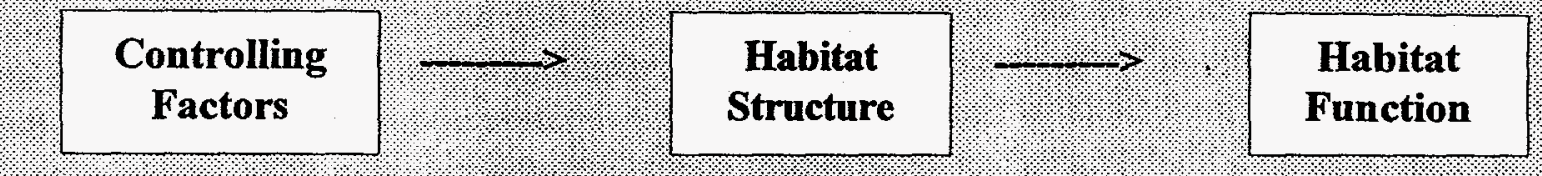

The conceptual model and baseline data provide the menu of parameters that could be selected for measurement. A subset of parameters that focus on the critical aspects of the project will be selected to allow the project manager to assess and track the project's progress.

\section{STEP 3: CHOOSE PERFORMANCE CRITERIA}

\section{Step 3A: Link Performance to Goals}

The most critical element in a restoration monitoring program is the link between the performance of the system and the goals of the project. If the goals are stated in a clear manner and can be reworded as a set of testable hypotheses, performance criteria can be developed. Performance criteria are standards by which to evaluate measurable or otherwise observable aspects of the restored system and thereby indicate the progress of the system toward meeting the project goals. The criteria define the acceptable or optimal range of values for a parameter that is measured. The closer the tie between goals and performance criteria, the better the ability to judge progress.

Example: Using the Riparian Forest Model to Select Criteria. The conceptual model provides a useful framework for assessing linkages and developing criteria. In the riparian wetland example (Figure IV.1), the major controlling factors and ecological response factors are identified. If, for example, the goal for this project were to restore a riparian wetland system to improve habitat quality for aquatic animals, then the model should be used to generate performance criteria. Many streams and rivers suffer from increased water temperatures because of loss of riparian forests. Increased temperature produces stress to fish and other aquatic animals not only through heating but also through changes in water chemistry (e.g., dissolved oxygen and blooms of noxious algae). Stream temperature is a key physical response parameter that will indicate the success of the restoration project in meeting its goal. A goal for the restoration project stated as a 
The water temperature goal should be developed in the planning phase of the project. During this phase, the feasibility of testing the goal must be considered. Mean summer temperature can be easily evaluated through frequent monitoring or through the use of inexpensive continuous temperature recorders. Hence, this parameter is probably feasible both technically and economically. It is strongly linked to the goal for the project and it has a well established basis in the scientific literature. Furthermore, it is well known that riparian forests provide shade, which reduces water temperatures. Hence, measurement of temperature is an indirect measure of the quality and state of development of the restored riparian forest.

Examples of Performance Criteria from Other Projects. Examples of performance criteria and goals are shown in Table IV.1. Most of the performance criteria are well linked to the goals either by way of controlling factors or ecological response parameters. Development of performance criteria should rely on information from previous studies as much as possible. For example, specific information on physical and chemical requirements for many fisheries and wildlife species have been developed by the USFWS through its "species profiles" (e.g., Lassuy 1989; Shaw and Hassler 1989).

\section{Step 3B: Develop the Criteria}

The task of developing performance criteria involves the following:

- linking criteria to the goals for the project

- linking criteria to the actual measurement parameters

- specifying the bounds or limit values for the criteria.

Development of criteria is often accomplished by a small group of individuals with system expertise. Larger groups, which may add useful information and input, could tend to result in monitoring programs that are too complex or elaborate. Criteria are usually developed through an iterative process that involves listing measures of performance relative to goals and refining these to arrive at the most efficient and relevant set of criteria.

The primary function of the monitoring program is to assess progress and to indicate the steps requited to fito system that is not meeting expectations. Itence, it is not necessary to develop a large number of complex measures if a sinall, simple set of measures will suffice: 
Example: Developing Criteria from the Riparian Forest Model. If the goal of the project were to "improve the habitat quality of a stream through restoring riparian vegetation," the conceptual model (Figure IV.1) could be used to help define performance criteria. Since riparian vegetation regulates stream temperature through shading and provides detritus to the food web, two obvious measures of performance are stream temperature and detritus concentration. Detritus concentration is somewhat difficult to accurately quantify, but stream invertebrates (the real biological measure of habitat quality) are more amenable to quantification. Hence, criteria would include a specific range of optimum stream temperatures and invertebrate abundances.

Simply measuring these two parameters will not provide a comprehensive picture of the system. Supplemental evidence regarding the species composition and density of riparian vegetation and the controlling factors affecting vegetation development would be useful. This supplemental evidence may not have to be included in formal statements of performance. Performance criteria for this example could be stated as follows:

1. mean stream temperature in summer will be within $\pm 1^{\circ} \mathrm{C}$ of that of reference riparian systems in the region

2. mean midsummer invertebrate densities and number of species will be within the range of values (e.g., 18-29) found in reference riparian systems in the region

3. midsummer invertebrate assemblage will have the same top three species according to density as those found in reference riparian systems in the region.

The degree of similarity between reference (i.e, natural, minimally disturbed) and restored systems should be stated in the performance criteria.

Example: Setting a "Time Frame" Criterion from the Riparian Forest Model. In a restoration project, a time frame may be prescribed for the judgement of performance. In a mitigation effort, a time frame is almost always required in order to judge whether the party responsible for implementing the mitigation project has met or not met the goals for the project. Relative to the riparian example, the fourth criterion would be:

4. criterion (1) will be met within 2 years and criteria (2) and (3) will be met within 3 years following restoration of the riparian zone.

In a restoration or mitigation setting, a time criterion is not always useful or desirable, however. Basic predictive capabilities, such as how long it takes for a restored or created system to reach full functional performance, are limited. Techniques to predict necessary initial conditions that result in the desired system structure and performance are also limited. It is generally 
understood that most systems take more than a few years to reach full function, and that the time needed may be related to the level of action necessary to establish the system. For example, creating a new riparian forest where none previously existed takes much longer and requires more effort than restoring a riparian forest that has suffered minimal disturbance. The predicted likelihood of success is also much higher in the second case.

The time frame for reaching performance criteria then needs to be established relative to several considerations, many of which are not well established in the literature. True functional equivalency with a natural system may take decades or centuries. Although monitoring of a few systems is extended over more than 10 years, this is by far the exception. Most monitoring programs extend 3 to 5 years. Performance criteria should reflect these concerns.

\section{Setting Criteria Based on Trends in the Development}

To make the time frame more meaningful with regard to the real goal for monitoring, trends in conjunction with or in place of explicit-type criteria should be used. With the riparian example, stream temperature may not be within $\pm 1^{\circ} \mathrm{C}$ of reference streams after 2 years, even if mean stream temperature has been steadily declining over the first 2 years. If the length of time necessary for the riparian forest to develop and have an effect on stream temperature is unknown, trends can be used to judge whether goals are being met. Explicit criteria not met within the time frame lead to a judgement of failure. Performance criteria stated in terms of trends can indicate that the system is on its way to being restored and meeting the goals of the project. Trends also indicate the rate at which this is occurring.

Trend criteria should be used in conjunction with hard and fast criteria. For example, if riparian restoration is designed to get the stream temperature back to "normal" (i.e., hard and fast criteria) and monitoring data show that the trend is in that direction and it is taking place at a rate of $0.5^{\circ} \mathrm{C} \mathrm{yr}^{-1}$, an assessment of the system performance and time to goal achievement can be determined. The trend information, when coupled with supplemental data, can form a powerful tool in assessing the need for midcourse corrections. Midcourse corrections are covered below in the section on Adaptive Management (Section VI).

The trends analysis can be plotted as performance curves (Figure IV.3; Kentula et al. 1992a). Kentula et al. pointed out that the performance curves can take on many different shapes (e.g., asymptotic, s-shaped), and that the shapes will vary depending upon the parameter. Shapes of these curves are often referred to as trajectories of development (Simenstad and Thom 1996), although it is argued that this term may not be the most accurate description (Zedler 1995). Figure IV.3 illustrates three different development patterns of a parameter value (e.g., density of marsh plants) through time. Initially, the value is zero and over time the value may increase to some point where it remains stable. The development pattern prior to this stable condition may vary depending on the parameter, the system type, and other factors. 


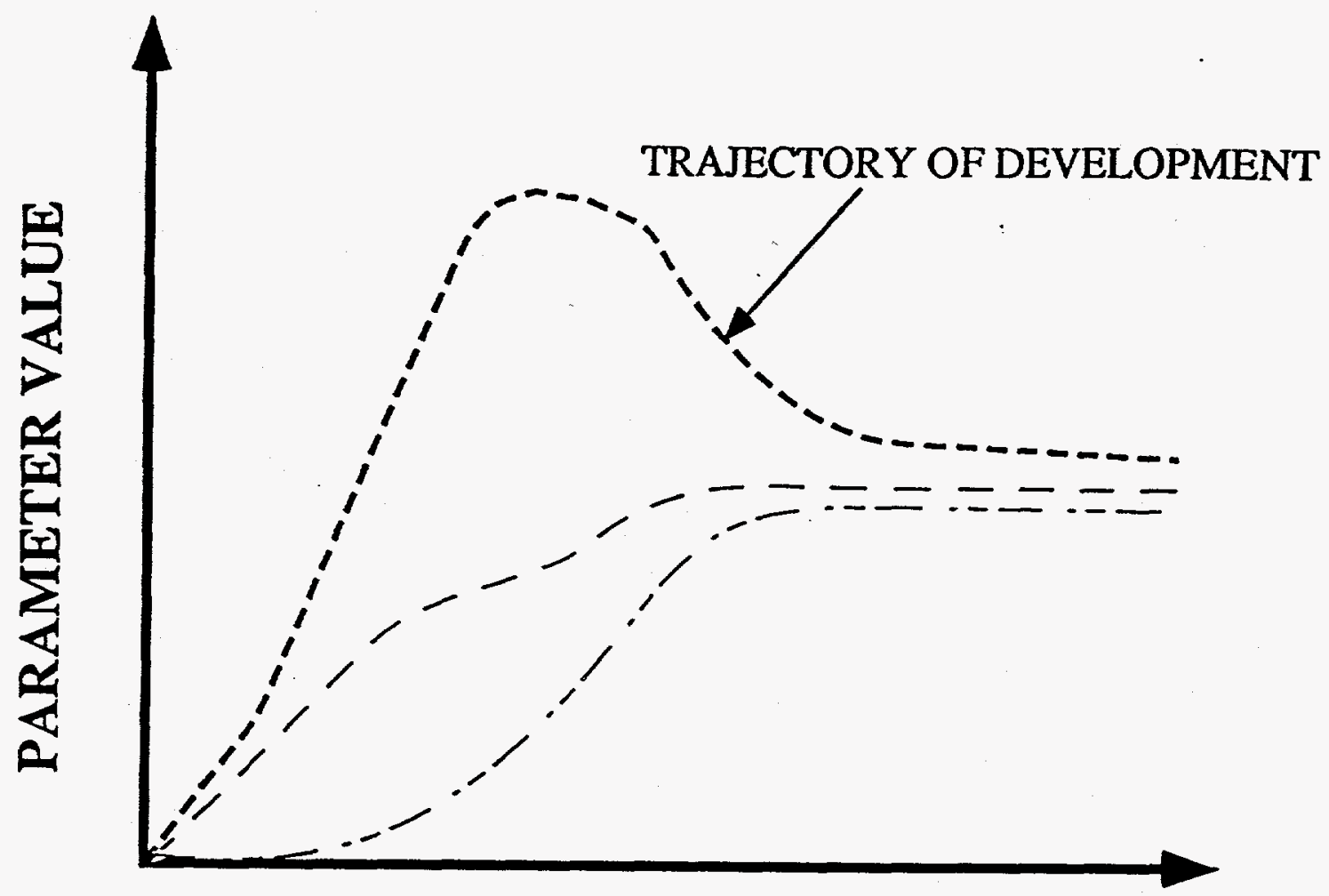

TIME

FIGURE IV.3. Examples of ecological performance curves

Example: Using Trend Criteria in the Development of Planted Eelgrass. An example of the use of trend and explicit criteria is provided in Figure IV.4, shows trend data and comparison for eelgrass (Zostera marina L.) patches in Grays Harbor estuary, Washington. The transplants were conducted to restore eelgrass in the area. The trend data indicates that eelgrass increased in total abundance in five of the six plots over the first 4 years, then declined in Year 5. Shoot density in Year 5 was similar (within the range of values) to that of reference plots (e.g., SCRef4), and declined in both reference and transplanted plots between Years 4 and 5. These data suggest that the plots developed in a positive way toward the performance criterion of matching natural shoot abundances, and that the transplanted plots are undergoing natural annual variations. The area of the plots generally increased (Figure IV.4) until Year 4, then declined. When the patches are arranged on a plot of length versus width, the transplanted plots differ in shape compared with the natural patches. This suggests that the shape and size of the transplanted patches are adjusting to the physical conditions at the site. 
(a)

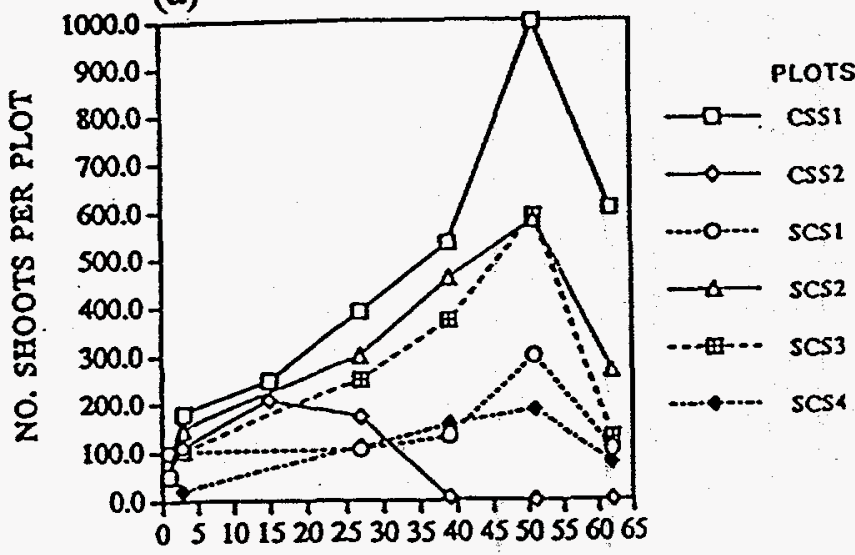

NO. MONTHS SLNCE TRANSPLANTING

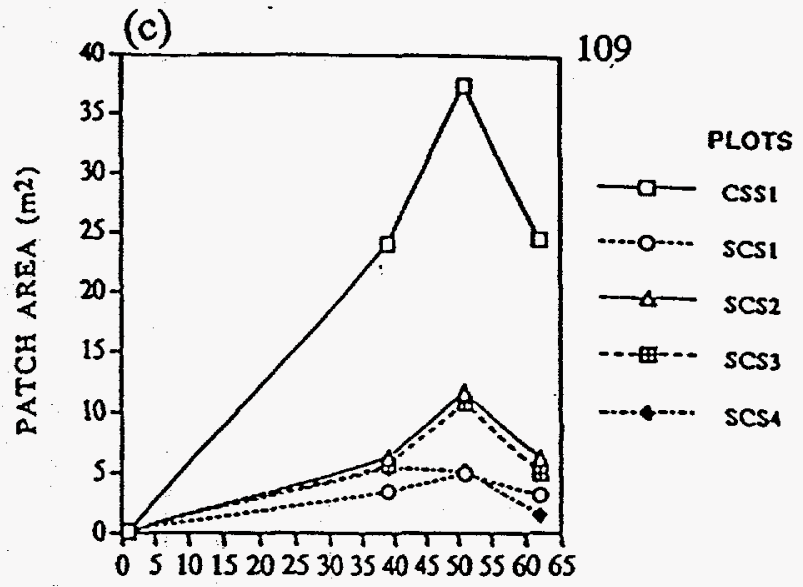

NO. MONTHS SINCE TRANSPLANTING

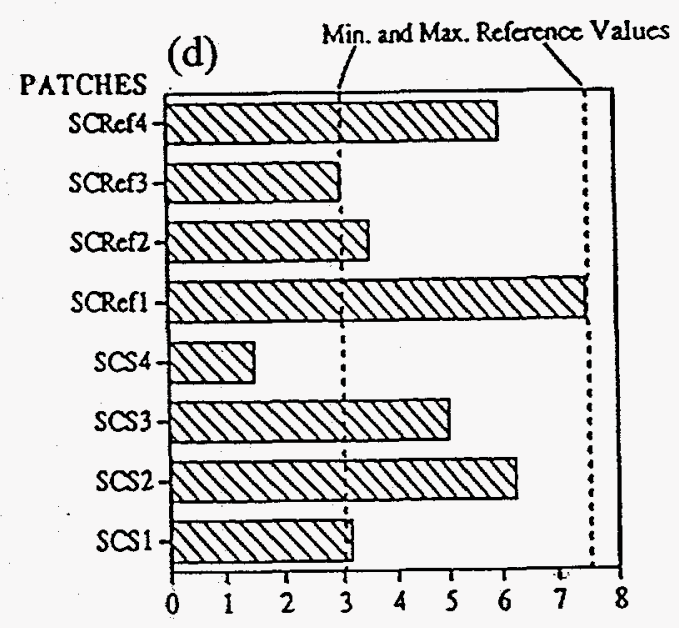

PATCH AREA $\left(\mathrm{m}^{2}\right)$

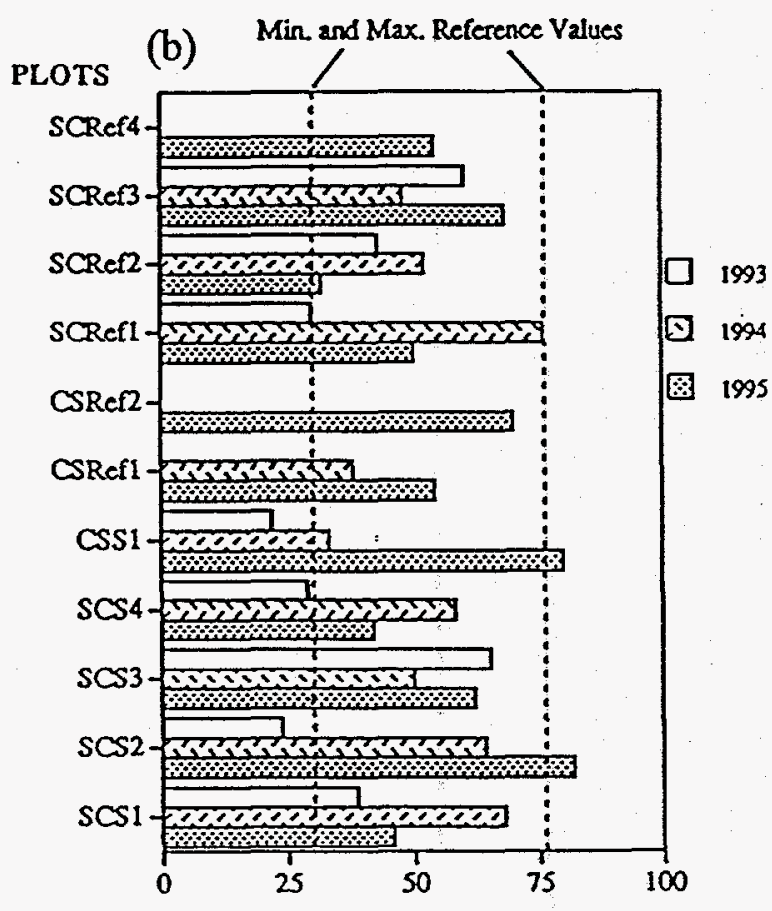

MEAN SHOOT DENSTTY (no. m-2)

Figure IV.4. Eelgrass transplant monitoring data from Grays Harbor, Washington (Thom 1995). (a) Temporal trend in total shoot abundance in transplanted plots; (b) Comparison of shoot densities of transplanted plots (CSS and SCS) with those from reference plots (CSRef and SCRef); (c) Temporal trend in transplanted patch area; (d) Comparison of patch areas in reference and transplanted plots 


\section{How long should the performance be maintained?}

The duration of performance is often not stated explicitly, but it is often assumed that once performance criteria have been met, this level will be maintained forever. Some projects have a criterion that performance must be maintained in perpetuity (e.g., Simenstad and Thom 1996). Since systems change naturally with time and are subjected to catastrophic disturbances that can dramatically alter them, an in-perpetuity criterion may not be realistic. Natural processes can shift performance gradually over time, which results in a lessening of some functions and the enhancement of others. Duration of maintained performance should be considered and specified in the planning phase. This may be stated as a performance criterion (e.g., in perpetuity) or with less precise terms. Information about the system type may indicate that once performance criteria are met, it would be expected that the system would continue to function within the criterion for an estimated 50-100 years, for example. Thereafter, the system would naturally develop into another system type with differing functions. In the planning phase, the long-term condition and performance of the project needs to be considered using the best available understanding of the system. Thereby, a realistic criterion for long-term performance can be developed and used for managing the system.

\section{Step 3C: Identify Reference Sites}

A reference site or sites should be monitored along with the restored site. Although pre- and post-construction comparisons of the system are useful in documenting the effect of the project, the level of performance can only be judged relative to reference systems.

Degraded reference sites can be

Sites established in reference systems serve three primary functions:

- they can be used as models for developing restoration actions for a site

- they provide a target from which performance goals can be derived and against which progress toward these goals can be compared

7. they provide a control system by which "natural" fluctuations, unrelated to the restoration action. can be assessed. used to show progress of the restored system away from the degraded condition (NRC 1992). In the Grays Harbor eelgrass transplant example above, inclusion of several reference sites in the monitoring program provided an indication of natural range of values and illustrated the annual variation for the parameters used in the monitoring program. The reference plots also showed the physically-driven morphology of the natural eelgrass patches, which could have been used to design transplant patches.

Appropriate reference sites are often as critical to a restoration monitoring program as they are difficult to find. This is particularly true in urban settings, where restoration actions are most frequent. 


\section{The Two-Tiered Approach for Selecting Reference Sites}

Boesch et al. (1994) pointed out that it is often difficult, if not impossible, to find appropriate reference sites, especially for large-scale restoration projects developed across a landscape as large and complex as coastal Louisiana. Boesch et al. recommended that a two-tiered approach be taken:

- Tier 1 a limited number of restoration sites be monitored intensively as a representative "class" of restoration sites

- Tier 2 other sites representative of the systems in the region should be monitored less intensively.

This two-tiered approach effectively reduces the size and cost of the monitoring program in situations where a large number of projects are planned and implemented within a defined geographic region.

\section{Definition of Wetland Reference Sites}

Brinson (1993) defines "reference wetland" as follows:

wetaind or one of a group of wetlands within a relatively homogenedus biogeographical region that represents, ypleal, representative, or common examples of a particular fy drogeomorplice wetland 1 ype, or examples of altered states.

further, he defines " reference wetland population'" as follows:

group of wetlands of the sanie hydrogeomorphic tyge that represents the variation that occurs within the ype because of natural or society. influenced causes:

Brinson's (1993) hydrogeomorphic system grouped wetlands according to their hydrology, soils, and geomorphology, which are the main factors controlling wetland functions. Further, his definition implied the need to choose reference wetlands within the region where the restoration will take place. These definitions generally work equally well for other aquatic systems, such as streams and rivers, riparian wetlands, prairie potholes, and coastal marshes. The NRC (1992) stated that reference streams should include more than one representative of each stream order so that variability within a stream order can be quantified. 
Criteria for Selecting a Reference Site Based on Degree of Similarity to Restored Site

The following are examples of features that may be assessed for degree of similarity between the reference site and the potential conditions at the mitigation site (Horner and Raedeke 1989):

- function

- climate and hydrology

- influences by human access, habitation, and economic activities, and in the quantity and quality of water runoff from those activities to the wetland

- history of and potential for such activities as grazing, mowing, and burning

- size, morphology, water depth, wetland zones and their proportions, and general vegetation types

- soils and nonsoil substrates

- access by fish and wildlife.

These criteria are broadly applicable for reference site selection for most wetland types as well as for aquatic habitats in general.

\section{Protecting Your Reference Sites}

Reference sites should be selected from areas that will receive minimal disturbance over the life of the project (NRC 1992; Brinson 1993). The Long Term Ecological Research (LTER) sites and Land Margin Ecosystem Research (LMER) sites of the National Science Foundation, the National Estuarine Research Reserve (NEER) sites of NOAA, national parks, and wildlife refuges are often mentioned as places where suitable reference sites and ecosystems could be established, maintained, and investigated. Systematic data bases on representative ecosystems would form a basis of information for restoration site design and monitoring.

In the next step, parameter and method selection are described. Parameters and methods are derived from the selection of criteria and sites, as discussed in the previous steps.

\section{STEP 4: CHOOSE MONITORING PARAMETERS AND METHODS}

\section{Step 4A: Choose Efficient Monitoring Parameters}

The performance criteria specify the expected structure, function, and appearance of the system, whereas the monitoring parameters are the aspects of system's structure and function that can be measured. 
The goal of this part of the planning process is to develop a scientifically-based, relatively easily-measured set of parameters that provide direct feedback on performance of a system toward meeting the goals.

There is an overwhelming array of parameters for monitoring aquatic systems and wetlands (e.g., Erwin 1990). With increasing numbers of parameters, the robustness of the monitoring assessment increases, and the confidence in conclusions

The NRC (1992) recommended that al least three parameters should be selected and that they inclide physical, liydrological and ecologital neasures; too few parameters may: provide insufficient information to evaliate performance or may provide information that is difficult to interpret. about performance increases. Because it is desirable to understand why a system is not meeting performance criteria, monitoring of key controlling factors is recommended. Increasing the number and types of parameters in the monitoring program increases the complexity and most likely the cost of the study. Therefore, selection of monitoring parameters needs to be well thought out. Several publications or methods that identify monitoring parameters are summarized in Appendix A. They are provided to show the variety of parameters available and the recommendations from recognized authorities and agencies.

Using the seagrass conceptual model (Figure IV.2), the general conceptual model format illustrated in Step 2C, and following the NRC's recommendations, we can relatively easily select monitoring parameters. To provide a strong data set for the seagrass system we would want to select key controlling parameters, habitat structure parameters, and habitat function parameters. The conceptual model in Figure IV.2 helps identify and classify these parameters. They are as follows:

\section{Controlling Parameters Affecting Seagrass}

Light (Irradiance)

Nutrient Concentrations*

Suspended Matter

Concentration

Chlorophyll $a$

Concentration

Epiphyte Biomass*
Examples of Structural Seagrass Habitat Parameters

\author{
Shoot Density* \\ Shoot Biomass \\ Seagrass Area
}

Examples Functional

Seagrass Habitat Parameters

Seagrass Productivity Rate

Shrimp Abundance

Fish Abundance*

The asterisks indicate four parameters that might be selected for the monitoring program. Nutrient concentration is the key factor affecting suspended matter, chlorophyll a and epiphyte biomass, all 
of which affect seagrass habitat structure. In addition, nutrients are the key management element for the Chesapeake Bay program. Hence, the measurement of nutrients is justified by their importance to the ecosystem as well as their importance to management decisions. Epiphyte biomass appears to show a strong negative correlation with seagrass biomass. Hence, epiphyte biomass may be another factor to consider that will assist in interpreting changes in the system. Seagrass shoot density (i.e., the number of individual shoots per unit area) will increase or decrease as nutrients are removed or added to the water. Shoot density is also important in that it can be correlated with shrimp and fish use of the system. Less dense areas have correspondingly fewer shrimp and fish. Hence, shoot density is a measurable parameter of the habitat that is sensitive to the controlling factors as well as important to the function of the habitat. Finally, measurement of fish abundance verifies that the increase or decrease of the seagrass habitat is affecting an important function of the habitat. It also allows one to assess if the system is recovering to meet the intended goals for the resoration project.

The conceptual model provides the framework for the decisions and the goals of the project and defines what components of the system to include in the monitoring program. The basic approach for developing a set of parameters involves the following steps:

1) simplify the system into controlling, structural, and functional components

2) identify one or more key parameters within each of the components

3) justify a subset of parameters from this initial set based upon ecological considerations and the project goal.

\section{Step 4B: Choose Methods for Sampling Design, Sampling Methods, Sample Handling, and Sample Processing}

\section{Criteria for Choice of Methods}

Monitoring methods include sampling design, sampling methods, and sample handling and processing. Monitoring methods used on restoration projects in the United States have been extremely varied (Shreffler et al. 1995).

The basic questions to ask when selecting methods for monitoring are as follows:

- does the method efficiently provide accurate data on the parameters?

- does the method provide reasonable replicable data?

- is the method feasible within time and cost constraints?

Most parameters that might be included in a restoration monitoring program are well established. Any methods used for sampling a particular parameter should have a documented 
protocol. In general, this means that the methods have been tried under many conditions and are reliable. New and poorly documented methods can open questions of accuracy and repeatability.

It is highly desirable to choose sampling methods that provide for collection of data on more than one parameter. For example, a soil core sample can provide information on soil conditions, root and rhizome development, hydrology, and invertebrate communities. Some of the information (e.g., soil color, texture, presence of indicators of hydrology) can be taken directly in the field, whereas others such as below ground biomass (i.e., root + rhizome biomass) would have to be assessed through use of appropriate laboratory methods. Collecting concordant data is efficient and allows for robust analysis.

A decision regarding the general approach to the program needs to be made early in the planning process. Whether the monitoring must show highly quantifiable results or whether the program only needs to illustrate general, qualitative, changes will influence the choice of monitoring methods.

\section{Qualitative Methods}

An example of qualitative monitoring is the very limited monitoring program used for wetland restoration projects in Washington state under the U.S. Natural Resources Conservation Service (NRCS). The goals of the project are to reestablish wetlands that formerly existed in agricultural fields. The NRCS program undertakes projects where only minimal effort is required to restore the hydrology. It may also conduct some tree plantings or other actions to enhance the quality of the system. Because the primary goal (and performance criterion) is reestablishing wetlands, the monitoring program consists of general observations and notes taken annually on the sites that indicate the relative area of wetland cover and the number of planted trees that survive. This highly qualitative monitoring program provides the type of information needed to judge whether the restoration is working and whether corrective actions are needed. More quantitative studies would be required to specifically identify corrective actions should the system not be recovering.

\section{Semiquantitative Methods}

Methods have been developed to rank the performance of habitats for certain functions. Two examples are the Habitat Evaluation Procedure (HEP; USFWS 1980) and the Wetland Evaluation Technique (WET; Adamus 1983). Both procedures are similar; they use scores of various features of the system to arrive at a numeric value for each function assigned to the system. HEP focuses on habitat, soils, and hydrology. In contrast, WET is highly directed toward assessing the latter qualities of the system. Both procedures rely on judgements made by one or more individuals (usually local experts on various aspects of the system). These judgements are often made during a visit to the site. The scores are recorded on score sheets and tallied. Supplemental information can be used to better understand how well the system is working. For example, data on bird use of a system available from a local observer may verify the presence of species for which the system was designed. The procedures have the advantages of being broad in coverage and easy 
and inexpensive to employ. The procedures are highly subjected to the opinions and knowledge of the persons carrying out the scoring, and therefore can be biased or incomplete.

\section{Quantitative Methods}

Quantitative methods develop numerical data sets from measurements taken at the site or from collected samples. In most cases where performance goals and criteria are quantitative, quantitative methods must be employed. For example, if performance criteria stated that the stream system will have a midsummer mean temperature between $15^{\circ} \mathrm{C}$ and $17^{\circ} \mathrm{C}$, then temperature must be measured in a way to develop an accurate and repeatable estimate of temperature.

\section{Combinations of Methods}

Qualitative and quantitative methods can be employed effectively in the same monitoring program. In the example of riparian forest restoration for improving stream habitat quality, a HEPtype analysis can be performed to assess the overall quality of the riparian system for selected fish and wildlife, in combination with quantitative assessments of temperature and stream invertebrates.

\section{Step 4C: Incorporate Supplemental Parameters}

Although the focus of the monitoring program is on parameters that relate directly to assessment of performance, data on other parameters are often useful and may add considerably to interpretation of the results. For example, in a case in which river flow is not part of the performance goal, it could nonetheless affect a stated goal of stream water temperature. Data on stream flow gathered from gauging stations serviced by the U.S. Geological Survey (USGS), might then be accessed during the monitoring program for a forest riparian restoration project. There are many ongoing monitoring programs such as this in most regions that can provide useful data. Examples include the U.S. Weather Service monitoring stations, air quality monitoring by state agencies, fish catch statistics, and bird surveys. When planning the monitoring program, it is a good idea to identify sources of potentially useful data and develop a plan for systematically acquiring the data.

In the previous steps we were concerned with selecting the criteria, parameters, and methods for assessing the performance of the restored system. In the next step, costs for the monitoring program are developed. 


\section{STEP 5: ESTIMATE COST}

\section{Step 5A: Make Choices}

The choice and extent of any monitoring program is in part dependent on the amount of information and level of accuracy desired. The quantity and quality of information desired is in turn dependent on the expenditures necessary to carry out the identified components of the monitoring program (i.e., the monitoring projects or methods). Past experience suggests that many monitoring methods require substantial funding. However, the ability of a decision-maker to fully fund all components of a restoration monitoring program is questionable, especially given current federal and state budgetary constraints. Although many organizations have begun to develop coordinated approaches to monitoring and evaluation, few have systematic and explicit strategies for prioritizing monitoring investments at any scale. At this time, there are no models to which program managers can turn for assistance in making decisions on the appropriate level and scale for monitoring certain components of the restoration project.

Faced with the need for methods and an approach that can address the inevitable uncertainties and time constraints encountered in monitoring, reliance may be placed on mathematical models. These models can theoretically address the need for an explicit, objective, and relatively quick method for evaluating the level and kind of information needed for objective determination of the level of success of various restoration projects. On the economic side, one of the most common evaluative approaches is to use some form of the cost-effectiveness model. The cost-effectiveness modeling approach facilitates the comparison among alternative monitoring methods or levels of monitoring effort. Such an approach allows decision-makers to build a frontier of cost-effective actions that highlight the higher marginal costs associated with conducting additional sampling. At some point, the small reduction in variability in monitoring data will not justify the increase in costs, and the decision-maker will have identified the efficient choice of monitoring component and level of sampling (See Orth 1994 for further guidance). .

An alternative approach that has been proposed (though not operationalized in the context of restoration monitoring) is the "value of information" framework (Paulsen 1995). Under such a framework, the information obtained from a monitoring program has value to the decision-maker only if it provides an indication of whether a restoration project has achieved previously identified goals and whether or not further action is needed. The value of information is high when monitoring advances sound decision-making on further restoration efforts and is low when it fails to inform these choices. This framework does not provide the ultimate decision rule by which one chooses the number or type of monitoring components, but it will guide decision-makers in articulating criteria to value monitoring information and in exploring how tradeoffs among these criteria influence restoration action priorities. 


\section{The Choice Framework}

In order to make a decision on what to include or exclude in a monitoring program, the overall requirements of the program should be kept in mind. The monitoring program should accomplish the following:

- be cost-effective

- target restoration project goals and performance criteria

- develop defensible information and data

- facilitate decisions on midcourse corrections.

The components included in the monitoring program should be assessed against these requirements. This can be facilitated by first prioritizing these requirements. Next, the list of potential monitoring components is compiled, along with a rough estimate of cost. Finally, the list is trimmed down based upon the prioritization of the requirements.

For example, if low cost is the highest priority then selection of measurement parameters and measurement methods are primarily made on the basis of cost. Below are shown the parameters selected from the seagrass conceptual model example (see Step 4).

Controlling Parameters Affecting Seagrass

Light (Irradiance)

Nutrient Concentrations*

Suspended Matter

Concentration

Chlorophyll $a$

Concentration

Epiphyte Biomass*
Examples of Structural

Seagrass Habitat Parameters

Shoot Density*

Shoot Biomass

Seagrass Area
Examples Functional

Seagrass Habitat Parameters

Seagrass Productivity Rate

Shrimp Abundance

Fish Abundance*

The asterisked parameters were selected previously as key elements to measure during the monitoring program. In the controlling factors group there are two parameters that were selected. If cost were a major factor, and there was a need to reduce the estimated cost of the program, one of these parameters could be eliminated. To make a choice between the two parameters, the costs and benefits of both must be evaluated. For example, if it is determined that a reasonable estimate of epiphyte biomass requires sample collection monthly throughout the year, then the costs of travel and labor for individuals collecting the samples in addition to the cost of laboratory sample analysis would result in the epiphyte monitoring being about twice as expensive as nutrient monitoring. It is decided that epiphyte monitoring will be eliminated but that relatively easily observed changes 
in epiphyte biomass will be noted during field trips to collect other samples. Another consideration in this decision was that nutrient concentration represents a chemical measure. Whereas, epiphyte biomass is a biological measure. By keeping nutrients as part of the program we maintain a mix of biological measures and chemical measures which is generally advisable.

In the above example, cost was the primary consideration. In other cases, there may be a need to acquire a strong data set on the physical and chemical components of this system. For example, if there is a need to know how light and nutrients interact with the concentration of suspended matter in the water columns, then these parameters would be included along with perhaps chlorophyll $a$ concentration. A decision might be made that, once the relationship is established (say, after a year of data gathering), one or more of the parameters can be dropped.

\section{Step 5B: Outline Cost Components}

The assessment of costs is aflected by a number of critical factors:

$\checkmark$ complexity

- duration

- . existence of performance bond

9. regulatory or pernit reguirement constraints that impose additional requirements.
The full cost of any monitoring program includes a number of varied components, ranging from the cost of sample analysis to the cost of report writing. Shreffler et al. (1995) reported that the total cost of monitoring programs associated with restoration projects ranged from $\$ 1,425$ to $\$ 1,048,600$ (Table IV.2). On average, monitoring accounted for $13 \%$ of the total project cost. However, few projects provide a comprehensive breakdown of actual monitoring program costs. Exceptions include the Gog-Li-Hi-Te Wetland Monitoring Program which outlines costs components (e.g., labor, equipment, supplies, and travel over a 7-year period) and Rincou Bayou, Nueces Marsh Wetlands Restoration and Enhancement Project, which notes the costs of particular sampling components.

Many of the costs of a monitoring program may not be obvious initially, but with careful thought and planning can be identified and documented. The following discussion provides the major cost components of a basic monitoring program. Each component includes a number of subcosts (e.g., labor, supplies, equipment), which are also outlined. 
TABLE IV.2. Monitoring costs as a percentage of total costs (1994 dollars; from Shreffler et al. 1995)

\begin{tabular}{lrcc} 
Restoration Project & Total Cost & Monitoring Cost & $\begin{array}{c}\text { Percentage of } \\
\text { Total Cost }\end{array}$ \\
\cline { 2 - 4 } Gog-Li-Hi-Te & $\$ 3,985,529$ & $\$ 262,462$ & $7 \%$ \\
Salmon River Estuary & 82,397 & 50,912 & 62 \\
Fraser Lands Habitat & 427,319 & 21,931 & 5 \\
McDonald Creek and & & & \\
Stone Lagoon & 45,185 & 1,143 & 3 \\
Hardrock Mine & 712,752 & 23,027 (a) & 3 \\
Triangle Marsh & 156,186 & 32,510 & 21 \\
Cascade Crossing & 589,567 & 78,510 & 13 \\
Christmas Tree & & & \\
Marsh & 193,214 & 6,679 & 3 \\
Davis Pond & 22,290 & 1,425 & 6 \\
Fort Say Brook & 34,640 & 1,425 & 4 \\
Village Creek & 16,610 & 1,425 & 9 \\
Manresa Island & 16,775 & 1,425 & 8 \\
Metzger Marsh & $5,301,253$ & $1,048,600$ (b) & 20 \\
Rincon-Bayou- & & & \\
Nueces Marsh & $1,215,096$ & 289,500 & 24 \\
& & & \\
AVERAGE & -- & & 13
\end{tabular}

(a) Estimate based on potential 5-year monitoring program.

(b) Based on estimated average annual monitoring costs 1994-2000.

\section{Program Planning}

Program planning is an important and often ignored component of a monitoring cost assessment. Program planning involves the determination of monitoring goals and strategies, acceptable and unacceptable results, and potential contingencies for addressing unacceptable results, and it should include agency and interested stakeholder coordination. The cost components of program planning are labor (including the indirect costs of benefits and overhead) and supplies. Labor should be reported in terms of cost per hour, whereas supplies will generally be reported as a lump sum. 
Depending on the scope and extent of the program, the program manager should also consider the cost of facilities; meeting supplies; outside technical reviews or experts (if desired) including honoraria, travel, per diem; and other general meeting preparation activities that take staff time (e.g., preparation of agendas, coordination of attendees, preparation of presentation materials and presentation media, such as overheads, computer simulations, and meeting recorders). In addition, depending on the size of the program, the program manager may need to consider the costs of preparing and disseminating discussion summaries and action items that take the form of either formal reports or meeting minutes.

\section{Quality Assurance}

A commitment to quality is an integral part of any monitoring program. At a minimum, it includes an independent review of the program to ensure that it meets the project goals, data quality objectives, and expectations of the project manager. Generally, quality assurance (QA) is performed at three levels. The first is review of field and laboratory data to ensure accuracy and completeness against a Quality Assurance Project Plan (QAPP). Laboratory QA is generally factored into cost of the analysis. The next level is document $\mathrm{QA}$, which includes review of interpretive and synthesis reports to ensure that methods, calculations, and presentations of reports are complete, accurate, and consistent with the original data files. The third level is programmatic and includes higher level technical reviews, ensuring that training and certifications are current, standard operating procedures (SOPs) are current and available, plus other review of other facility records to ensure consistency within the program and adherence to the client needs. Costs for the third level are generally within the program management budget or facility overheads, depending on the client's definition of the scope. The major cost component of QA is labor (on a per-hour basis), including the indirect costs of benefits and overhead.

\section{Data Management}

Programs should have a data management plan that includes specifications that start with sample tracking (i.e., that define the protocols and procedures) and conclude with the final archiving of the information. This generally includes pre-project planning and project coordination. The effort is project-dependent, but can be a major cost in large multidisciplinary programs. Major costs include the following:

- staff labor time for data manager

- data entry

- database maintenance

- computer time

- data audits. 


\section{Field Sampling Program}

Sampling may range from the very simple, such as photo monitoring, and wildlife use and behavioral observations (e.g., feeding, resting, movement), to the more complex such as nutrient and contaminant measurements, water quality parameters measurement, plankton group measurement, productivity measurement in water column and substrate surface, macrophytes/vegetation sampling, and hydrological monitoring. The cost components for a complex program may include the following:

- project management and field staff labor

- subcontracts for specific field sampling or measurement activities (including costs of managing and overseeing the subcontracted activities)

- mobilization and demobilization costs (includes fully burdened staff time, materials, and supplies)

- purchase, rental, or lease of equipment such as boats, sampling devices such as animals traps, sediment grab samplers, sediment coring devices, water samplers, plankton nets, sieving tables, and costs of specialty sampling equipment

- supplies (e.g., sample bottles, bags, coolers, filters, ice, labels, chain-of-custody forms, notebooks)

- travel (including mileage, per diem, room, trucks/vans or other transportation media), and shipping (e.g., equipment, sample containers).

\section{Laboratory Sample Analysis}

For some complex projects, the analysis of samples collected in the field is critical to determining the effectiveness of restoration actions. Analysis may involve the sampling of chemical, physical, and biological components of the system. Samples requiring laboratory analysis may range from simple water chemistry parameters, such as turbidity, to highly complex and expensive tests, such as organic contaminant analyses and ecotoxicological assays. The cost components of laboratory sample analysis are usually estimated in terms of dollars per sample and include the following:

- project management and technician labor (including benefits and overhead)

- use rates for elemental analyzers, analytical instrumentation for organic and metals analysis (usually on a per sample basis and included in the sample costs), balances, and computers

- supplies including solvents, acids, digestion vessels, general laboratory ware such as beakers, bottles, glassware, computer storage media, sample storage charges, and waste disposal

- laboratory QA/quality control (QC). 


\section{Data Analysis and Interpretation}

The analysis of field and laboratory data and their interpretation make one of the final, critical steps. Analysis and interpretation may require the expertise of trained personnel and may include database management, which can be conducted by a data management specialist if the data are complex, or a technician or project manager if they are relatively straightforward. The three major cost components for a complex monitoring program may include the following:

- labor (including benefits and overhead) for a research scientist, database manager

- computer time

- software (if necessary).

\section{Draft and Final Report Preparation}

Like any other applied research project, one of the final steps in the monitoring program is to prepare a draft and final report outlining the restoration action, monitoring goals, methods, and findings. These documents are meant to serve as interpretative reports, synthesizing the field and lab data analysis results. The generation of these reports will probably require a certain amount of management/meeting time, and will be handled by a research scientist with the aid of a research assistant. There are two major cost components of this step:

- labor (including benefits and overhead for a lead scientist and any assistants)

- supplies (including copies and mailing expenses).

Production costs will depend on the type and quality of reports requested. Glossy public outreach documents are more expensive than scientific reports.

\section{Presentation of Results at Professional Meetings}

Though not often considered a critical component of a monitoring program, presentation of program results at professional meetings should be considered as appropriate. Few comprehensive examples of monitoring programs that include the level of detail outlined in this document currently exist. The two major cost components of a presentation include labor (including benefits and overhead of the presenter) and per diem for

The dissemination of information. such as goals, methods, data and results of monitoring programs, is extremely important to the ongoing success of restoration activities. the duration of the conference, workshop, or meeting.

\section{Management of System}

Management consists of the activities of the project manager and support staff, such as coordination meetings, contractor meetings, report review, contract management, and related tasks. Costs include labor, travel (to the site and to meetings), and supplies. Project management may include day-to-day administration, management, and support services associated with the monitoring program. 


\section{Step 5C: Determine Present Value of Costs}

The program manager may wish to express monitoring costs (present and future) in terms of average annual equivalents. This is especially true if the program manager is interested in conducting a benefit-cost or cost-effectiveness analysis of monitoring programs. However, because monitoring program costs are typically incurred over time, it may be impoitant to discount all costs to some base year. Discounting allows the decision-maker to assess the estimated costs of a monitoring program in real terms and if desired, to weigh the costs of a monitoring program against its benefits (if monetary assessment is possible). Constant price levels are used to account for inflation. Then, discounting is used to account for time value of dollars. Benefits of an action will often be realized at a time other than when the costs are incurred. The discount formula is as follows:

$$
\text { Present value }(P)=F(1+i)^{n} \text {, }
$$

where $F$ is some future value, $i$ is the discount rate, and $n$ is the number of time periods involved. Market interest rates, interest on bonds, or corporate portfolios may all be used as discount rates. Despite extensive literature, a consensus does not yet exist on an appropriate rate for discounting costs and benefits of public programs and regulations. However, a real discount rate of 7.38 is to be used by the Corps in FY97. The discount rate for water resource development projects is based on average yield during the prededing fiscal year of marketable U.S. securities, with 15 years or more maturity. The formula for the rate was established by Section 80 of the Water Resources Development Act of 1974. The Corps Headquarters Planning Division notifies field offices annually of rate changes.

$$
\text { Ammortization }(A)=P\left\{i(1+i)^{n} /(1+i)^{n}-1\right\}
$$

The decision-maker may also be interested in determining the cumulative cost of the monitoring program. The cumulative present value cost is the sum of the stream of discounted costs.

Now that the costs have been estimated, there are two final steps in the process that will necessarily affect cost. These steps include defining the data types and determining level of effort. 


\section{STEP 6: CATAGORIZE THE TYPES OF DATA}

There are several types of data gathered as part of the monitoring program that may be useful in developing the program or that may provide additional information on the performance of the system.

\section{Baseline Data}

Baseline data are those developed on the site prior to restoration. This information is useful in several ways, but principally to (1) understand the existing conditions, and (2) to plan the types of actions needed in the restoration project. Data on existing conditions can be compared with those on post-construction conditions to assess the effect of the restoration project. The baseline

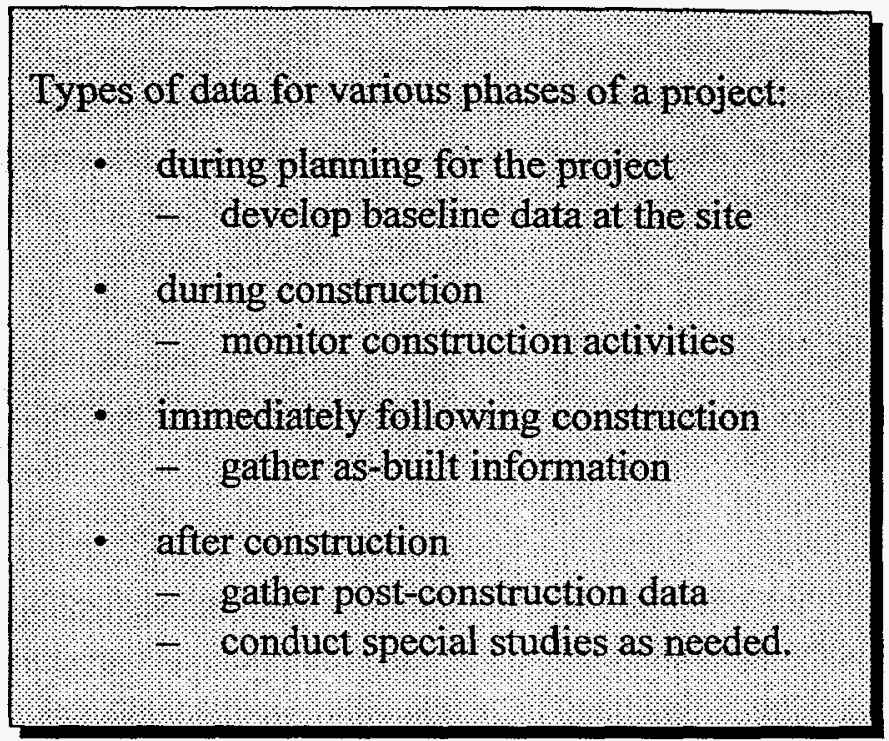
data can also describe the hydrological, soil, vegetation, and landscape setting, which can be used to, for example, plan steps to improve and maintain hydrology and to identify types of plants that grow best in the area.

Baseline studies can and should be carried out when there are specific questions about the site. For example, construction of the Gog-Le-Hi-Te wetland in Tacoma, Washington, required excavation of approximately 5 to 8 meters of soil to bring elevations down to those appropriate for tidal conditions. Because the site was a former domestic waste dump, borings were collected down to the maximum depth of excavation to analyze for potential chemical contaminants. The samples from the boring were also characterized for their sediment type. This revealed that former wetland sediment existed at approximately 4 meters depth, which helped determine the exäct depth of excavation. To establish an ecological baseline for the site, vegetation was mapped and a HEP analysis was performed prior to construction.

\section{Construction Monitoring Information}

Monitoring of the construction process by the project manager is very important. Especially in wetland systems where a few centimeters may mean the difference in success or failure of the project, frequent visits to the site are essential for assuring that the site is constructed to specifications.

\author{
Problems frequently arise during \\ construction of large and complex \\ projects:
}

During construction of the Gog-Le-Hi-Te project, several problems arose that needed immediate attention. First, a pipeline used for oil transport was uncovered during excavation that required rerouting 
before construction could continue. In addition, just before final breaching of the river dike that would open the new system to tidal inundation, a pocket of thick oily material was discovered near the breach site. This material turned out to be polychlorinated biphenyls (PCBs). Cleanup operations halted construction for 2 weeks. Years after construction, it was discovered that the system was excavated to incorrect depths, and although the system functioned acceptably, correct depths may have improved functioning (Simenstad and Thom 1996).

Although not detailed here, any relevant protocols for monitoring construction should be followed with special attention to aspects of the construction that may affect performance of the system. Any variations or unusual occurrences or findings should be documented as part of the overall monitoring program. This information may become useful in interpreting the results produced by the monitoring program.

\section{As-Built Data}

Immediately following construction, elevational surveys and other relevant data should be collected to verify that the construction met the specifications for the project. These as-built surveys provide the best indicator of the starting conditions for fundamental aspects of the systems such as elevation and soil type. As-built surveys can reveal that the conceptual design produced by the restoration planners has not been carried out exactly.

\section{Post-Construction Data}

The major aspects of the monitoring program are gathered post-construction. This involves the data and information gathered specifically on the site and at reference sites, as well as supplemental information collected by others that may be of use to the restoration project.

\section{Data Sources from Outside the Monitoring Program}

The project manager should be aware of available information that is not part of the monitoring program, but that could be useful to it. Consultation with agency personnel, local universities and consultants, citizen environmental groups (e.g., Audubon chapters), and landowners in the area can reveal information of this type. For example, USGS hydrological monitoring data, topographic maps, bird observations, hunting reports, fishing reports, trapping reports, Natural Resource Conservation Service (NRCS) soils maps, local and regional water quality monitoring data, and a vast array of other information may be available for the site, or at least for the region. It is very useful to have a working knowledge of this information, and the methods for accessing this information. If there is a commitment to continue to collect this information, it is useful to incorporate it as a part of the analysis of the monitoring program.

Many volunteer groups and agencies are looking for ways to make their data-gathering efforts more useful, and are generally willing to cooperate with restoration programs that are carried out in their locale. A review of volunteer monitoring and environmental groups by the Puget Sound Water Quality Authority turned up a total of approximately 150 groups and individuals with some information or resources to offer to monitoring of Puget Sound. The Volunteer Monitor newsletter 
is a good source for contacts in local areas (Ely 1996). It is important to establish a close tie with these groups and develop a mechanism for acquiring the information in a systematic manner. As an example, a local bird expert with interest in the Gog-Le-Hi-Te project supplied weekly information for several years on birds observed in the system. This intensity of sampling would be very costly to a program.

\section{Special Studies}

Special studies include those on the site that are not planned as part of the restoration project. These may be carried out for research purposes or for the purpose of evaluating some questions that have arisen during any phase of the project. Opening a restoration site to researchers is generally advisable, especially if the researchers will provide relevant data to the monitoring program. Special studies may be used to investigate why a particular part of the system is not developing well, so that adjustments can be made to improve performance.

\section{STEP 7: DETERMINE THE LEVEL OF EFFORT AND DURATION}

How much monitoring is required? The answer to this question is dependent on the goals and performance criteria for the project as well as on the type of ecological system being restored. The appropriate level of effort is that which will produce a well-designed, systematic program that targets key parameters tied to performance criteria and reports the results of the monitoring effort in a concise and informative way.

A monitoring progran does not need to be complex and expensive to be effective.

\section{Step 7A: Incorporate Landscape Ecology}

Owing to the greater number of factors that must be considered and understood and the increase in uncontrollable factors that can influence the system, large, complex systems may be more difficult to restore than small, simple systems. Furthermore, the more controversial or contentious a project is, the more complex and elaborate the monitoring program may need to be. The uncertainty associated with the system is a major determinant in the level of effort. Uncertainty arises from lack of experience restoring a type of system, large numbers of poorly controlled stressors on the system, very strict performance criteria, and other factors. A restoration project with high uncertainty and/or very restrictive performance criteria may require a very elaborate and complex monitoring program.

The size or scale of a project affects its complexity. As the size of the restored ecosystem increases, so does habitat heterogeneity (see Forman and Godron 1986). Even in the most homogeneous of systems, increasing size results in small but significant variations in the structural 
and functional aspects of the system. Small habitats become distinguishable and are measurably different from the surrounding system. As heterogeneity increases, the problem of effectively sampling the entire system becomes more complex. As the perimeter of the system increases in length, the number of interacting systems from the surrounding area increases. This means that there is a greater number of influences external to the system. In contrast, small restored systems may likely interact with fewer surrounding systems, but the interactions (or influence of) the surrounding systems may be great.

For the restoration project manager, this means that the system does not reside in a vacuum. Rather, external influences may significantly affect the performance of the restored system. These potential influences and interactions must be considered in planning the monitoring program. At the very least, the project manager must be cognizant of the potential effect on system performance by such things as road noise, dogs, dune buggies, air pollution, water-borne contamination, stream flow diversions, human trampling, grazing animals, and a myriad other elements. Whether these elements are included in the monitoring program depends on the potential level of influence they may have. A major potential disturbance probably should be monitored or tracked at some level by the monitoring program.

The project manager needs to have information that will guide effective midcourse corrections, should they be necessary. The goal is to maximize the probability of success, and the manager must take action if the project is failing. What basic information does the manager need to have to develop midcourse corrective actions? This question can be partially addressed during the planning phase. If hydrology is identified as a large uncertainty, monitoring of key aspects of hydrology would be important to include. Similarly, if channel maintenance is questionable, some measures of channel morphology should be recommended. Factors influencing hydrology (e.g., rainfall) and channel morphology (e.g., sediment transport) should be monitored and evaluated.

\section{Step 7B: Determine Timing, Frequency, and Duration of Sampling}

The monitoring program should be carried out according to a systematic schedule. Timing, frequency, and duration are dependent on the aspects of system type and complexity, controversy, and uncertainty.

\section{Timing}

The monitoring program should be designed prior to conducting any baseline studies.

The monitoring plan should include the following:

9. a start and end date for the progran

9. the time of the year during which field studies should take place

- . the frequency of field studies. The sampling and analysis that will be used for the monitoring program is also employed during the baseline study. These studies provide an initial data base and are important in analyzing any resultant effects from the restoration action. 
Performance monitoring should commence as soon as possible after construction: that is, at the point in time when the major restorative actions have taken place, and the system is left to develop more or less on its own. In the NRCS program, for example, major restorative actions may involve removing drain tiles and planting clumps of trees. The objective of the initial post-construction sampling is to document as-built conditions of the system as the starting point from which development can be documented.

A problem often encountered with this initial sampling is seasonality. Construction may be completed in midwinter, when vegetation and other conditions are not as relevant to the performance criteria and goals of the project, which may focus on midsummer conditions (as in the example of riparian forest restoration to improve stream temperature). If the season is inappropriate for the desired sampling, it is usually best to wait until the first opportunity to sample in the appropriate season following construction (e.g., the next summer). However, some data can be gathered immediately after construction that is independent of season. This information can include structural elements, such as number of trees planted, their distribution, and the slope of the site. These are often useful, because large physical changes typically occur very soon after construction as the system "adjusts" to the physical conditions. Information acquired during off-seasons, when physical factors such as floods and freezes can have devastating effects on the ecosystem, will help interpret changes seen in the system during normal monitoring.

The field studies should be carried out during an appropriate time of the year. The driving consideration is the performance criteria. For example, migratory bird populations should be studied during the month(s) when they are typically found in the region; midsummer water temperatures should be sampled in midsummer; juvenile salmonid use of estuarine systems should be sampled during their spring out migration; wetland hydrology should be sampled during the growing season in spring. What seems to be common-sense decisions are not always apparent to everyone. The seasons (month, time of the month) should be based on data from the ecoregion as much as possible.

Well-timed sampling minimizes the number of samplings that need to be conducted and thereby reduces the cost of the program. Because weather varies from year to year, it is wise to "bracket" the season with the sampling. For example, sampling temperature four times during the midsummer would be better than a single sampling in the middle of the season. An example of concentrated bracketing is carried out under the Puget Sound Ambient Monitoring Program. To understand and document water chemistry on beaches, samples are collected daily for 14 days before and after the winter and summer solstices. These periods for sampling were chosen because they represent periods of maximum and minimum light, respectively. The duration of sampling is based on a full lunar month, which covers all tidal conditions around the solstices. This sampling strategy was based on a very good data set developed in the Puget Sound system.

Scheduling of monitoring of wetland mitigation sites and associated reference sites has been outlined by Horner and Radaeke (1989). They indicated that monitoring can be performed either 
by concentrating all tasks during a single site visit, or by carrying out one task or a similar set of tasks at several sites in a single day. The latter strategy is considered better because it minimizes seasonal effects. Repeating the same task on the same day may also be more efficient. Timing for various tasks in Horner and Radaeke's wetland monitoring guide is broken into tasks conducted (1) during the initial site visit; (2) during the initial visit and after 1 year, followed by 3-year intervals; (3) after winter storms and runoff; and (4) in late spring-summer (Table IV.3).

\section{Frequency}

Frequency of sampling refers to the period of time between samplings. Frequency can vary within a year as well as among years. In general, "new" systems change rapidly and should be monitored more often than older systems. This is especially true for systems in which success is highly uncertain. Problems in development, if detected early, may be corrected more easily than those allowed to progress further. For example, if erosion is greater than expected, shoreline modifications may be made before the entire restored area is lost. As the system becomes established, it is generally less vulnerable to disturbances. Hence, monitoring can be less frequent.

Frequent monitoring in the early stages also is necessary to understand major processes that can affect the system. Annual monitoring may provide a good indication of development, but cannot document damages caused by winter storms. A simple visit to a new site after a major storm event may be useful in documenting the exact cause of loss or malfunctioning in the system seen the next summer. The project manager needs to understand the vulnerabilities of the restored system to natural or anthropogenic events and to document these effects, if possible. Often the most effective documentation in these cases is photographs, videotapes, and field notes.

An example of how sampling frequency is incorporated into a monitoring program is presented next in the discussion of monitoring duration.

\section{Duration}

The duration of the monitoring program is a controversial issue. The monitoring program should extend long enough to provide reasonable assurances that the system has either met its performance criteria or that it will or will not likely meet the criteria. A restored system should be reasonably self-maintaining after a certain period of time. Fluctuations on an annual basis in some parameters of the system will occur even in the most stable mature systems. It is important for the program to extend to a point somewhere after the period of most rapid change and into the period of stabilization of the system.

Ecosystems at the scale of most restoration projects take decades or centuries to develop to what has been termed a "climax community." Hence, we cannot expect restored systems to be stable in 1 year. The time for development is dependent on the initial conditions.

4 growing body of evidence on constructed systems shows that most aquatic systems do not reach stability in less than 5 years: 
Table IV.3. An example of timing and schedule for wetland mitigation site monitoring tasks (as proposed by Horner and Radaeke 1989)

\begin{tabular}{lll}
\hline Timing and Schedule & Tasks & \\
\cline { 1 - 2 } Initial Visit & Task A1. & Wetland Mapping \\
& Task A2. Transect Establishment \\
\hline $\begin{array}{l}\text { Initial visit, after 1 year, } \\
\text { then at 3-year intervals } \\
\begin{array}{l}\text { intervals reflect anticipated, } \\
\text { relatively slow changes in soil } \\
\text { characteristics) }\end{array}\end{array}$ & Task C1. Soil Organic Content Measurement \\
\hline
\end{tabular}

After winter storms and runoff (following the period of maximum potential erosion and sedimentation)
Task C3. Sediment Accumulation Gauging (some specific objectives may require additional monitoring)

Task C4. Shoreline Stability Monitoring (if performed)

\section{Late spring-summer}

(anticipated periods of maximum biological activity for the communities of interest)
Task B1. Water Temperature and $\mathrm{pH}$ Measurement (repeat during all site visits, if possible)

Task B2. Dissolved Oxygen Measurement (repeat during all site visits, if possible)

Task B3. Specific Conductivity Measurement (repeat during all site visits, if possible)

Task D1. Plant Community Assessment (exact timing should depend on community composition)

Task D2. Phytoplankton Biomass Measurement (if performed; repeat during all summer visits, if possible)

Task E1. Aquatic Invertebrate Community Assessment (repeat during each summer visit, if possible) 
If the system is essentially what Cairns (1989) terms a "new ecosystem" (i.e., a system is constructed that is new for the site), that contains no vegetation and for which hydrology must be established, development will take a long time. In contrast, systems that are minor adjustments of existing aquatic habitats will require less time.

Example: The Chehalis River Slough in Grays Harbor. Washington. The Chehalis Slough mitigation project is an example of a monitoring program tied to the life of a Corps navigation project. In 1990, the Corps in conjunction with the local sponsor (Port of Grays Harbor) constructed a tidal slough adjacent to the Chehalis River in Grays Harbor, Washington. The slough serves as mitigation for loss of juvenile salmonid habitat caused by navigation channel improvements. Because the slough was essentially dug out of upland habitat, it represents an entirely new ecosystem for the site. The monitoring program, which focuses on vegetation, fish prey (i.e., insects), and fish use of the system, was conducted annually in spring and summer during the first 2 years (Simenstad et al. 1993). Vegetation (sedge) is monitored annually for 4 years following transplanting. Fish will be monitored annually for 2 years, then in Years 4,7 and 9. Sedimentation, site stability, and retention of large organic debris is scheduled to be monitored in Year 10. The Corps is committed to post-construction monitoring over 50 years to ensure that the mitigation is effectively fulfilling its designed objectives and is maintaining its integrity. The frequency of monitoring is not presently specified beyond the initial 10 -year period. This monitoring program is long and intense, because the action is related to a permit for a large project, and the constructed system is essentially a new system with a high degree of uncertainty regarding functional performance.

The frequency and duration of the Chehalis River slough project typifies the present strategy for monitoring restoration projects. Ten years of monitoring is not unreasonable for most projects of a significant size. An attenuated frequency of sampling from an annual basis initially to every 2 to 4 years later is considered adequate and appropriate for documenting major changes in the system. If the system is not going to work, this will often become apparent after 1 to 3 years. If the system is going to develop into a functioning system but may not meet expectations in the long-term, this will be apparent in later years. This strategy for attenuating samplings allows for adaptive management of the system while minimizing monitoring effort and cost.

\section{Step 7C: Develop Statistical Framework}

The monitoring study design needs to include consideration of statistical issues, including location of sample collection, number of replicate samples to collect, and sample size. These decisions should be made based upon an understanding of the accuracy and precision required for the data. As discussed below, protocols should be used that identify the precision and accuracy of the method. In addition, the ultimate use of the data must be kept in mind when developing the 
sampling plan. It is useful to frequently ask, "Will this sampling method give me the answers I need to evaluate how the system is doing relative to the performance criteria and goals?" This question should be asked even after the sampling has been completed, and at a time when further monitoring may be modified to provide better and more efficient information.

On a broader scale, many scientists view restoration projects as experiments that can be set up to test hypotheses. Performance goals and criteria could be considered informal statements of testable hypotheses. The NRC (1992) recommended that at least some part of the restoration action incorporate experiments that will evaluate aspects of restoration actions. The result of these experiments will then add to the technology of restoring ecosystems. In contrast, the goal of a restoration action is generally to improve the system function. Although accurate quantification of some functions of aquatic systems is possible, overall ecosystem "performance" is much more complex and less tractable to evaluate.

A rigorous experimental design that evaluates one or more null hypotheses is appropriate on a limited basis for most restoration efforts, but less rigorous analyses are more appropriate for supplying evidence for the development of the ecosystem. Yoccuz (1991) argued that ecological studies often use statistical "overkill," when simple bar graphs with error bars are sufficient to interpret trends. The analysis of the results should be driven by an understanding of the ecosystem rather than by statistics. Although rigorous statistical designs and testing document statistical significance at an a priori level of confidence, this type of study requires intensive sampling, and many of the assumptions of true replication and appropriate controls are often not easily met (Hurlbert 1984; Boesch et al. 1994).

An example of a study in which useful results were attained without a rigorous experimental design is the examination by Short et al. (1995) of reducing the number of eelgrass shoots during restoration planting. Short et al. showed that using planting bundles of two eelgrass shoots rather than the standard 10 shoots per bundle resulted in similar survival, development rates, and patterns for the eelgrass patches. This significant reduction in planting stock not only saves expense, but reduces impact to donor stocks. The experiment by Short et al. conducted to validate their hypothesis was not set up with a rigorous statistical design but was carried out on a scale large enough to provide convincing and valid results that help the technology.

\section{Step 7D: Choose the Sampling Level (number of replicates)}

The appropriate level of sampling or the number of replicates under any particular field or laboratory sampling effort depends on information and needed level of accuracy. Quantity and quality of information desired is in turn dependent in part on the expenditures necessary to carry out the identified components of the sampling plan. To judge the value of the information that could be obtained compared with the cost of obtaining it, the program manager may wish to develop a framework similar to that described in Step 5. Under such a framework, the information obtained from a sampling plan is judged to be of value if it indicates whether a restoration project 
has achieved previously identified goals and whether or not further action is needed. This framework would not provide the program manager with a rule for determining the number of sample replicates or individual sample components. However, it could guide the program manager in assigning value criteria for sampling information and in exploring how tradeoffs among these criteria influence restoration action priorities.

The seven steps described above have now resulted in a defined monitoring program. The next section points out how to implement and manage the program. 
Planning Aquatic Ecosystem

Restoration Monitoring Programs 


\section{IMPLEMENTING AND MANAGING THE MONITORING PROGRAM}

Because monitoring continues well after construction actilities, there is o naturat tendency for the program to $10 \mathrm{se}$ montentwin. for the data to accummiate with Iitle andissis, and for litle documentation and dissemination of the information.
Management of the monitoring program is perhaps the least appreciated but one of the most important components of a restoration project. A national review of restoration projects (Shreffler et al. 1995) indicated that documentation of the projects in general was incomplete. This is

partially due to attrition in project managers, increased time demands on the project manager in areas other than on the monitoring program, loss or reduction in funds for the monitoring program, lack of follow-through on the part of those conducting the monitoring, and a variety of other lesser causes. This section presents methods for preventing or minimizing these problems.

\section{ENVISIONING THE PROGRAM}

A well-designed monitoring program coupled with a simple, efficient management plan can make the monitoring program easy to complete and meaningful to future projects. Well-documented data on a restored system, can be shared at meetings and forums to verify the progress of a project and to assist in the design of future projects.
The project manager must have a vision of the iffe of the nonitoring progran, and nust see how the program its into the broader topic of? restoration as a viable $100 \mathrm{l}$ for carying out the mission of both the agency and the cost sharing sponsor.

\section{DETERMINING ROLES}

The responsibility for carrying out the monitoring program generally is that of the project sponsor. However, responsibility should be established clearly in writing during the development of the restoration project, because this responsibility can last for a decade or more. Time allotted for the process must allow for obtaining approval from higher authorities. Financial resources to support the program for the duration need to be set aside. Even with the best coordination, problems can arise. 
Many restoration monitoring efforts rely on several levels of involvement. The project manager can take the overall responsibility of coordinating and managing the program. The program manager can also carry out some aspect of the monitoring study, depending on time, other responsibilities, interest, and expertise. An advantage of involvement in the field work is the intimate awareness of how the system is developing, which can make interpretation of the data more realistic and meaningful. Other aspects of the monitoring program can be carried out by other individuals and groups, such as staff of the sponsoring agency or of other participating agencies, consultants, university researchers, and citizen volunteers. The larger and more diverse the team, the more difficult and sometimes frustrating, it can become to manage the project. Although potentially more expensive, it may be simpler to contract the work to one group. However, collaborative monitoring efforts can benefit from more funds, a larger pool of individuals to draw from to conduct the work, broader awareness of the program, and wider expertise in conducting the work and interpreting the results.

There could be different individuals involved in the monitoring program over time. Therefore it is imperative that all methods employed have a well-established, clearly written protocol. There should be documentation of all results and notes on the methods, sampling sites, frequency of sampling, and all other pertinent information, that would be clear to any new staff joining the project.

\section{ASSURING QUALITY}

Scientifically defensible data require that at least minimal QA procedures are in place. For example, in order to assure data quality, the Wetlands Research Program of Data quality should be considered a high priority in the monitoring program. EPA (Kentula et al. 1992a) recommended the following:

- standard sampling and operating protocols be developed and evaluated by knowledgeable individuals

- possible sources of error and bias in the procedures be acknowledged

- quality assurance replicates be collected and evaluated during all phases of field and laboratory work

- copies of the procedures, data, and results be filed with permanent project records and be made available as needed. 
Individuals participating in the studies must be trained in the methods. This training should include safety issues related to the hazards of the site, sample processing, chemicals, and equipment. At least one copy of all data should be made and stored in a location separate from that of the original to prevent loss of all data by fire or other event.

\section{INTERPRETING RESULTS}

The project manager is at least partially responsible for interpretation of the results generated by the monitoring program. In addition, the local cost-sharing sponsor may bear coresponsibility or full responsibility in interpreting the results. Involvement by the manager or local sponsor can range from being sole or principal author of the monitoring report to his or her serving as peer technical reviewer of reports produced by the consultant or others in the agency who carry out the monitoring program. The level of involvement depends on the project manager's time, funds, expertise, interest, and responsibilities. The roles of the project manager and local sponsor need to be determined prior to any data-gathering effort. The project manager should seek appropriate technical expertise as needed.

Results of the monitoring program should be analyzed with objectivity, completeness, and relevance to the project objectives. Aquatic system restoration projects are often vulnerable to misinterpretation of monitoring results, because of poorly defined goals and performance criteria. For example, if the project goal is to improve the habitat quality of a stream, the terms "improve" and habitat "quality" can be potential sources of misinterpretation, and these terms need to be well defined either in quantitative or qualitative terms during the planning process. With well-defined criteria, the project manager (or whoever is responsible for interpreting the data) can answer definitively "yes," "no," or "cannot be determined" to questions about the performance of the restored system relative to the goals for the project. Answers should be reinforced with data, either from the project and/or from additional data sources outside the project. Although "best professional judgement" does have a place in interpreting monitoring results, it should be used sparingly. People frequently involved in restoration actions understand the developmental nature of restoration and that results are often ambiguous and difficult to interpret. Hence, interpretations that seem reasonable as supported by "the weight of evidence" are likely to be accepted by most knowledgeable individuals.

It is the responsibility of the project manager to assure that the interpretations meet the criteria of objectivity, completeness and relevance. Objectivity in interpreting the results is imperative. Bias in any way reduces the credibility of the person or agency responsible for the interpretation of the results, makes future interactions with others difficult due to mistrust, makes midcourse corrections problematic to plan, and does not advance the technology of restoration. 
Race and Christi (1982) reviewed a large number of wetland mitigation projects and found that based on very limited qualitative observations, most were reported to be successful and to meet performance criteria. However, when simple quantitative sampling was carried out, the results for most projects were inconclusive. In most cases, the qualitative sampling was not appropriately matched to the performance criteria, and the interpretations exceeded that which had been documented.

\section{MANAGING DATA}

Data should be stored in a systematic and logical manner that facilitates analysis and presentation. Planning of the monitoring program should address the types of graphs and tables that will be used to summarize the results of the monitoring program. Most monitoring data sets can be organized to allow direct graphing of the data using database or spreadsheet software. Data sets should be arranged in an orderly fashion facilitating the addition of new data.

\section{MANAGING CONTRACTS}

One of the most difficult aspects of managing a monitoring program can be management of the contracts required to conduct the program. Most projects require at least some of the work be contracted to a consultant or another agency. Because monitoring programs are frequently carried out on a seasonal basis, timing is important. Funds must be available for the contract, the contractor must be selected, and the contract must be in place in time for seasonal sampling to occur. The project manager must look to the future when planning contracts to assure that funds are available and that the contractor is on-board in time to carry out the sampling. Multi-year contracts to a single contractor who handles all of the sampling and reports can be the easiest to manage in comparison with annual contracts for pieces of the program that must be re-competed each year.

Contracts normally address final scope of work development, kickoff meeting, field study preparation, field studies, sample processing, data summary and quality assurance, data analysis, draft report production, meeting on the draft report, and final report production. The schedule for these activities must be well specified in the contract to meet seasonal sampling requirements, reporting schedules, and funding deadlines.

The final component of a monitoring program is acting on the results. That is, what to do with the information that is now known about the project? The final section describes the fundamental actions a manager can take. In addition, the next section provides guidance on how to let others know about the results of the project. 


\section{ACTING ON THE RESULTS}

\section{MONITORING AS A MANAGEMENT TOOL}

Because these are natural systems, unexpected consequences of restoration activities may occur. The three basic options available to the manager are as follows:

- no action

- maintenance

- modification of project goals and/or performance criteria.

The no action option simply means that no corrective action will be taken and that there is no change in goals or performance criteria. This option is appropriate if the project is meeting its goals and perfomance criteria or if additional time is going to be allowed for the project to progress toward the intended goals.

The second option, maintenance, refers to physical actions required to maintain the course of project development toward its goals. For example, unusual amounts of sediment may be deposited in a stream system by a 100-year flood event, requiring dredging to open channels to allow fish access and detritus flow. Poor plant survival may indicate a need to replant in some areas of a site or to modify hydrology to enhance plant growth and cover.

Maintenance can include simple measures, such as removing trash that accumulates in the system, to major physical actions, such as dredging channels or placing riprap to minimize erosion. A monitoring program provides an information base for deciding what actions are feasible and advisable. It is beneficial, especially in mitigation projects, to define potential maintenance actions and contingency plans.

Under the option of modification of project goals and/or performance criteria, changes are made in the expectations of the project. This latter option does not involve any corrective measures, and should be used only after careful consideration. Since restoration is uncertain, some flexibility should be allowed for in achieving the goals if it is obvious that the original goals will never be achieved and/or the cost or level of difficulty in making the system meet the original goals is too high. This latter option is really a variation on the no action option. An example is the Windmill Point project along the James River, Virginia. The Corps constructed an 8-hectare dredged material island in the James River in 1974-1975, primarily to evaluate whether dredged material islands could be made into viable wetland habitat (Landin et al. 1989). Although the plans called for planting a number of herbaceous wetland species on the dike and interior of the island, the island interior rapidly colonized with several freshwater species during the first summer. Monitoring 
showed that although the island had undergone subsidence and erosion, it supported marsh habitat, fisheries, and wildlife species at or above levels occurring at three reference marshes. By 1989 , the island had separated into two pieces but was continuing to function for fish and wildlife. To maintain near-original morphology, Landin et al. concluded that additional dredged material would have been needed as well as repair of the dike. Although the original goals of this project were not met in terms of marsh species and system morphology, the overall functioning of the system was acceptable. If left alone, the system will predictably develop into a self-maintaining aquatic ecosystem supporting these functions.

\section{CONTINGENCIES}

The contingency plan addresses what will be done if the project fails. Primarily because of poor follow-through on projects, differences in definition of failure, lack of guidance on when maintenance and contingencies should be implemented, and lack of funds, this maintenance/contingency approach has not always been successful.

\section{ADAPTIVE MANAGEMENT}

\section{Background}

Perhaps one of the most significant developments in aquatic system restoration has been the trend toward use of adaptive management principles in managing projects (e.g., Boesch et al. 1994). Aquatic system restoration is a technology in an early stage of evolution. Restorationists are applying science and technology in an attempt to maximize the predictability and probability of success of restoration projects. Cairns (1990) stated that "whatever restoration measures we take, the outcome is highly uncertain." Success of wetland restoration and creation often depends on long-term management, protection, and manipulation of wetlands and adjacent buffer areas (Shreffler and Thom 1993).

10 assure success, restored systems are ofter in need of mid course corrections and managenent.

The NRC (1992) recommended as 1 of 10 options for a national restoration strategy that individual restoration projects be designed and executed according to the principles of adaptive planning and management. It suggested that rather than relying on a fixed goal for restoration and an inflexible plan to achieve the goal, adaptive management recognizes the imperfect knowledge of interdependencies within and among natural and social systems. This requires that plans be modified as technical knowledge improves and social preferences change. Central to the success of adaptive management is monitoring of restoration 
policy, programs, and individual projects. The knowledge gained must be translated into restoration policy and program redesign. In terms of individual projects, knowledge based on the monitoring program, relevant work in other systems, and changing attitudes regarding performance goals need to be considered during the developing phase of a restoration project. According to Shabman (1995), adaptive management places a premium on making decisions that are the most costeffective means of information discovery.

In a major study of forest practices and endangered species issues in Pacific Northwest, the special report by the Forest Ecosystem Management Assessment Team (FEMAT 1993) recommended adaptive management as a critical element in the management and restoration of forest ecosystems. It defined the process as involving planning, action, monitoring, evaluation, and adjustment. Goals are revised based on monitoring, new knowledge, inventories, research, and new technologies (Figure VI.1).

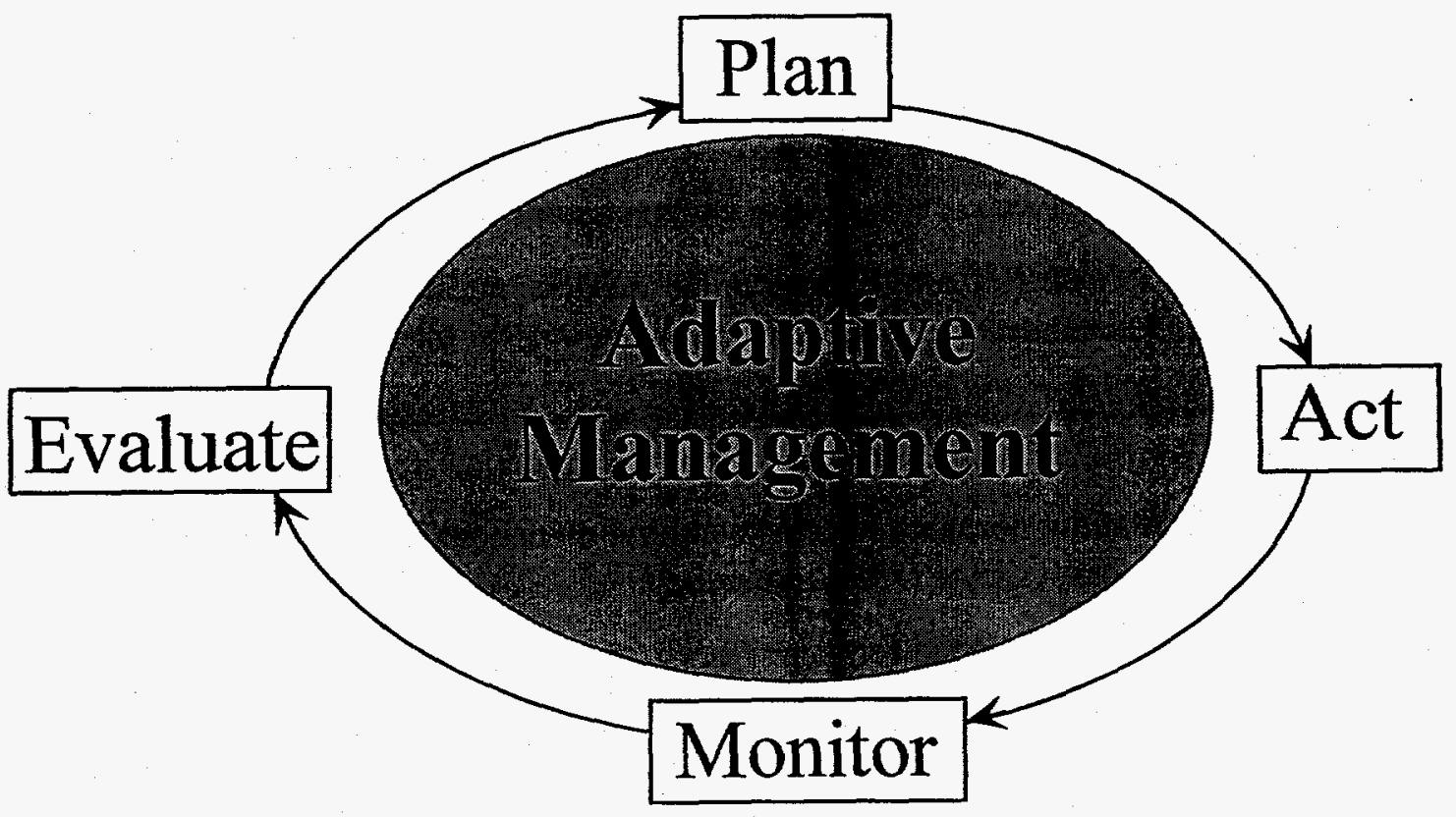

FIGURE VI.1. Diagram of components of adaptive management strategy for a restoration project (redrawn from FEMAT 1993) 
The panel that reviewed wetland loss and restoration in Louisiana (Boesch et al. 1994) recommended the use of adaptive management in the evaluation of restoration projects in that region. The adaptive approach coupled with effective monitoring provides a method to reduce the number of failed projects through providing cause-and-effect input to the management process.

Circular No. 1105-2-210

The Corps has recently released a circular titled "Ecosystem Restoration in the Civil Works Program" (Corps 1995). In this circular's section on monitoring and adaptive management, it is stated that because restoration is uncertain, it is prudent to allow for contingencies to address problems during or after project construction. Points put forth in the section on monitoring and post-project considerations are as follows:

- at the heart of adaptive management is a carefully designed monitoring program that begins during construction and continues after the project has been completed

- improving the knowledge base is a significant subset of the overall goal of adaptive management

- because of the potential costs, careful consideration must be given to the expected ecosystem benefits before pursuing adaptive management

- to be meaningful and cost effective, monitoring must be correlated to specific objectives and needs for information, and would not continue indefinitely

- when it is determined that adaptive management and extensive post-construction monitoring is warranted, it will be cost-shared with the local sponsor

- the sponsor will assume normal operations and maintenance (O\&M) responsibility for the project upon receipt of the O\&M manual

- if monitoring indicates the need for minor adjustments to achieve restoration benefits, the adjustments can be pursued as part of the O\&M program

- creativity in the development of monitoring arrangements is encouraged, as cooperative efforts may improve cost efficiency for the Corps and the sponsor.

The project manager may want to include in the project plans a provision for an adaptive management strategy to be implemented during the monitoring phase. 
Specifics on development of adaptive management for Corps restoration projects is provided in another IWR document (Yozzo et al. 1996). This document recommends annual assessments of the progress of the system. At that time, decisions can be made regarding any midcourse corrections or other alternative actions, including modification of goals. The annual assessments would use monitoring data, and may require additional data or expertise from outside the project. Because the overall objective is to make the project "work" while not expending large amounts of funds to adhere to inflexible and unrealistic restoration project goals, decisions would be made about the combination of physical actions that may be needed versus alterations in project goals.

\section{DOCUMENTING AND REPORTING}

\section{Background}

Documenting and reporting the progress and development of the restoration project provides written evidence that can be used for a variety of purposes by the project manager. In general, documenting and reporting of restoration projects has been inadequate. Shreffler et al. (1995) found it extremely difficult to access information on over 200 non-Corps restoration projects they reviewed. Likewise, Kentula et al. (1992b) found in a review of project mitigation permits issued under Section 404 of the Clean Water Act that the quality of documentation was inadequate to allow reliable descriptions of trends in the status of the wetland resource or to evaluate the success or failure of mitigation and of management strategies.

Information on restoration projects is most likely used by a varied audience. The information has been used for both project-specific purposes and for broader long-range purposes such as the following:

- judging the progress of the site toward its performance goals

- planning midcourse adjustments to meet performance goals

- assessing costs for planning, constructing, monitoring, and maintaining the project
Reasons to prepare some form of written documentation are as follows:

- . demonstrates that the project is being conducted

6. demonstrates that the project meets the design criteria and performance eriteria

( 1 assists in discussions with others about the status of the project

- documents details that may otherwise be forgotten

- . provides valuable information to new individuals assigned to the project

4. provides valuable information for futare restoration projects: 
- assessing success of techniques for restoration

- assessing success of materials for restoration

- assessing success and efficiency of monitoring methods

- assessing planning process methods (e.g., goal-setting, performance criteria selection)

- obtaining data on habitats, resources, and hydrology from the region

- evaluating realistic ecological performance goals for restored systems in the region and nationally

- developing of regional and national restoration policies.

\section{Documentation of Project Information}

\section{Three simple concepts are common anong the best doctmented projects:}

1) a singte file was developed that was the repository of all project information

2) the events and tasks of the project were recorded chronologicalty in a systenatic nanier

3). well ivititen documents (i.e. planning and monitoring) were produced and distributed widely to increase the regional or national awareness of the project.

A systematic documentation and reporting protocol with a set of minimum requirements would remedy problems encountered in the reviews by Shreffler et al. (1995) and Kentula et al. (1992b). Shreffler et al. found that the best documented restoration projects provided sufficient information for both project-specific and broader purposes. The information was easy to access, complete, concise, and well written. Often, the projects were presented at appropriate regional and national meetings to broaden awareness and to promote discussion about the project. These concepts generally follow a standard method employed by scientists and engineers in a research project.

The overriding objective is to develop documentation in such a manner that a person new to the project could, with no help, develop an accurate understanding of the project by consulting the available documentation. From this understanding, the new person could write a detailed report on the project. A second objective is to disseminate the information to the appropriate audience to advance the state of understanding on the topic. Dissemination of the results of the project is often given low priority, especially in permit-driven mitigation actions where the party responsible for the mitigation expends most of the effort constructing the project and is not interested or required to report the results to anyone but the permitting agency. Often, these reports are short, cryptic, and only discernable by those intimately involved in the project. 
Holland and Kentula (1991) and Kentula et al. (1992a) provided guidance on the required information needed by EPA's Permit Tracking System (PTS) for wetland compensatory mitigation projects. The PTS information along with information on the project planning, costing, adaptive management, report production, and the dissemination of information is summarized in Table VI.1. The file for the project should contain sections (or appropriate equivalents) for each of these topics. The information that is disseminated from the project should identify where copies of the files are held and who is the appropriate contact for obtaining information from the files. Since personnel often change during the life of a project, the office or responsible agency should be identified in the file, along with the person presently responsible for the files.

\section{Outline for a Monitoring Report}

The project manager should assure that the monitoring reports are concise and well organized for ease of reading and for minimization of costs for production, copying, mailing and storage. Annual or periodic progress reports should be in a logical and consistent format that can be repeated for each report. Each report may repeat some basic information, such as the location of the project, goals and criteria, and methods. This material should be concise but detailed enough to permit an understanding of the fundamental aspects of the project. Reports written in a consistent manner can be easily updated; new data are added to the previous data, and interpretations are refined based on the latest information.

Photographs, drawings; data graphs, and tables are all useful media that can be incorporated into monitoring reports. These should be kept simple to minimize cost while preserving quality of representation. Color photographs, although highly informative, are often costly to reproduce in reports. High-contrast black and white photographs, with adequate legends and labeling can be nearly as effective. These photographs can be digitized for relatively easy reproduction, or photocopied.

Main sections in a general format for a monitoring report should include a title page, summary or abstract, introduction, site description, methods, results, discussion, conclusions, recommendations, acknowledgments, and literature cited (Table VI.2).

The title page provides information on authorship and addresses of the authors, as well as current information about the location of project files and the person or agency responsible for maintaining them. The project manager should also be identified on this page. It is useful to indicate the proper citation for the report. The title could include some indication of the report's chronology and significance in the series of monitoring reports. For example, the title could state that the report is for Year 3 of a 5-year monitoring program. 
TABLE VI.1. Information recommended for inclusion in a data base on restoration projects (taken in part from EPA's Permit Tracking System, Holland and Kentula 1991)

Location

Dates

Wetland Type(s)

(Cowardin et al. 1979)

Area of the Project

Contact

Planning Documents

Project Sponsor(s)

Project Type

Project Costs

Planning

Construction

Monitoring

Management

Contingency

Project Goals

Project Performance Criteria

Management plan

Construction

Monitoring

Adaptive Management

Monitoring Information

"As-built" plans

Construction monitoring documents

Performance monitoring documents

Participating/Interested Parties 
An abstract or bulleted summary should be placed directly following the title page and should provide a concise restatement of the results, conclusions, and recommendations from the report.

The introduction should contain a brief history of the project, the goals and performance criteria for the project, approach to monitoring, a statement relative to the specific objective of the monitoring reported in the present report, the planned duration of the program, and other relevant background information.

There should be a brief site description including the location of the monitoring stations. This section should include a map, photograph or other illustration that identify the geographic location of the site in the watershed or landscape. This illustration can be used later when discussing influences from outside the project site, as well as the contributions the site makes to the region.

The methods section should briefly describe the methods used, the location of the sampling stations, the timing of the sampling, modifications from past sampling methods or stations, statistical methods employed, and other relevant information.

The results section should outline the data and other observations made during the present monitoring period: the results only, with no interpretation. The data should be organized so that temporal changes in the system are easily seen. For example, the change in area of vegetation during every monitoring effort since construction can be displayed in a simple $x-y$ graph or in a simple table. Other data taken in the same time frame, such as stream temperature, can be displayed using axes that allow easy comparison between graphs. Statistical analyses are also presented in the results section.

In the discussion section, the results are interpreted. The results should be concisely discussed in the context of the goals and criteria for the project. Information from outside the project may be introduced if it is relevant to the interpretation of the results. Unique or surprising results should be highlighted, any problems with the system discussed, and potential solutions identified to the extent possible. The results and discussion sections can be combined in brief reports.

The conclusion is a brief statement of progress of the project toward achieving goals and meeting performance criteria.

In the recommendations section, necessary actions are identified. If problems are identified, an action may be to call together a small group of experts to analyze the problem further. In some cases, additional special studies may be in order. In development of the recommendations section, the monitoring agent can provide information that is extremely 
TABLE VI.2. Main sections and contents of a general performance monitoring report

Main Sections

Title Page

\begin{abstract}
Introduction
\end{abstract}
Abstract or Summary

Site Description

Methods

Results

Discussion

Conclusion

Recommendations

Acknowledgments

References

Appendices
Contents

Authorship and addresses

Location of project files

Person responsible for maintaining the files

Project manager

Proper citation for the report

Series number for report

Concise restatement of the results, conclusions, and recommendations

Brief history of the project

Goals

Performance criteria for the project

Monitoring approach relative to goals and criteria

Objective of this report

Where this reports fits in series

Planned duration of the program

Location of site

Location of reference sites

Description of the methods used

Location of the sampling stations

Timing of the sampling

Modifications from past sampling methods or stations

Statistical methods employed

Concise presentation of the data and other observations

Statistical analyses

Interpretation of results relative to goals and criteria

Introduction of relevant information from outside the project, as appropriate

Highlight unique or surprising results

Discussion of problems with the system

Identification of potential solutions

Brief statement of progress of the project toward goals and criteria

Identification of necessary actions

Identification of additional special studies

Identification of all those involved in the monitoring program and the funding entity

Proper citations for all published and unpublished documents named in the report

Appendices may be used for items not needed in the body of the report, such as QA results, species lists, etc. 
useful to the project manager. The project manager should attempt to fully understand these recommendations prior to developing an action strategy.

All parties involved in the monitoring program, as well as the funding entity should be included in the acknowledgments section.

The literature cited section should consist of proper citations for all published documents according to an appropriate citation format. A technical journal should be consulted for an acceptable format. Other unpublished sources of information should be cited appropriately, including personal communications. If unpublished information is cited, this section may be more appropriately titled the references section.

\section{Length of the Monitoring Report}

The length of a monitoring report will vary with the size and complexity of the project. Small projects with simple performance goals and criteria, few target parameters, and limited physical modification of the site can normally be reported in 10 or fewer pages of double-spaced text, with additional pages for figures and tables. Larger, more complex projects may require up to 30 pages of text. However, much of this material can be "boiler plate" from previous reports. The new material is contained in the results, discussion, conclusion, and recommendation sections. This new material may constitute a small part of the report. This will minimize cost for producing and disseminating the report, but will maximize useful information.

The strategy for the project manager is to nake reports simple to prodince, concise. and complete.

\section{Dissemination of the Results}

Recipients of the report and other monitoring information should include all interested parties, and those who by regulation must get copies (e.g., all state and federal agencies involved in a permit action). In addition, complete files should be maintained. The audience can include beach-goers, birders, fishers, developers, industry representatives, engineers, government environmental managers, politicians, and scientists. The recipient list and schedule for delivery of the reports should be developed by the project manager. If appropriate, a meeting with interested parties should be held to present the results of the monitoring effort and to discuss the future of the project. Large, complex, and expensive projects may have wide appeal and interest, and meetings on these projects will require more planning. Presentations should be tailored to the audience to provide the information in the clearest and most relevant form.

Sharing of fundamental information is an integral part of developing the technology for aquatic ecosystem restoration.
It is strongly recommended that restoration projects be presented at appropriate technical meetings and workshops, at which new and interesting findings can be presented and emphasized. 
The results of the monitoring program can be of great use to others planning or conducting restoration projects. In addition, the project manager can discuss problematic aspects of the project with colleagues. Once a project has been presented to a professional audience, the members look forward to periodic updates of its progress. Professional societies that often feature aquatic habitat restoration in the meetings include the American Fisheries Society, Estuarine Research Federation, Ecological Society of America, Society for Ecological Restoration, Society of Wetland Scientists, and American Society of Civil Engineers.

Consideration should be given to publication of the results of the monitoring program in a peer-reviewed scientific journal. Although large, complex, and controversial projects are always of interest, small, well-conceived and well-implemented projects can also be worthy of publication. Publication disseminates results to a wide and interested audience. The peer review process formally assures that the information and interpretation meets the highest technical standards. Publication is often reserved for completed projects, that have essentially ended, but for projects with longer monitoring programs, a report summarizing early results may be appropriate. The societies listed above frequently have symposia devoted to restoration, the proceedings from which are often published in the societies' journals.

From time to time, requests may be made for copies of reports and data. If the report format is such that the current report contains all of the monitoring information to date, it will generally suffice. However, if reports contain varied types of information, all reports may need to be sent. If possible, copies of the reports should be placed with an office or group that handles dissemination of information and that can also handle billing for publications.

Finally, the general public is often interested in restoration projects. Volunteer monitors and others in the region want to hear of the progress of the system. The project manager can develop special summary reports of one to two pages that present the fundamental findings from the monitoring program in nontechnical terms. These reports can also be published as articles in the periodicals issued by the agency, or reported by the local news media. 


\section{LITERATURE CITED}

Adamus, P.R. 1983. A Method for Wetland Functional Assessment. Report FHWA-IP-82-24 Vol. II. U.S. Department of Transportation, Washington, D.C.

Anderson, J.R., E.E. Hardy, J.T. Roach, and R.E. Witmer. 1976. A Land Use and Land Cover Classification System for Use with Remote Sensor Data. U.S. Department of Interior, Geological Survey, Professional Paper 964. Washington, D.C.

Apogee Research, Inc. 1994. National Wetland Mitigation Banking Study. An Examination of Wetland Programs: Opportunities for Compensatory Mitigation. IWR Report 94-WMB-5. Prepared for Institute for Water Resources, U.S. Army Corps of Engineers, Alexandria, Virginia.

Apogee Research, Inc. 1995. Resource Significance in Environmental Project Planning. IWR Report 95-R-10. Prepared for Institute for Water Resources, U.S. Army Corps of Engineers, Alexandria, Virginia and Waterways Experimental Station, U.S. Army Corps of Engineers, Vicksburg, Mississippi.

Armstrong, N.E. 1987. The Ecology of Open-Bay Bottoms of Texas: A Community Profile. Biological Report 85(7.12). U.S. Fish and Wildlife Service, Washington, D.C.

Bahr, L.M., and W.P. Lanier. 1981. The Ecology of Intertidal Oyster Reefs of the South Atlantic Coast: A Community Profile. FWS/OBS-81/15. U.S. Fish and Wildlife Service, Washington, D.C.

Batiuk, R.A., R.J. Orth, K.A. Moore, W.C. Dennison, J.C. Stevenson, L.W. Staver, V. Carter, N.B. Rybicki, R.E. Hickman, S. Kollar, S. Bieber, and P. Heasley. 1992. Chesapeake Bay Submerged Aquatic Vegetation Habitat Requirements and Restoration Targets: a Technical Synthesis. U.S. Environmental Protection Agency, Chesapeake Bay Program, Annapolis, Maryland.

Boesch, D.F., M.N. Josselyn, A.J. Mehta, J.T. Morris, W.K. Nuttle, C.A. Simenstad, and D.J.P. Swift. 1994. Scientific Assessment of Coastal Wetland Loss, Restoration and Management in Louisiana. Journal of Coastal Research, Special Issue No. 20.

Brinson, M.M. 1993. A Hydrogeomorphic Classification for Wetlands. Wetlands Research Program Technical Report WRP-DE-4. U.S. Army Corps of Engineers, Waterways Experimental Station, Vicksburg, Mississippi.

Brooks, R.P., and R.M. Hughes. 1988. Guidelines for Assessing the Biotic Communities of Freshwater Water Wetlands. In Proceedings of the National Wetland Symposium: Mitigation of Impacts and Losses, eds. J.A. Kusler, M.L. Quammen, and G. Brooks, pp. 276-280 Association of State Wetland Managers, Berne, New York.

Brooks, R.P., E.D. Bellis, C.S. Keener, M.J. Croonquist, and D.E. Arnold. 1991. A Methodology for Biological Monitoring of Cumulative Impacts on Wetland, Stream, and Riparian Components 
of Watersheds. In Proceedings of the International Symposium: Wetlands and River Corridor Management, eds. J.A. Kusler and S. Daly, pp. 387-398. Association of State Wetland Managers, Berne, New York.

Brower, J.E., and J.H. Zar. 1984. Field and Laboratory Methods for General Ecology, Second Edition. William L. Brown Company, Dubuque, Iowa.

Brumbaugh, R., and R. Reppert. 1994. National Wetland Mitigation Banking Study. First Phase Report. IWR Report 94-WMB-4. Prepared for Institute for Water Resources, U.S. Army Corps of Engineers, Alexandria, Virginia.

Cahoon, D.R. and R.E. Turner. 1989. Accretion and Canal Impacts in a Rapidly Subsiding Wetland. II. Feldspar Marker Horizon Technique. Estuaries 12(4):260-268.

Cairns, J., Jr. 1989. Restoring Damaged Ecosystems: Is Predisturbance Condition a Viable Option? Environ. Prof. 11:152.

Cairns, J., Jr. 1990. Gauging the Cumulative Effects of Developmental Activities on Complex Ecosystems. In Ecological Processes and Cumulative Impacts: Illustrated by Bottomland Hardwood Wetland Ecosystems, eds. J.G. Gosselink, L.C. Lee, and T.A. Muir, pp. 239-256. Lewis Publishers, Inc., Chelsea, Michigan.

Copeland, B.J., R.G. Hodson, and S.R. Riggs. 1983. The Ecology of Albemarle Sound, North Carolina: An Estuarine Profile. FWS/OBS-83/01. U.S. Fish and Wildlife Service, Washington, D.C.

Copeland, B.J., R.G. Hodson, and S.R. Riggs. 1984. The Ecology of Pamlico River, North Carolina: An Estuarine Profile. FWS/OBS-82/06. U.S. Fish and Wildlife Service, Washington, D.C.

Corps (U.S. Army Corps of Engineers). 1992. Upper Mississippi River System Environmental Management Program. Midterm Evaluation Report. U.S. Army Corps of Engineers, North Central Division.

Corps (U.S. Army Corps of Engineers). 1995. Ecosystem Restoration in the Civil Works Program. Circular No. 1105-2-210. U.S. Army Corps of Engineers, Headquarters, Washington, D.C.

Cowardin, L.M., V. Carter, F.C. Golet, and E.T. LaRoe. 1979. Classification of Wetlands and Deepwater Habitats of the United States. FWS/OBS-79/31. U.S. Fish and Wildlife Service, Washington, D.C.

Deegan, L.A., J.T. Finn, S.G. Ayvazian, and C. Ryder. 1993. Feasibility and Application of the Index of Biotic Integrity to Massachusetts Estuaries (EBI). Final Report to Massachusetts Executive Office of Environmental Affairs, Department of Environmental Protection, North Grafton, Massachusetts. 
Doll, A. 1994. Review and Evaluation of Programs for Determining Significance and Prioritization of Environmental Resources. IWR Report 94-R-7. Prepared for Institute for Water Resources, U.S. Army Corps of Engineers, Alexandria, Virginia.

Ely, E., ed. 1996. The Volunteer Monitor Newsletter. San Francisco, California.

Environmental Law Institute. 1994. National Wetland Mitigation Banking Study. Wetland Mitigation Banking: Resource Document. IWR Report 94-WMB-2. Prepared for Institute for Water Resources, U.S. Army Corps of Engineers, Alexandria, Virginia.

EPA (U.S. Environmental Protection Agency). 1991a. Biological Criteria: Research and Regulation, Guide to Technical Literature. EPA-440/5-91-004. U.S. Environmental Protection Agency, Washington, D.C.

EPA (U.S. Environmental Protection Agency). 1991b. Biological Criteria: Research and Regulation, Proceedings of a Symposium. EPA-440/5-91-005. U.S. Environmental Protection Agency, Washington, D.C.

Erwin, K.L. 1988. A Quantitative Approach for Assessing the Character of Freshwater Marshes and Swamps Impacted by Development in Florida. In Proceedings of the National Wetland Symposium: Mitigation of Impacts and Losses, eds. J.A. Kusler, M.L. Quammen, G. Brooks, pp.295-297. Association of State Wetland Managers, Berne, New York.

Erwin. K.L. 1990. Wetland Evaluation for Wetland Creation and Restoration. In Wetland Creation and Restoration, the Status of the Science, eds. Kusler, J.A. and M.E. Kentula, pp 429458. Island Press, Washington, D.C.

Faber, P.M., E. Keller, A. Sands, and B.M. Massey. 1989. The Ecology of Riparian Habitats of the Southern California Coastal Region: A Community Profile. Biological Report 85(7.27). U.S. Fish and Wildlife Service, Washington, D.C.

Feather T.D., and D.T. Capan. 1995a. Compilation and Review of Completed Restoration and Mitigation Studies in Developing and Evaluation Framework for Environmental Resources, Volume I. IWR Report 95-R-4. Prepared for Institute for Water Resources, U.S. Army Corps of Engineers, Alexandria, Virginia and Waterways Experimental Station, U.S. Army Corps of Engineers, Vicksburg, Mississippi.

Feather T.D., and D.T. Capan. 1995b. Compilation and Review of Completed Restoration and Mitigation Studies in Developing and Evaluation Framework for Environmental Resources, Volume II. IWR Report 95-R-5. Prepared for Institute for Water Resources, U.S. Army Corps of Engineers, Alexandria, Virginia and Waterways Experimental Station, U.S. Army Corps of Engineers, Vicksburg, Mississippi.

Feather, T.D., C.S. Russel, K.W. Harrington, and D.T. Capan. 1995a. Review of Monetary and Nonmonetary Valuation of Environmental Investments. IWR Report 95-R-2. Prepared for Institute for Water Resources, U.S. Army Corps of Engineers, Alexandria, Virginia and Waterways Experimental Station, U.S. Army Corps of Engineers, Vicksburg, Mississippi. 
Feather, T.D., K.W. Harrington, and D.T. Capan. 1995b. Tradeoff Analysis for Environmental Projects: An Annotated Bibliography. IWR Report 95-R-8. Prepared for Institute for Water Resources, U.S. Army Corps of Engineers, Alexandria, Virginia and Waterways Experimental Station, U.S. Army Corps of Engineers, Vicksburg, Mississippi.

FEMAT (Forest Ecosystem Management Assessment Team). 1993. Forest Ecosystem Management: An Ecological, Economic, and Social Assessment. U.S. Forest Service, U.S. Department of Agriculture, Washington, D.C.

FICWD (Federal Interagency Committee for Wetland Delineation). 1989. Federal Manual for Identifying and Delineating Jurisdiction Wetlands. U.S. Army Corps of Engineers, U.S. Environmental Protection Agency, U.S. Fish and Wildlife Service, and U.S. Department of Agriculture Soil Conservation Service, Cooperative Technical Publication. Washington, D.C.

Fonseca, M.S., 1990. Regional Analysis of the Creation and Restoration of Seagrass Systems. In Wetland Creation and Restoration, the Status of the Science, eds. Kusler, J.A. and M.E. Kentula, pp. 175-198. Island Press, Washington, D.C.

Forman, R.T.T., and M. Godron. 1986. Landscape Ecology. John Wiley \& Sons, New York, New York.

Foster, M.S., and D.R. Schiel. 1985. The Ecology of Giant Kelp Forests in California: A Community Profile. Biological Report 85(7.2). U.S. Fish and Wildlife Service, Washington, D.C.

Gosselink, J.G. 1984. The Ecology of Delta Marshes of Coastal Louisiana: A Community Profile. FWS/OBS-84/09. U.S. Fish and Wildlife Service, Washington, D.C.

Gosselink, J.G. and L.C. Lee. 1989. Cumulative Impact Assessment in Bottomland Hardwood Forests. Wetlands 9:89-174.

Greeley-Polhemus Group, Inc. 1991. Economic and Environmental Considerations for Incremental Cost Analysis in Mitigation Planning. IWR Report 91-R-1. Prepared for Institute for Water Resources, U.S. Army Corps of Engineers, Alexandria, Virginia.

Gwin, S.E., and M.E. Kentula. 1990. Evaluating Design and Verifying Compliance of Wetlands Created Under Section 404 of the Clean Water Act in Oregon. EPA/600/3-90/061. U.S. Environmental Protection Agency, Environmental Research Laboratory, Corvallis, Oregon.

Hay, M.E., and J.P. Sutherland. 1988. The Ecology of Rubble Structures of the South Atlantic Bight: A Community Profile. Biological Report 85(7.20). U.S. Fish and Wildlife Service, Washington, D.C.

Herdendorf, C.E. 1987. The Ecology of the Coastal Marshes of Western Lake Erie: A Community Profile. Biological Report 85(7.9). U.S. Fish and Wildlife Service, Washington, D.C. 
Hobbie, J.E. 1984. The Ecology of Tundra Ponds of the Arctic Coastal Plain: A Community Profile. FWS/OBS-83/25. U.S. Fish and Wildlife Service, Washington, D.C.

Holland, C.C., and M.E. Kentula. 1991. The Permit Tracking System (PTS): A User's Manual. EPA/600/8-91/054. U.S. Environmental Protection Agency, Environmental Research Laboratory, Corvallis, Oregon.

Horner, R.R., and K.J. Raedeke. 1989. Guide for Wetland Mitigation Project Monitoring. Report No. WA-RD 195.1. Washington State Department of Transportation, Olympia, Washington.

Hunsaker, C.T., and D.E. Carpenter, eds. 1990. Environmental Monitoring and Assessment Program. Ecological Indicators. EPA 600/3-90/060. U.S. Environmental Protection Agency, Office of Research and Development, Research Triangle Park, North Carolina.

Hurlbert, S.H. 1984. Pseudoreplication and the Design of Ecological Field Experiments. Ecological Monographs 54:187-211.

Josselyn, M. 1983. The Ecology of San Fransisco Bay Tidal Marshes: A Community Profile. FWS/OBS-83/23. U.S. Fish and Wildlife Service, Washington, D.C.

Karr, J. R. 1993. Measuring Biological Integrity: Lessons from Streams. In Ecological Integrity and the Management of Ecosystems, eds. S. Woodley, J. Kay, and G. Fransis, pp. 83-104. Sponsered by Heritage Resource Centre, University of Waterloo and Canadian Parks Service, Ottawa.

Karr, J.R., and M. Dionne. 1991. Designing Surveys to Assess Biological Integrity in Lakes and Resevoirs. In Biological Criteria: Research and Regulation, Proceedings of a Symposium, pp.6272. EPA-440/5-91-005. U.S. Environmental Protection Agency, Washington, D.C.

Kentula, M.E., R.P. Brooks, S. Gwin, C. Holland, A.D. Sherman, and J. Sifneos. 1992a. An Approach to Improving Decision Making in Wetland Restoration and Creation. U.S. Environmental Protection Agency, Environmental Research Laboratory, Corvallis, Oregon.

Kentula, M.E., J.C. Sifneos, J.W. Good, M. Rylko, and K. Kunz. 1992b. Trends and Patterns in Section 404 Permitting Requiring Compensatory Mitigation in Oregon and Washington, USA. Environmental Management 16(1):109-119.

Kistner, D.H., D.G. Alexander, and H.R. Jacobson. 1995. Vernal Pool Creation and Restoration in California: A Study Plan for Evaluation of Attainable Quality and Functional Performance. EPA/600/R-95/073. U.S. Environmental Protection Agency, National Health and Environmental Effects Laboratory, Corvallis, Oregon.

Klein, V., T.P. Fiock, E.M. Pettit, and T.D. Feather. 1993. Annotated Bibliography: Value of Environmental Protection and Restoration. IWR Report 93-R-4. Prepared for Institute for Water Resources, U.S. Army Corps of Engineers, Alexandria, Virginia. 
Kusler, J.A. and M.E. Kentula, eds. 1990. Wetland Creation and Restoration, the Status of the Science. Island Press, Washington, D.C.

Laderman, A.D. 1989. The Ecology of Atlantic White Cedar Wetlands: A Community Profile. Biological Report 85(7.21). U.S. Fish and Wildlife Service, Washington, D.C.

Landin M.C., E.J. Clairain and C.J. Newling. 1989. Wetland Habitat Development and Long-term Monitoring at Windmill Point, Virginia. Wetlands 9(1):13-25.

Langis, R., M. Zalejko, and J.B. Zedler. 1991. Nitrogen Assessments in a Constructed and a Natural Salt Marsh of San Diego Bay, California. Ecological Applications 1:40-51.

Lassuy, D.R. 1989. Species Profiles: Life Histories and Environmental Requirements of Coastal Fishes and Invertebrates (Pacific Northwest)--Pacific Herring. Biological Report 82(11.126). U.S. Fish and Wildlife Service, Washington, D.C.

Leibowitz, N.C., L. Squires, and J.P. Baker. 1991. Research Plan for Monitoring Wetland Ecosystems. EPA/600/3-91/010. U.S. Environmental Protection Agency, Environmental Research Laboratory, Corvallis, Oregon.

Livingston, R.J. 1984. The Ecology of the Apalachicola Bay System: An Estuarine Profile. FWS/OBS-82/05. U.S. Fish and Wildlife Service, Washington, D.C.

Mitsch, W.J., and J.G. Gosselink. 1993. Wetlands, Second Edition. Van Nostrand Reinhold, New York, New York.

Muncy, J., J.C. Fischenich, and E.A. Dardeau. 1996. National Review of Corps Environmental Restoration Projects. Prepared for Institute for Water Resources, U.S. Army Corps of Engineers, Alexandria, Virginia and Waterways Experimental Station, U.S. Army Corps of Engineers, Vicksburg, Mississippi. (In preparation)

Newling, C.J., and M.C. Landin. 1985. Long-Term Monitoring of Habitat Development at Upland and Wetland Dredged Material Disposal Sites 1974-1982. U.S. Army Corps of Engineers, Waterways Experimental Station, Vicksburg, Mississippi.

Nixon, S.W. 1982. The Ecology of New England High Salt Marshes: A Community Profile. FWS/OBS-81/55. U.S. Fish and Wildlife Service, Washington, D.C.

NRC (National Research Council). 1990. Managing Troubled Water, the Role of Marine Environmental Monitoring. National Academy Press, Washington, D.C.

NRC (National Research Council). 1992. Restoration of Aquatic Ecosystems. National Academy Press, Washington, D.C.

NRC (National Research Council). 1995. Wetlands: Characteristics and Boundaries. Draft. National Academy Press, Washington, D.C. 
Odum, W.E., C.C. McIvor, and T.J. Smith, III. 1982. The Ecology of the Mangroves of South Florida: A Community Profile. FWS/OBS-81/24. U.S. Fish and Wildlife Service, Washington, D.C.

Odum, W.E., T.J. Smith, III., J.K. Hoover, and C.C. McIvor. 1984. The Ecology of Tidal Freshwater Marshes of the United States East Coast: A Community Profile. FWS/OBS-83/17. U.S. Fish and Wildlife Service, Washington, D.C.

Onuf, C.P. 1987. The Ecology of Mugu Lagoon, California: An Estuarine Profile. Biological Report 85(7.15). U.S. Fish and Wildlife Service, Washington, D.C.

Orth, K.D. 1994. Cost Effectiveness Analysis for Environmental Planning: Nine Easy Steps. IWR Report 94-PS-2. Prepared for Institute for Water Resources, U.S. Army Corps of Engineers, Alexandria, Virginia.

Paulsen, C.M. 1995. Information System Development for a Cost-Effective Monitoring Program: A Workplan from Resources for the Future. Prepared for the Division of Fish and Wildlife, Office of Power Sales, Bonneville Power Administration, Portland, Oregon.

PERL (Pacific Estuarine Research Laboratory). 1990. A Manual for Assessing Restored and Natural Coastal Wetlands with Examples from Southern California. California Sea Grant Report No. T-CSGCP-021. La Jolla, California.

Peterson, C.H., and N.M. Peterson. 1979. The Ecology of Intertidal Flats of North Carolina: A Community Profile. FWS/OBS-79/39. U.S. Fish and Wildlife Service, Washington, D.C.

Phillips, R.C. 1984. The Ecology of Eelgrass Meadows in the Pacific Northwest: A Community Profile. FWS/OBS-84/24. U.S. Fish and Wildlife Service, Washington, D.C.

Race, M.S., and D.R. Christie. 1982. Coastal Zone Development: Mitigation, Marsh Creation, and Decision-making. Environmental Management 6(4):317-328.

Reed, P.B., Jr. 1988. National List of Plant Species that Occur in Wetlands: Northwest (Region 9). Biological Report 88(26.9). U.S. Fish and Wildlife Service. Washington, D.C. (This citation refers to the Pacific Northwest volume. Other volumes are appropriate for specific areas).

Russell, C.S. 1992. First Steps in the Development of a Method for Evaluating Environmental Restoration Projects. IWR Report 92-R-9. Prepared for Institute for Water Resources, U.S. Army Corps of Engineers, Alexandria, Virginia.

Scodari, P.F., C.C. Bohlen, and A. Srivastava. 1995. Prototype Information Tree for Environmental Restoration Plan Formulation and Cost Estimation. IWR Report 94-R-3. Prepared for Institute for Water Resources, U.S. Army Corps of Engineers, Alexandria, Virginia.

Seliskar, D.M. and J.L. Gallagher. 1983. The Ecology of Tidal Marshes of the Pacific Northwest Coast: A Community Profile. FWS/OBS-82/32. U.S. Fish and Wildlife Service, Washington, D.C. 
Shabman, L.A. 1995. Making Watershed Restoration Happen: What Does Economics Offer? In Rehabilitating Damaged Ecosystems, ed. J. Cairns, pp. 35-47. Lewis Publishers, Boca Raton, Florida.

Sharitz, R.R., and J.W. Gibbons. 1982. The Ecology of Southeastern Shrub Bogs (Pocosins) and Carolina Bays: A Community Profile. FWS/OBS-82/04. U.S. Fish and Wildlife Service, Washington, D.C.

Shaw, W.N., and T.J. Hessler. 1989. Species Profiles: Life Histories and Environmental Requirements of Coastal Fishes and Invertebrates (Pacific Northwest)-Lingcod. Biological Report 82(11.119). U.S. Fish and Wildlife Service, Washington, D.C.

Short, F.T.,R. Davis, D.M. Burdick, D. McHugh, and W.S. Bosworth. 1995. Restoration and Creation of Eelgrass, Saltmarsh and Mudflat Habitats in the Piscataqua River, New Hampshire. In Abstracts from the Estuarine Research Federation, 13th Biennial International Conference, pp. 124. National Oceanic and Atmospheric Administration, Washington, D.C.

Shreffler, D.K., and R.M. Thom. 1993. Restoration of Urban Estuaries: New Approaches for Site Location and Design. Washington State Department of Natural Resources, Olympia, Washington.

Shreffler, D.K., R.M. Thom, M.J. Scott, K.F. Wellman, M.A. Walters, and M. Curran. 1995. National Review of Non-Corps Environmental Restoration Projects. IWR Report 95-R-12. Prepared for Institute for Water Resources, U.S. Army Corps of Engineers, Alexandria, Virginia and Waterways Experimental Station, U.S. Army Corps of Engineers, Vicksburg, Mississippi.

Simenstad, C.A. 1983. The Ecology of Estuarine Channels of the Pacific Northwest Coast: A Community Profile. FWS/OBS-83/05. U.S. Fish and Wildlife Service, Washington, D.C.

Simenstad C.A., and R.M. Thom. 1996. Functional Equivalency Trajectories of the Restored GogLe-Hi-Te Estuarine Wetland. Ecological Applications 6(1):38-56.

Simenstad, C. A., C.D. Tanner, R.M. Thom, and L. Conquest. 1991. Estuarine Habitat Assessment Protocol. Report to U.S. Environmental Protection Agency-Region 10, Wetland Ecosystem Team. UW-FRI-8918/-8919. Fisheries Research Institute, University of Washington, Seattle, Washington.

Simenstad, C.A., J.R. Cordell, J.A. Miller, W.G. Hood, and R.M. Thom. 1993. Ecological Status of a Created Estuarine Slough in the Chehalis River Estuary: Assessment of Created and Natural Estuarine Sloughs, January-December 1992. U.S. Army Corps of Engineers, Seattle District, Seattle, Washington.

Steyer, G.D., and R.E. Stewart. 1992. Monitoring Program for Coastal Wetlands Planning, Protection, and Restoration Act Projects. Open File Report 93-01. U.S. Fish and Wildlife Service, National Wetlands Research Center, Washington, D.C.

Teal, J.M. 1986. The Ecology of Regularly Flooded Salt Marshes of New England: A Community Profile. Biological Report 85(7.4). U.S. Fish and Wildlife Service, Washington, D.C. 
Thayer, G.W. 1992. Restoring the Nation's Marine Environment. A Maryland Sea Grant Book. College Park, Maryland.

Thayer, G.W., W.J. Kenworthy, and M.S. Fonseca. 1984. The Ecology of Eelgrass Meadows of the Atlantic Coast: A Community Profile. FWS/OBS-84/02. U.S. Fish and Wildlife Service, Washington, D.C.

Thom, R.M. 1990. A Review of Eelgrass (Zostera marina L.) Transplanting Projects in the Pacific Northwest. Northwest Environmental Journal 6:121-137.

Thom, R.M. 1995. Year Five Eelgrass (Zostera marina L.) Transplant Monitoring in Grays Harbor, Washington. Letter Report to the U.S. Army Corps of Engineers, Seattle District, Seattle, Washington.

USFWS (U.S. Fish and Wildlife Service). 1980. Habitat Evaluation Procedures. ESM 102. U.S. Department of the Interior, Fish and Wildlife Service, Division of Ecological Services, Washington, D.C.

Wharton, C.H., W.M. Kitchens, and T.W. Sipe. 1982. The Ecology of Bottomland Hardwood Swamps of the Southeast: A Community Profile. FWS/OBS-81/37. U.S. Fish and Wildlife Service, Washington, D.C.

Whitlatch, R.B. 1982. The Ecology of New England Tidal Flats: A Community Profile. FWS/OBS-81/01. U.S. Fish and Wildlife Service, Washington, D.C.

Wiedemann, A.M. 1984. The Ecology of Pacific Northwest Coastal Sand Dunes: A Community Profile. FWS/OBS-84/04. U.S. Fish and Wildlife Service, Washington, D.C.

Wiegert, R.G. and B.J. Freeman. 1990. Tidal Salt Marshes of the Southeast Atlantic Coast: A Community Profile. Biological Report 85(7.29). U.S. Fish and Wildlife Service, Washington, D.C.

Yoccuz, N.G. 1991. Commentary: Use, Overuse, and Misuse of Significance Tests in Evolutionary Biology and Ecology. Bull. Ecol. Soc. Am. 72:106-111.

Yozzo, D., J. Titre, and J. Sexton, eds. 1996. Planning and Evaluating Restoration of Aquatic Habitats from an Ecological Perspective. IWR Report 96-EL-4. Waterways Experiment Station, Prepared for Institute for Water Resources, U.S. Army Corps of Engineers, Alexandria, Virginia and Waterways Experimental Station, U.S. Army Corps of Engineers, Vicksburg, Mississippi.

Zedler, J.B. 1982. The Ecology of Southern California Coastal Salt Marshes: A Community Profile. FWS/OBS-81/54. U.S. Fish and Wildlife Service, Washington, D.C.

Zedler, P.H. 1987. The Ecology of Southern California Vernal Pools: A Community Profile. Biological Report 85(7.11). U.S. Fish and Wildlife Service, Washington, D.C. 
Zedler, J.B. 1995. "Salt Marsh Restoration: Lessons from California." In Rehabilitating Damaged Ecosystems, ed. J. Cairns, pp. 75-95. Lewis Publishers, Boca Raton, Florida.

Zieman, J.C. 1982. The Ecology of the Seagrasses of South Florida: A Community Profile. FWS/OBS-82/25. U.S. Fish and Wildlife Service, Washington, D.C.

Zieman, J.C. and R.T. Zieman. 1989. The Ecology of the Seagrass Meadows of the West Coast of Florida: A Community Profile. Biological Report 85(7.25). U.S. Fish and Wildlife Service, Washington, D.C. 


\section{APPENDIX A. EXAMPLES OF MONITORING PARAMETER SELECTION}

\section{Examples of General Recommendations}

Example 1: Measurement Selection in Wetlands by Erwin (1990)1. Erwin suggested that a quantitative wetland evaluation plan should be implemented "when the construction technique is unproven, where the ability to successfully create or restore a habitat is unproven, or when success criteria are related to obtaining specific thresholds of plant cover, diversity, and wildlife utilization." This quantitative wetland evaluation should include hydrological monitoring and vegetation analysis. Qualitative evaluations can be carried out in situations where there is more certainty of success, and where performance is not tied to specific quantitative criteria. As an example of qualitative evaluations used for wetlands, Erwin recommended the following:

- baseline vegetation survey

- fixed point panoramic photographs

- rainfall and water level data

- plan view of sampling points

- wildlife utilization observations

- fish and macroinvertebrate data

- annual reporting for 5 years.

Erwin stated that criteria for performance must be established prior to the evaluation effort and must be "fundamental to the existence, functions, and contributions of the wetland system and its surrounding landscape."

Example 2: Measurement Selection in Wetlands by the NRC. The NRC (1992) stated that for wetland restoration projects, the structural and functional attributes should form the basis for evaluating success of the restoration project. Further, it suggested that two factors influence the success rating: (1) the specific criteria used, and (2) the reference data or sites used for comparison. The NRC recommended the following conditions for a restoration monitoring program:

- assessment criteria should include structural as well as functional attributes

- criteria should be established before the assessment takes place

- criteria should be linked to objectives for the project

- several criteria should be used for evaluation

- criteria may need to be regionalized

- reasonable reference sites and long-term data set should be available for comparison

- measurements should take into account temporal and spatial heterogeneity

- there should be an a priori indication of degree of similarity expected between the restored sites and reference sites

${ }^{1}$ References are included in Literature Cited, Section VII. 
- a time frame for monitoring should be established a priori

- criteria and methods should stand up to peer review.

The NRC (1992) developed a list of seven wetland functions that should be considered in assessing equivalency between natural and constructed wetland systems (Table A.1). These were based upon experiences in coastal salt marshes, but apply generally to all wetland systems. For each function, the NRC suggested measures that could be used for quantification.

The NRC (1995) recently reviewed wetland delineation methods and concluded that the use of three wetland indicators, hydrology, soils, and wetland plants, were valid and reliable indicators of the presence of a wetland. Although some of the details regarding the period and depth of soil saturation, and the percentage of facultative and obligate wetland plants needs to be resolved, the $\mathrm{NRC}$ recommended the use of manuals already in place for delineating wetlands. For restoration projects, the 1987 Corps method for wetland delineation may be adequate to evaluate wetland development and the area occupied by a wetland.

Example 3: Measurement Selection in Wetlands by the U.S. Army Corps of Engineers HGM Method. For decades, the Corps has been assessing structure and function of wetlands and other aquatic and terrestrial habitats. A relatively new approach has been developed through Corps funding that synthesizes much of the work that is relevant to wetland systems. Brinson (1993) developed an approach for classifying wetlands that is based upon hydrology and geomorphology HGM. This approach de-emphasizes biological components of the system, and relies on water quality, hydrology, and soils as indicators of ecological conditions of a wetland. For example, northern, cold systems with a positive water balance and a low $\mathrm{pH}$ may favor Sphagnum peat development. Hence, by characterizing the hydrological conditions, along with other aspects of the system, one can predict the wetland type and ecological functions (or significance). This system is beginning to gain wide acceptance, and may prove useful in developing broadly-applicable The Corps is developing the models for various systems types. From this model developrnent, region-specific models and assessment guidance will be developed. The HGM approach is a growing effort within the Corps.

Example 4: Measurement Selection in Aquatic Systems the Index of Biological Integrity. Karr (Karr and Dionne 1991; Karr 1993) developed the Index of Biological Integrity (IBI) which is designed to provide a cost-effective method for evaluating the biological conditions in streams. The IBI focuses on attributes of fish communities to evaluate the effects of humans on streams and watersheds. An IBI is developed based upon sampling of these attributes in a disturbed stream, and ranking them according to their deviations from values expected at an undisturbed reference stream. When several attributes are combined and scaled, the sites can be graded as having excellent, good, fair, or poor biological integrity. This method has been applied throughout much of the United States, and has recently been tested in estuarine systems in New England (Deegan et al. 1993). 
TABLE A.1. Wetland functions and measures for assessing restored wetland equivalency to natural wetlands (from Table 6.4, NRC 1992)

Function Suggested Measures

Hydrologic function

Nutrient supply functions and their limiting factors

Persistence of the plant community

Plant growth(a) and its limiting factors

Persistence of consumer populations
- Ground water recharge: Monitor water level in nearby wells

- Shoreline stabilization: Map shorelines from aerial photographs or install and monitor markers

- Flood-peak reduction: Monitor water levels in relation to flow velocity

- Restoration tidal flows: Monitor water levels over tide cycles; determine amplitude and lags; monitor salinity of water and soil

- Development of hydrologic equilibria: Measure erosion and accretion of channels and marsh

- Sample inflowing waters for nutrient concentrations $(N, P)$ and flow rates

- Analyze soil texture and organic matter content

- Determine nutrient concentrations $(N, P)$ in soil and pore water

- Survey for toxic substances (heavy metals, selenium, and others)

- Determine cover of dominant species and map using aerial photographs and ground truthing

- Survey populations of sensitive species quantitatively

- Determine the life history characteristics of sensitive plant populations to predict their ability to persist in the restored wetland (e.g., numbers, flowering, seed production, seed germination potential, seedling establishment, and successful recruitment)

- Measure end-of-season live standing crop (EOSL); estimate biomass by measuring total stem length (meters/square meter) of species such as cordgrass

- Measure redox potential in soil profiles, and measure $\mathrm{pH}$

- Assess/monitor organic matter decomposition

- Assess cover of floating or epibenthic algae by dominant type

- Determine nutrient content of inflowing waters

- Arthropods: Document outbreaks; document presence of carnivores that could control potential pest species

- Fish and aquatic invertebrates: Sample community composition (seasonal sampling probably needed) 
TABLE A.1. (contd)

Function

Resilience

Resistance to

invasive

exotics

Other items

\section{Suggested Measures}

- Birds: Survey seasonally for abundance

- Record activities (habitat use and movements between habitats) in relation to changes in water levels (e.g., tidal inundation); identify areas used for feeding, nesting, and refuge during adverse conditions

- Follow the recovery of populations that die back during periods of environmental extremes

- Map the occurrence of weedy plants, and rank their abundance by species

- Census exotic animals, and determine whether populations are increasing, stable, or declining

- Monitor trash so that the area can be cleaned up at appropriate intervals

- Document any visual disturbances or noise problems that are correctable

(a) Productivity rates of algae and vascular plants are highly variable--the former on a weekly basis, the latter yearly. However, measures of peak biomass are useful.

Example 5: Measurement Selection in Wetlands by the EPA. The most specific guidance on selection of restored wetland monitoring parameters comes from the EPA (Kusler and Kentula 1990; Kentula et al. 1992a). Kentula et al. (1992a) presented a list of 26 wetland system variables, justification for selection, suggested uses, and general procedures (Table A.2). The variables are divided into categories of general information: morphometry, hydrology, substrate, vegetation, fauna, water quality, and additional information. These variables are well justified in the scientific literature, and many have been investigated directly by the EPA Wetlands Researsh Program. 


\begin{tabular}{|c|c|c|c|c|c|}
\hline \multicolumn{6}{|l|}{ GENERAL } \\
\hline Location & identifies site on local map & $\begin{array}{l}\text { provide baseline map for } \\
\text { future assessments }\end{array}$ & $\begin{array}{l}\text { use existing map or create map } \\
\text { with property boundaries, scale, } \\
\text { north arrow, date, latitude } \\
\text { \& longitude, county \& state } \\
\text { (add addresses in urban areas } \\
\text { \& landmarks in rural areas) } \\
\end{array}$ & & \\
\hline Wetland Type & $\begin{array}{l}\text { documents project goals, } \\
\text { successional changes over } \\
\text { time }\end{array}$ & $\begin{array}{l}\text { serve as benchmark for future } \\
\text { comparisons, document } \\
\text { expected/approprate } \\
\text { development of the project } \\
\end{array}$ & $\begin{array}{l}\text { classify intended type(s) } \\
\text { (Cowardin et al. 1979) }\end{array}$ & $\begin{array}{l}\text { classify intermediate type(s) } \\
\text { (Cowardin et al. 1979) }\end{array}$ & $\begin{array}{l}\text { classify resulting type(s) } \\
\text { (Cowardin et al. 1979) }\end{array}$ \\
\hline Drainage Area & $\begin{array}{l}\text { determines position in water- } \\
\text { shed and related functions, } \\
\text { flood storage computation }\end{array}$ & $\begin{array}{l}\text { relates to projects functional } \\
\text { capability }\end{array}$ & $\begin{array}{l}\text { planimeter area from topo- } \\
\text { graphic map (ha) }\end{array}$ & & \\
\hline $\begin{array}{l}\text { Surrounding Land } \\
\text { Use }\end{array}$ & $\begin{array}{l}\text { determines inputs to wetland } \\
\text { (e.g., nonpoint source } \\
\text { pollution, industrial outfalls) }\end{array}$ & $\begin{array}{l}\text { evaluate the need for buffers } \\
\text { around wetland, explain } \\
\text { changes in wetland } \\
\text { performance }\end{array}$ & $\begin{array}{l}\text { estimate \% of surrounding } \\
\text { land use, \& photograph major } \\
\text { types within a minimum of } \\
300 \mathrm{~m} \text { from the site } \\
\text { (Anderson et al. 1976) }\end{array}$ & $\begin{array}{l}\text { estimate \% of surrounding } \\
\text { land use, \& photograph major } \\
\text { types within a minimum of } \\
300 \mathrm{~m} \text { from the site } \\
\text { (Anderson et al. 1976) }\end{array}$ & $\begin{array}{l}\text { estimate \% of surrounding } \\
\text { land use, \& photograph major } \\
\text { types within a minimum of } \\
300 \mathrm{~m} \text { from the site } \\
\text { (Anderson et al. 1976) }\end{array}$ \\
\hline \multicolumn{6}{|l|}{ MORPHOMETRY } \\
\hline Area & $\begin{array}{l}\text { documents project goals, } \\
\text { influences habitat value, } \\
\text { and flood storage }\end{array}$ & $\begin{array}{l}\text { compare with project goals, } \\
\text { construction specifications, } \\
\text { and future assessments }\end{array}$ & $\begin{array}{l}\text { determine jurisdictional } \\
\text { boundary \& use basic survey } \\
\text { techniques to create a map of } \\
\text { the project (ha) }\end{array}$ & & $\begin{array}{l}\text { determine jurisdictional } \\
\text { boundary (FICWD 1989) \& } \\
\text { use basic survey techniques to } \\
\text { create a map of the project (ha) } \\
\end{array}$ \\
\hline Slope & $\begin{array}{l}\text { influences hydrologic } \\
\text { gradient, plant establish- } \\
\text { ment, animal access, char- } \\
\text { icteristics of wetted edge } \\
\end{array}$ & $\begin{array}{l}\text { determine min., max., \& mean } \\
\text { depths \& slopes from topo- } \\
\text { graphic profiles for each } \\
\text { transect }\end{array}$ & $\begin{array}{l}\text { measure elevation changes at } \\
\text { intervals along transects } \\
\text { (Gwin and Kentula 1990) }\end{array}$ & & \\
\hline $\begin{array}{l}\text { Perimeter-to-Area } \\
\text { Ratio }\end{array}$ & $\begin{array}{l}\text { influences habitat, edge } \\
\text { effect, project goals }\end{array}$ & $\begin{array}{l}\text { determine variation in shape } \\
\text { from original design, and } \\
\text { changes in shape over time }\end{array}$ & $\begin{array}{l}\text { planimeter boundary of wetland } \\
\text { indicated on the project } \\
\text { map \& based on jurisdictional } \\
\text { boundary (m/ha) }\end{array}$ & & $\begin{array}{l}\text { planimeter boundary of wet- } \\
\text { land indicated on the project } \\
\text { map \& based on jurisdictional } \\
\text { boundary }(\mathrm{m} / \mathrm{ha})\end{array}$ \\
\hline \multicolumn{6}{|l|}{ HYDROLOGY } \\
\hline Water Depth & $\begin{array}{l}\text { influences flood storage } \\
\text { potential, vegetation } \\
\text { patterns, wildlife \& fisheries } \\
\text { habitat }\end{array}$ & $\begin{array}{l}\text { determine hydroperiod, flood } \\
\text { storage (Simon et al. 1988), } \\
\text { proportion of open water, } \\
\text { temporal/seasonal changes } \\
\end{array}$ & $\begin{array}{l}\text { measure inundation above } \\
\text { ground (staff gauge), depth } \\
\text { below ground (shallow well, } 50 \text { - } \\
\text { 70mm dia. slotted PVC pipe) }\end{array}$ & \begin{tabular}{|l|} 
measure inundation above \\
ground (staff gauge), depth \\
below ground (shallow well, $50-$ \\
70mm dia. slotted PVC pipe)
\end{tabular} & $\begin{array}{l}\text { measure inundation above } \\
\text { ground (staff gauge), depth } \\
\text { below ground (shallow well, s0. } \\
70 \mathrm{~mm} \text { dia. slotted PVC pipe) }\end{array}$ \\
\hline
\end{tabular}




\begin{tabular}{|c|c|c|c|c|c|}
\hline \multicolumn{6}{|c|}{ TABLE A.2. (contd) } \\
\hline 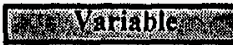 & 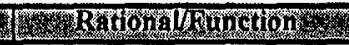 & 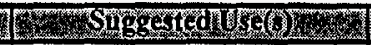 & Finiter & AL - & mpleden \\
\hline Flow Rates & $\begin{array}{l}\text { affects wetland } \\
\text { charateristics and stability }\end{array}$ & $\begin{array}{l}\text { evaluate water sources, } \\
\text { hydrologic modeling }\end{array}$ & $\begin{array}{l}\text { measure inflow and outflow } \\
\text { discharge, if present, with } \\
\text { flumes or weirs }\left(\mathrm{m}^{3} / \mathrm{s}\right)\end{array}$ & & $\begin{array}{l}\text { measure inflow and outflow } \\
\text { discharge, if present, with } \\
\text { flumes or weirs }\left(\mathrm{m}^{3} / \mathrm{s}\right)\end{array}$ \\
\hline Flow Patterns & $\begin{array}{l}\text { influences plant establish- } \\
\text { ment, substrate stability \& } \\
\text { chemistry }\end{array}$ & $\begin{array}{l}\text { serve as benchmark for future } \\
\text { assessments of performance }\end{array}$ & $\begin{array}{l}\text { use direct observation to } \\
\text { indicate major pathways on } \\
\text { map }\end{array}$ & $\begin{array}{l}\text { use direct observation to } \\
\text { indicate major pathways on } \\
\text { map }\end{array}$ & $\begin{array}{l}\text { use direct observation to } \\
\text { indicate major pathways on } \\
\text { map }\end{array}$ \\
\hline \begin{tabular}{|l} 
Indirect \\
Indicators
\end{tabular} & $\begin{array}{l}\text { provides evidence of } \\
\text { hydrology in absence of } \\
\text { water during sampling, } \\
\text { boundary delineation }\end{array}$ & $\begin{array}{l}\text { establish presence and } \\
\text { periodicity of hydrology }\end{array}$ & $\begin{array}{l}\text { record observations of } \\
\text { indicators (FICWD 1989) }\end{array}$ & \begin{tabular}{|l} 
record observations of \\
indicators (FICWD 1989)
\end{tabular} & $\begin{array}{l}\text { record observations of } \\
\text { indicators (FICWD 1989) }\end{array}$ \\
\hline \multicolumn{6}{|l|}{ SUBSTRATE } \\
\hline \begin{tabular}{|l} 
Soil Depth \\
\end{tabular} & $\begin{array}{l}\text { influences suitability as } \\
\text { planting \& growth medium }\end{array}$ & $\begin{array}{l}\text { verify construction } \\
\text { specifications }\end{array}$ & $\begin{array}{l}\text { use soil auger or dig pit to } \\
\text { depth of compacted soil or } \\
\text { liner (FICWD 1989) }\end{array}$ & & $\begin{array}{l}\text { use soil auger or dig pit to } \\
\text { depth of compacted soil or } \\
\text { liner (FICWD 1989) }\end{array}$ \\
\hline Soil Color & $\begin{array}{l}\text { indicates hydric } \\
\text { characteristics }\end{array}$ & $\begin{array}{l}\text { determine extent and time of } \\
\text { formation of hydric soils, } \\
\text { boundary delineation }\end{array}$ & $\begin{array}{l}\text { use Munsell color chart to deter- } \\
\text { mine chroma \& hue of matrix } \\
\text { \& mottles (FICWD 1989) }\end{array}$ & & $\begin{array}{l}\text { use Munsell color chart to deter- } \\
\text { mine chroma \& hue of matrix } \\
\text { \& mottles (FICWD 1989) }\end{array}$ \\
\hline \begin{tabular}{|l} 
Soil Texture \\
\end{tabular} & $\begin{array}{l}\text { influences suitability as } \\
\text { planting \& growth medium, } \\
\text { root growth \& infiltration }\end{array}$ & \begin{tabular}{|l|} 
verify construction \\
specifications, benchmark for \\
temporal changes
\end{tabular} & $\begin{array}{l}\text { use soil texture triangle to } \\
\text { classify soil based on feel } \\
\text { (Homer and Raedeke 1989) }\end{array}$ & & $\begin{array}{l}\text { use soil texture triangle to } \\
\text { classify soil based on feel } \\
\text { (Homer and Raedeke 1989) } \\
\text { or standard methods }\end{array}$ \\
\hline Soil Source & $\begin{array}{l}\text { provides baseline } \\
\text { information }\end{array}$ & $\begin{array}{l}\text { verify construction } \\
\text { specifications and identify } \\
\text { potential plant propagules }\end{array}$ & $\begin{array}{l}\text { document source location and } \\
\text { addition of any soil amend- } \\
\text { ments (e.g., fertilizer, organic } \\
\text { matter, salvaged marsh surface) }\end{array}$ & & \\
\hline Organic Matter & $\begin{array}{l}\text { indicates suitability as } \\
\text { planting \& growth medium, } \\
\text { condition of soil processes } \\
\text { (Langis et al. 1991) } \\
\end{array}$ & $\begin{array}{l}\text { compare with natural } \\
\text { wetlands, document temporal } \\
\text { changes }\end{array}$ & $\begin{array}{l}\text { sample during as-built } \\
\text { assessment if salvaged marsh } \\
\text { surface or other organic } \\
\text { materials are added }\end{array}$ & & $\begin{array}{l}\text { determine ash-free dry weight } \\
\text { from samples } \\
\end{array}$ \\
\hline \begin{tabular}{|l} 
Sediment Flux \\
\end{tabular} & $\begin{array}{l}\text { indicates potential for } \\
\text { sediment accretion, } \\
\text { removal, disturbance }\end{array}$ & \begin{tabular}{|} 
measure rates of sediment \\
accretion or erosion for com- \\
parisons with natural wetlands \\
document temporal changes \\
changes, document/correct
\end{tabular} & $\begin{array}{l}\text { install clay pads at substrate } \\
\text { surface as reference points } \\
\text { s(Cahoon and Turner 1989) }\end{array}$ & & $\begin{array}{l}\text { install clay pads at substrate } \\
\text { surface as reference points } \\
\text { (Cahoon and Turner 1989) }\end{array}$ \\
\hline \multicolumn{6}{|l|}{ VEGETATION } \\
\hline Species Lists & $\begin{array}{l}\text { defines wetland type, } \\
\text { habitat, and plant diversity }\end{array}$ & \begin{tabular}{|l|} 
verify permit or project \\
planting conditions, \\
delineation, calculate \\
weighted averages and ratios
\end{tabular} & $\begin{array}{l}\text { identify species and wetland } \\
\text { indicator \& native/introduced } \\
\text { status (Reed 1988), document } \\
\text { planting locations \& methods }\end{array}$ & $\begin{array}{l}\text { identify species and wetland } \\
\text { indicator \& native/introduced } \\
\text { starus (Reed 1988) }\end{array}$ & $\begin{array}{l}\text { identify species and wetland } \\
\text { indicator \& native/introduced } \\
\text { status (Reed 1988) }\end{array}$ \\
\hline
\end{tabular}




\begin{tabular}{|c|c|c|c|c|c|}
\hline \multicolumn{6}{|c|}{ TABLE A.2. (contd) } \\
\hline 沕 & V. & 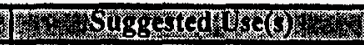 & 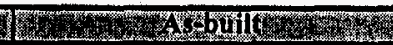 & 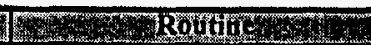 & 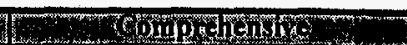 \\
\hline Coverage & influences use as habitat & $\begin{array}{l}\text { verify project goals, } \\
\text { benchmark for future } \\
\text { assessments }\end{array}$ & $\begin{array}{l}\text { estimate cover visually to } \\
\text { nearest } 10 \% \text {, map plant } \\
\text { communities }\end{array}$ & $\begin{array}{l}\text { estimate cover visually to } \\
\text { nearest } 10 \% \text {, map plant } \\
\text { communities }\end{array}$ & $\begin{array}{l}\text { estimate cover visually to nearest } \\
10 \% \text {, map plant communities, } \\
\text { collect plot data along } \\
\text { transects (Brower and Zar 1984, } \\
\text { Leibowitz et al. 1991), collect } \\
\text { data for productivity studies }\end{array}$ \\
\hline Survivorship & $\begin{array}{l}\text { indicates effectiveness of } \\
\text { planting methods, influences } \\
\text { project goals }\end{array}$ & $\begin{array}{l}\text { evaluate planting success, } \\
\text { suggest replanting strategies }\end{array}$ & $\begin{array}{l}\text { visually determine \% of } \\
\text { plants alive }\end{array}$ & & $\begin{array}{l}\text { visually determine \% of plants } \\
\text { alive, tag individual shrubs \& } \\
\text { trees }\end{array}$ \\
\hline \multicolumn{6}{|l|}{ FAUNA } \\
\hline Observations & indicates use as habitat & $\begin{array}{l}\text { evaluate use by common, } \\
\text { rare, \& exotic species over } \\
\text { time }\end{array}$ & $\begin{array}{l}\text { record direct \& indirect } \\
\text { observations of wildlife, fish, } \\
\text { \& inverebrates }\end{array}$ & $\begin{array}{l}\text { record direct \& indirect } \\
\text { observations of wildlife, fish, } \\
\text { \& inverebrates }\end{array}$ & $\begin{array}{l}\text { record direct \& indirect } \\
\text { observations of wildlife, fish, } \\
\text { \& inverebrates }\end{array}$ \\
\hline \begin{tabular}{|l|} 
Habitat \\
Evaluations
\end{tabular} & evaluates potential habitat & $\begin{array}{l}\text { determine habitat potential } \\
\text { over time }\end{array}$ & $\begin{array}{l}\text { use Habitat Evaluation } \\
\text { Procedures (USFWS 1980) } \\
\text { or comparable method for } \\
\text { selected species }\end{array}$ & & $\begin{array}{l}\text { use Habitat Evaluation } \\
\text { Procedures (USFWS 1980) or } \\
\text { comparable method for } \\
\text { selected species }\end{array}$ \\
\hline \begin{tabular}{|l|} 
Species or \\
Community \\
Specific Sampling \\
\end{tabular} & $\begin{array}{l}\text { evaluates targeted species } \\
\text { or groups of concern }\end{array}$ & $\begin{array}{l}\text { evaluate presence and } \\
\text { abundance data over time }\end{array}$ & & & $\begin{array}{l}\text { select appropriate census tech- } \\
\text { niques (Brooks and Hughes 1988; } \\
\text { Brooks et al. 1991; Erwin 1988) }\end{array}$ \\
\hline \multicolumn{6}{|l|}{ WATER QUALITY } \\
\hline Water Samples & $\begin{array}{l}\text { indicates water treatment at } \\
\text { the site or, disturbance in or } \\
\text { around the site }\end{array}$ & $\begin{array}{l}\text { provide baseline data for } \\
\text { specific project goals, } \\
\text { evaluate water treatment } \\
\text { function, explain variations in } \\
\text { vegetative performance, } \\
\text { correlate with faunal use }\end{array}$ & $\begin{array}{l}\text { measure appropriate } \\
\text { parameters based on } \\
\text { project objectives (e.g., pH, } \\
\text { conductivity, total suspended } \\
\text { solids, nutrients, pollutants) }\end{array}$ & & $\begin{array}{l}\text { measure appropriate parameters } \\
\text { based on project objectives } \\
\text { (e.g., pH, conductivity, total } \\
\text { suspended solids, nutrients, } \\
\text { pollutants) }\end{array}$ \\
\hline \multicolumn{6}{|c|}{ ADDITIONAL INFORMATION } \\
\hline $\begin{array}{l}\text { Photographic } \\
\text { Record }\end{array}$ & $\begin{array}{l}\text { provides permanent record } \\
\text { for permit file on condition o } \\
\text { wetland \& surrounding land } \\
\text { use }\end{array}$ & $\begin{array}{l}\text { henchmark for temporal } \\
\text { assessments, allows for office } \\
\text { review of wetland \& } \\
\text { surrounding buffer }\end{array}$ & $\begin{array}{l}\text { photograph wetland \& } \\
\text { surrounding landscape from } \\
\text { several directions with } 50 \mathrm{~mm} \\
\text { lens using } 35 \mathrm{~mm} \text { film from } \\
\text { permanent photo stations } \\
\text { (Horner and Raedeke 1989) }\end{array}$ & $\begin{array}{l}\text { photograph wetland \& } \\
\text { surrounding landscape from } \\
\text { several directions with } 50 \mathrm{~mm} \\
\text { lens using } 35 \mathrm{~mm} \text { film from } \\
\text { permanent photo stations } \\
\text { (Horner and Raedeke 1989) } \\
\end{array}$ & $\begin{array}{l}\text { photograph wetland \& } \\
\text { surrounding landscape from } \\
\text { several directions with } 50 \mathrm{~mm} \\
\text { lens using } 35 \mathrm{~mm} \text { film from } \\
\text { permanent photo stations } \\
\text { (Homer and Raedeke } 1989 \text { ) } \\
\end{array}$ \\
\hline $\begin{array}{l}\text { Descriptive } \\
\text { Narrative }\end{array}$ & $\begin{array}{l}\text { provides additional } \\
\text { information \& explanation }\end{array}$ & $\begin{array}{l}\text { benchmark for future } \\
\text { comparisons }\end{array}$ & $\begin{array}{l}\text { describe \& explain notable } \\
\text { features \& changes for each } \\
\text { major variable }\end{array}$ & $\begin{array}{l}\text { describe \& explain notable } \\
\text { features \& changes for each } \\
\text { major variable }\end{array}$ & $\begin{array}{l}\text { describe \& explain notable } \\
\text { features \& changes for each } \\
\text { major variable }\end{array}$ \\
\hline
\end{tabular}


The EPA, through its Environmental Monitoring and Assessment Program (EMAP; Hunsaker and Carpenter 1990), has been developing parameters to monitor the status and trends of the ecological conditions of the ecosystems of the United States. For wetlands and surface waters, EMAP has developed a list of 20 and 18 "candidate indicators" for surface waters and wetland ecosystems, respectively (Table A.3). Each of these indicators is graded high, medium, or low relative to 12 selection criteria. The selection criteria identify the following about an indicator:

- can it be correlated with unmeasured ecosystem components

- is it applicable on a regional basis, is related unambiguously and monotonically to an environmental value or habitat value

- can it be easily sampled

- does it exhibit low measurement error

- is it cost effective.

Although EMAP was not specifically designed to monitor restoration sites, the analysis of ecosystem indicators is useful in selecting defensible and relevant parameters for this purpose.

Example 6: Measurement Selection in Water Quality Assessments by the EPA. The EPA (1991a, $1991 \mathrm{~b}$ ) has attempted to develop biological criteria for water quality assessments in a variety of system types. Biological criteria are not universally recognized or used in the United States, because they have not been developed to a state that allows broad application (Richard Albright, personal communication 1995, EPA Region 10, Seattle, Washington). Biological water quality criteria can be developed for local areas and used for monitoring changes in the conditions in a particular watershed or stream. These same criteria could also be used to assess the changes in water quality associated with restored systems.

Example 7: Measurement Selection in the U.S. Army Corps of Engineers Civil Works Program. Circular No. 1105-2-210 (Corps 1995) identified structural and functional characteristics of the ecosystem that are potentially useful for measuring the progress of restoration projects. The circular provided a discussion of the following characteristics:

Structural
water quality
water quantity
soil condition
geology
topography
flora and fauna
concepts (patch size,
edge, etc.)
morphology

- Structural

water quality

woil condition

geology

topography

flora and fauna

edge, etc.)
- Functional

water storage, recharge, supply

floodwater and sediment retention

transport of organisms, nutrients, etc.

oxygen production

biomass production, food web support

nutrient cycling

shelter

detoxification of wastes

energy flow. 
TABLE A.3. Candidate indicators for inland surface waters and wetlands developed by EMAP (from Hunsaker and Carpenter 1990)

Inland Surface Waters

Selected as Research Indicators

Lake Trophic Status

Fish Index of Biological Integrety

Top Carnivore Index: Fish

Macroinvertebrate Assemblage

Sedimentary Diatom Assemblage

Semiaquatic Vertebrates

External Pathology: Fish

Water Column/Sediment Toxicity

Chemical Contaminants: Fish

Physical Habitat Quantity

Routine Water Chemistry

Biomarkers

Water-Column Bacteria

Man-Made Organics/Heavy Metals

\section{Considered but not Selected}

Phytoplankton

Zooplankton

Growth Rate

Primary Production

Community Respiration

Nutrient Cycling

\section{Wetlands}

\section{Selected as Research Indicators}

Wetland Extent/Type

Diversity

Organic Matter/Sediment Accretion

Abundance/Species Composition:

Vegetation

Water Birds

Nutrients in Water/Sediments

Chemical Contaminants in Water/Sediments

Hydroperiod

Macroinvertebrates

Leaf Area/Transmittance/Greenness

Soil and Aquatic Microbes

Chemical Contaminants in Tissues

Bioassays

\section{Considered but not Selected}

Biomass

Primary Production

Nutrient Cycling

Retrogression

Decomposition

Fish Community Structure 


\section{Region and System-Specific Parameters}

The relevance of evaluation criteria depends highly on the system type, region, and question under consideration. For example, three categories of functions are often recognized for wetland systems: hydrologic, water quality improvement, and food chain support (Mitsch and Gosselink 1993). However, hydrologic functions such as groundwater recharge and flood peak reduction may be unimportant functions in coastal salt marshes in southern California (Pacific Estuarine Research Laboratory [PERL] 1990). In contrast, other hydrologic functions may be important along with the habitat support of the system for a variety of fish and wildlife. Therefore, measuring the typical hydrologic functions in a restored southern California coastal wetland, although not completely irrelevant, may not provide interpretable data and may not be a wise use of funds.

Criteria development must be based on a thorough knowledge of the system under consideration. Although there is a vast array of system-specific studies, it is useful to consult a document that summarizes the fundamental knowledge about the system. A good source of this information comes from the "Community and Estuarine Profile" series published by the USFWS (Table A.4). These reports cover the general ecology of selected systems throughout the country, and have sections on physical, chemical, and biological conditions of these systems. Many of the profiles also cover restoration.

A wealth of information on regionalized and system-specific wetland criteria development is available in Kusler and Kentula (1990). Six examples, presented below, of regionalized and system-specific wetland and aquatic system parameter development specifically for restoration projects come from southern California coastal wetlands (PERL 1990), western vernal pools (Kistner et al. 1995), estuarine habitats in the Pacific Northwest (Simenstad et al. 1991), bottomland hardwood forests (Gosselink and Lee 1989), Louisiana coastal marshes (Steyer and Stewart 1992), and seagrass systems (Fonseca 1990).

Example 8: Regional Parameter Selection in Coastal Wetlands in Southern California. Based upon over a decade of research on constructed wetlands in southern California's coastal zone, PERL (1990) considered the following functions and characteristics essential for the success of restoration projects in southern California coastal wetlands:

- provision of habitat for wetland-dependent species

- support for food chains

- transformation of nutrients

- maintenance of plant populations

- resilience (ability to recover from disturbances)

- resistance to invasive species (plant or animal)

- resistance to herbivore outbreaks

- pollination 
TABLE A.4. List of selected Community and Estuarine Profile Reports published by the U.S. Fish and Wildlife Service

\section{System}

Atlantic White Cedar wetlands

Bottomland hardwood swamps

Riparian habitats

Vernal pools

Shrub bogs (pocosins)

Tundra ponds

Freshwater coastal marshes

Tidal freshwater marshes

High salt marshes

Regularly flooded salt marshes

Tidal salt marshes

River delta marshes

Salt marshes

Tidal marshes

Tidal marshes

Estuarine tidal flats

Estuarine tidal flats

Oyster reefs

Seagrasses

Seagrasses

Seagrasses

Seagrasses

Mangroves

Estuarine channels

Open-bay bottoms

Pamlico River

Mugu Lagoon

Apalachicola Bay

Albermarle Sound

Giant kelp

Coastal sand dune

Rubble structures

\section{Region}

Atlantic and Gulf coasts

Southeast

Southern California

Southern California

Southeast and Carolinas

Arctic

Western Lake Erie

East coast

New England

New England

Southeastern Atlantic coast

Coastal Louisiana

Southern California

San Francisco Bay

Pacific Northwest

New England

North Carolina

South Atlantic coast

Atlantic coast

South Florida

Florida west coast

Pacific Northwest

South Florida

Pacific Northwest

Texas

North Carolina

Southern California

Gulf coast

North Carolina

California

Pacific Northwest

South Atlantic coast

\section{Reference}

Laderman (1989)

Wharton et al. (1982)

Faber et al. (1989)

Zedler (1987)

Sharitz and Gibbons (1982)

Hobbie (1984)

Henderdorf (1987)

Odum et al. (1984)

Nixon (1982)

Teal (1986)

Wiegert and Freeman (1990)

Gosselink (1984)

Zedler (1982)

Josselyn (1983)

Seliskar and Gallagher (1983)

Whitlach (1982)

Peterson and Peterson (1979)

Bahr and Lanier (1981)

Thayer et al. (1984)

Zieman (1982)

Zieman and Zieman (1989)

Phillips (1984)

Odum et al. (1982)

Simenstad (1983)

Armstrong (1987)

Copeland et al. (1984)

Onuf (1987)

Livingston (1984)

Copeland et al. (1983)

Foster and Schiel (1985)

Wiedemann (1984)

Hay and Sutherland (1988) 
- maintenance of local gene pools

- access to refuges during high water

- accommodation of rising sea level.

All of these functions are directly measurable and have been justified through research. Because this list was developed specifically for the region and system type, it can be used in the planning process to define the vision and goals for the project. The monitoring program can then develop performance criteria and measurable parameters with confidence that they will be highly relevant and sensitive indicators of the progress of the system.

Example 9: Regional Parameter Selection in Vernal Pools in California. California vernal pools are seasonal wetlands that contain a unique assemblage of plants and animals adapted for extended dry periods. These systems have been heavily impacted by development and agriculture. Kistner et al. (1995) described protocols for assessing performance of constructed vernal pools. Although several functions are commonly recognized for these systems (i.e., aesthetics, education, flood control, food chain support), they considered the principle function of vernal pools to be the preservation of biodiversity. Therefore, their protocols are designed to quantify the abundance of plants and invertebrate species in constructed pools. The similarity between constructed pools and natural pools is then assessed based upon these values.

Example 10: Regional Parameter Selection in Estuarine Habitats in the Pacific Northwest. Simenstad et al. (1991) developed the Estuarine Habitat Assessment Protocol (EHAP) to provide a standardized approach and sampling protocols for assessing the performance of restored or constructed estuarine systems in the Pacific Northwest. EHAP proposes characteristic (termed attributes) of estuarine habitats that promote fish and wildlife utilization and fitness. These attributes indicate the potential to provide a specific function, which can provide design criteria for habitat restoration. The attributes selected were based on a comprehensive survey of approximately 200 estuarine scientists in the region and was supported by published information. A total of 105 "protocol" species were identified, which included fish, invertebrates, birds and mammals. The occurrence of the species in each major habitat type is shown, and the reason for the occurrence (e.g., feeding, rearing, reproduction, resting) is provided. Finally, specific methods for sampling attributes of each habitat that are related to the occurrence of the protocol species are described. The EHAP further identifies three levels of sampling complexity: minimum, recommended, and preferred.

Example 11: Regional Parameter Selection in Bottomland Hardwoods in the South. Regional losses of bottomland hardwoods (BLH) are as high as 80\%-98\% (Gosselink and Lee 1989). Hence, management of these systems to control losses has been a major focus of a number of agencies. Losses have resulted in a fragmentation of the original landscape, which has resulted in cumulative impacts to the ecosystems. To attain management and restoration goals in the BLH, Gosselink and Lee proposed that this set of "tools" are needed: (1) an analysis of the scale or size at which 
cumulative impacts should be assessed; (2) a regional survey of the present state of conditions; and (3) development of indices of "health" of the system. They proposed the following eight indicators of health or "integrity" of the system:

- fraction of BLH remaining

- BLH patch size distribution

- BLH continuity to stream and to upland forest

- water quality

- nutrient loading

- stage-discharge relations

- water detention

- balanced indigenous populations.

Gosselink and Lee provided data sources for information on these indicators and standards for some of the indicators.

Example 12: Regional Parameter Selection in Coastal Wetlands in Louisiana. The CWPPRA was established to provide guidance and means to implement projects that stop further loss of Louisiana's coastal wetlands and that restore coastal wetlands in the region. As part of the effort under CWPPRA, monitoring protocols were developed to provide guidance on minimum monitoring standards to assess performance of restored systems relative to goals, and to provide information for developing costs for restoration programs (Steyer and Stewart 1992). Subgroups of technical experts developed protocols in seven categories: water quality, hydrology, soils and sediments, vegetative health, habitat mapping, wildlife, and fisheries. Monitoring plans were developed for nine project types: freshwater introductions and diversions, sediment diversions, marsh management, hydrologic restoration, beneficial use of dredged material, shoreline protection, barrier island restoration, vegetative planting, and sediment and nutrient trapping. Variables (i.e., measurable elements) are developed for each monitoring category and prioritized for each project type. Priorities range from a primary objective (Priority 1) through lower priority-long term evaluation (Priority 4), with an additional priority, as needed, unique to a specific project (Priority $\mathrm{N}$ ). Cost estimates are provided for instrumentation, analysis and related items. Methods are provided in varying degrees of detail for the variables.

Example 13: Regional Parameter Selection Selection in Seagrass Systems. Seagrass systems occur in most coastal areas of the United States, where they form important habitat for a variety of fish and aquatic invertebrates. They are very productive habitats but have suffered severe losses and are under constant pressure from coastal development (Thom 1990). Fonseca (1990) found that seagrass restoration has historically resulted in a net loss of habitat primarily because performance goals and criteria were inappropriate. He recommended the following goals for which criteria can be formulated:

- development of persistent cover 
- generation of equivalent or increased area

- replacement with the same seagrass species that suffered an impact

- restoration of faunal production.

These goals are applicable to seagrass systems throughout the United States. 